\title{
Beyond protest: Ethics of reconciliation in post-Apartheid South African white writing
}

\author{
Sohinee Roy \\ West Virginia University
}

Follow this and additional works at: https://researchrepository.wvu.edu/etd

\section{Recommended Citation}

Roy, Sohinee, "Beyond protest: Ethics of reconciliation in post-Apartheid South African white writing" (2011). Graduate Theses, Dissertations, and Problem Reports. 4778.

https://researchrepository.wvu.edu/etd/4778

This Dissertation is protected by copyright and/or related rights. It has been brought to you by the The Research Repository @ WVU with permission from the rights-holder(s). You are free to use this Dissertation in any way that is permitted by the copyright and related rights legislation that applies to your use. For other uses you must obtain permission from the rights-holder(s) directly, unless additional rights are indicated by a Creative Commons license in the record and/ or on the work itself. This Dissertation has been accepted for inclusion in WVU Graduate Theses, Dissertations, and Problem Reports collection by an authorized administrator of The Research Repository @ WVU.

For more information, please contact researchrepository@mail.wvu.edu. 
BEYOND PROTEST: ETHICS OF RECONCILIATION IN POST-APARTHEID SOUTH AFRICAN WHITE WRITING

by

Sohinee Roy

Dissertation submitted to the Eberly College of Arts and Sciences at West Virginia University in partial fulfillment of the requirements for the degree of

\author{
Doctor of Philosophy \\ in \\ English Literature
}

Approved by

Dr John Ernest, Committee Chair

Dr Dennis Allen

Dr Gwen Bergner

Dr Jonathan Burton

Dr Joseph Hodge (History)

Department of English

Morgantown, West Virginia

2011

Keywords: Reconciliation, South Africa, Race, Apartheid

Copyright 2011 Sohinee Roy 


\section{Abstract \\ BEYOND PROTEST: ETHICS OF RECONCILIATION IN POST-APARTHEID SOUTH AFRICAN WHITE WRITING}

\section{Sohinee Roy}

Beyond Protest: Ethics of Reconciliation in Post-Apartheid South African White Writing examines the politics and poetics of reconciliation in South Africa by comparing the defining (or, at least the initiating) document the Truth and Reconciliation Commission Report (TRC) with the ways in which concepts of "racial harmony" are presented in the post-apartheid novels of white authors like J.M.Coetzee, Nadine Gordimer, Antje Krog, and Andre Brink. South Africa’s complex racial history dating back to the colonial times, the consequent internalization of imposed racial identities within resistance movements, and the institutionalization of racist practices through state policies mean that its effort to move beyond racism suffers from a perpetual lag-effect. The intertwining of race and colonialism also means that eradication of racism must account for colonial history. Racial reconciliation, under the circumstances, is an openended, dynamic, spatially and temporally sensitive process. By defining reconciliation as a dynamic process I identify a discrepancy between the celebration of the end of apartheid as end of racism in South Africa and the sedimentation of past racist practices in the present social and political structures. My dissertation uses postcolonial and race theory, primarily Goldberg's Foucauldian concept of race and Spivakean ethics, to explore how moving beyond apartheid and the nation's complex racist colonial past places signal demands on representation politics. Central to my argument is my claim that imaginative literature needs to be recognized as vital to reconciliation and to the reconceptualization of historical process required if reconciliation is to be a successful, ongoing project.

I explore reconciliation as policy and practice-a policy and practice that literature, particularly white literature, critiques and supports. For the white authors, beneficiaries of the persisting white supremacy, reconciliation involves, among other things, aesthetic strategies used to map the limits of empathy for the non-white other. Chapter 1 charts the central claims, the theoretical framework, and the historical context of my project. In Chapter 2 I examine the TRC's Final Report through the lens of the theoretical and historical framework of the first chapter to explore ethics as a temporal, rhetorical, and textual construct, and the TRC as the primary site of that construction. In Chapter 3 I argue that J. M. Coetzee's Disgrace presents reconciliation as an irony where acknowledging the impossibility of understanding the other, especially in relations marked by historical power imbalance and violence, opens the possibility of ethical relations. Chapter 4 argues that Andre Brink's post-apartheid novels use magic realism to challenge the possibility of recovering an authentic past as the basis of justice. My final chapter compares Nadine Gordimer's None to Accompany Me with Antje Krog's Country of My Skull to discuss the role of women in patriarchal conceptions of reconciliation. A brief epilogue explores the more universal currency of my conception of racial reconciliation. 


\section{DEDICATION}

I dedicate this dissertation to my grandmother, the Late Tapatee Roy to the rest of the world, and Amma to me. Your stories about your traumatic experiences during the 1947 Partition, on the lazy Thursday afternoons of my childhood, first made me realize the power of narratives. 


\title{
ACKNOWLEDGEMENTS
}

\author{
a grateful mind \\ By owing owes not, but still pays, at once \\ Indebted and discharg'd. \\ John Milton, Book 3, Paradise Lost.
}

In this spirit I thank

My committee. Without your generosity, patience, and encouragement this dissertation would have been a much lesser work.

Dr. John Ernest, my dissertation director, for always being gracious, encouraging, demanding, patient and unfailingly generous. You were never too busy to read my drafts, write references or discuss knotty theoretical problems. If there is a patron saint of dissertation directors, it is you.

Dr. Dennis Allen for being a fantastic teacher, a demanding and critical reader, and such a positive and encouraging $\mathrm{PhD}$ program director. You were always available and never too busy to look through a draft or address my concerns.

Dr. Gwen Bergner, for demanding more than my best all the time, for taking time off her busy career to help me with mine.

Dr. Katherine Ryan for being a friend. You welcomed me into your world and shared your insights about pedagogy and books so generously.

My fellow PhD students: Dibyadyuti Roy and Yvonne Hammond. Your friendship and warmth sustained me the last year.

Aparajita De, for being a staunch friend and colleague through all these years.

John Henry Hagen for his friendship and support.

Romi, Jijo and Souro, my three musketeers from our Four Musketeers Club. Some people helped by reminding me to work. Others helped by taking me away from work, by reminding me of a life outside the dissertation. Your insistence on the monthly Skype conference calls filled my ivory tower with laughter and love.

Sourajeet Roy (Souro to me), my brother, best friend, and co-conspirator through life. Your belief sustained me and your sense of humor cheered me on the darkest days. 
My parents Tarit Kanti Roy and Shanghamitra Roy, for putting their lives on hold so that mine could go forward. Your encouragement and unconditional love have been a source of support and energy all my life.

I thank you with all my heart. You all made this journey not only possible, but pleasureable. 


\section{TABLE OF CONTENTS}

INTRODUCTION 2

$\begin{array}{ll}\text { CHAPTER } 1 & 32\end{array}$

TRUTH AND RECONCILIATION COMMISSION OF SOUTH AFRICA: AN EVENT THAT LAUNCHED A PROCESS

CHAPTER 2

SPEAKING WITH A FORKED TONGUE: DISGRACE AND THE IRONY OF RECONCILIATION IN POST-APARTHEID SOUTH AFRICA

CHAPTER 3

MAKING FRIENDS WITH GHOSTS: MAGIC REALISM AND THE DEMANDS

OF HISTORY IN ANDRE BRINK'S POST-APARTHEID NOVELS

CHAPTER 4

BETWEEN FACT AND FICTION: WITHHELD AUTOBIOGRAPHY AS AN ETHICAL RESPONSE TO THE OTHER.

EPILOGUE

NOTES:

WORKS CITED: 
One morning

My people will hang on a sunrise ... we shall stand face to face with the sun leaving behind us

so many dead

wounded

mad

so many senseless things

We shall have buried apartheid ...How shall we shake hands

how shall we hug each other that day? What first words will we utter?

Mongane Wally Serote 


\section{Introduction}

The novels written by white South African authors in the eighties, the dying years of apartheid, represent a dystopian world in its death throes. Described as apocalyptic novels, they depict the violence and anarchy that accompanied the collapse of law and order in the final years of apartheid. Despite the destruction of the old order and the ongoing revolution, the new kingdom remains stubbornly invisible in these novels. For example, J. M. Coetzee’s Age of Iron presents a world marked by death, disease and civic anarchy. Mrs. Curren, the old academic, is on her deathbed with cancer, vainly hoping for a reunion with her expatriate daughter. At the end of the novel she is still waiting, even though there is little hope that her dying wish for reconciliation with her daughter will be fulfilled. Similarly, in Nadine Gordimer’s July’s People Maureen Smales, who has been hiding from the revolution, in the forest, in her former servant's home, dashes towards the sound of a helicopter at the end of the novel. But we do not know if the helicopter belongs to enemies or friends. If Coetzee signals the moribund times through the trope of sickness and death, then Gordimer signals the end of an order through signs of infertility. In the apocalyptic fiction of the eighties South Africa is depicted as caught in the transition between the old and the new: the demise of the old order is certain, but the new remains mysteriously, almost frighteningly, unknown.

The future that was nebulous and undefined for Mrs. Curren or Maureen in the novels became a reality for South Africans with the end of apartheid, in 1991, and the election of the first non-white government, in May 1994. Authors such as Andre Brink and Njabulo Ndebele hoped that the political change would liberate literature from political determinism and encourage engagement with and celebration of the ordinary 
aspects of life. ${ }^{i}$ Despite formal experimentation and movement away from realism, the post-apartheid texts by white authors continued to be marked by bleak pictures of contemporary South Africa. In J.M Coetzee, Andre Brink, and Nadine Gordimer’s fictions, post-apartheid South Africa is very different from apartheid South Africa. They are characterized by violence and terror, and examples of racial discord, instead of accord. The pessimistic images of post-apartheid South Africa in their novels raise the question: Why are white authors such as Gordimer, Brink, Krog, and Coetzee, who have been active against the apartheid state, unable to imagine a positive post-apartheid age? Is it a sign of their allegiance to the apartheid? Is it a reflection of the true reality of the times? Or, is it a sign that true reconciliation is impossible?

The pessimistic picture of contemporary South Africa in post-apartheid white writing relates to the peculiar nature of the end of apartheid. For South Africa, where racial discrimination against the indigenous African population was a part of its long colonial history, the end of apartheid was a step into uncharted waters of desegregated racial interaction. A further complication was the fact that the ANC's triumph in the elections cannot be read as a victory of the non-white faction. Economic bankruptcy and the breakdown of law and order as a result of the civil war forced the ruling Nationalist Party (NP) to reconsider its exclusive racial policy and negotiate with the ANC. ${ }^{\text {ii }}$ Since there were no outright victors in this struggle and the end of political power did not mean the end of white supremacy, there were questions about the possibility, under the circumstances, of equality and justice, freedom and agency.

These political changes reconfigured the literary landscape from one characterized by the strategic imperatives of "protest literature" to one defined by the 
nebulous terrain of cross-racial relation. Much of the certainties that defined protest literature disappeared as suppressed stories of apartheid shattered linear correspondences of white with evil and good with black. The emergence of suppressed apartheid narratives revealed complicity and collaboration across racial lines and division along the ethnic front. Black and white violence was matched by Black-on-Black violence. The apartheid strategy of sabotaging any potential for a unified Black resistance in the cities by dividing them along ethnic lines through the creation of Bantustans, exclusive tribal enclaves, reinforced strong ethnic identities within the Black community. ${ }^{i i i}$ The most dominant of them, the Zulus, resisted attempts by Black organization such as the ANC to unite all Africans. Similarly, the white community is divided into the Afrikaners, who were of Dutch descent, and the other Whites including English South Africans. ${ }^{\text {iv }}$ The rigid racial and ethnic identities hinder possibilities of discovering common ground among the hostile divided subjects. ${ }^{\vee}$ The end of apartheid and the complex racial and ethnic terrain of South African society required a shift from protest to exploration of the possibilities of positive relations that challenge hostility and violence as the only means of interacting with the other.

Reconciliation as a means of establishing common ground by erasing differences is impossible in South Africa because ideologies and identity categories from the past continue in the present. These past ideologies and institutional structures can be traced back to the colonial period. The rivalry between the two European settler groups: the Boers and the British settlers, over control of the land led to the violent dispossession of the indigenous population during the colonial period that set the tone for South Africa's racial patterns. The apartheid was a consequence of settler politics and settler rivalry that 
dates back to the colonial times in South Africa. ${ }^{\text {vi }}$ The persistence of South Africa’s deep racial history in the present means that, tempting as it may be, the desire to atone for the past by identifying with and speaking for the racial other has to give precedence to the need to recognize differences. If we regard these differences as the foundation for reconciliation, if acknowledgement of differences can be seen as the basis for discovering common ground beyond abstract notions of universal humanity, then possibilities of a newer and more ethical paradigm of interaction between the different groups becomes imaginable.

In this project I argue that reconciliation is not an event. It is a process, a dynamic, open-ended and flexible process of renegotiating the relation between the past and the present, and marking the boundaries between the self and the other through the flux of history. Politically it means changing the structure and institutions of society to heal historical inequalities. Ethically it means respecting the threshold to identifying with the other, the limit to complete understanding created by different experiences of history . Ethical relations under reconciliation are, thus, based on an essential alienation between the self and the other. This alienated empathy, this relationship grounded in the history of animosity between the self and the other, opens up the possibility of a new dynamic that bypasses the dead end of uncritical fellowship. Implicit in my conception of reconciliation is the understanding that power imbalances do not disappear, identity categories formed in response to a history of oppression do not miraculously vanish with political change, and the past cannot be conveniently wished away. Reconciliation is an endless striving towards an ever-receding horizon of common ground. It does not offer a clean slate, a fresh start. In fact, the reality of reconciliation is an endless negotiation 
between the ideal of perfect accord and the practice of living in a messy historical reality. Efforts at reconciliation are, thus, caught in the double bind of history. Reconciliation is a double bind because it seeks to transform the existing relation with history, but is constrained and marked by the parameters of that history. In the end, I see reconciliation less as erasing of differences, and more as a process of establishing common ground by recognizing that history is embodied differently in its subjects. ${ }^{\text {vii }}$

I define reconciliation as an ethical process of negotiating the imperfect understanding between hostile groups because apology, forgiveness, friendship, or advocacy as the basis of cordial relations place the burden of moving ahead squarely on the shoulders of the victims. All these actions require and expect the victims, who are already suffering from injustice, to perform the morally difficult task of forgiving, or accepting the perpetrator's friendship or being grateful. I am not denying that the victims have a role, but to expect victims, who have been traumatized by violence and continue to struggle for survival in the new dispensation, to forget the past is presumptuous. Moreover, in post-conflict societies like South Africa the victims are so scarred by violence and discrimination that they have little luxury to feel forgiveness. Reconciliation as a dynamic process of negotiating difference recognizes that perpetrators have a critical role to play—a role that involves moving beyond the naïve belief that forgiveness can magically minimize the effects of a history of violent abuse.

In order to explore the nature of negotiations involved in creating a new social order in post-conflict societies I focus on the ethics of reconciliation for white South Africans. Continuation of white supremacy makes their resources and skills necessary for rebuilding South Africa. In addition, guilt over complicity with racist apartheid 
ideologies and the desire to ingratiate themselves with the new government make the whites eager to erase differences and identify with the racial other. The desire to atone for past wrongs to create a new, more acceptable identity opens the possibility of whites imposing their views on the non-whites and co-opting their new found voice and authority. As Bishop Tutu pointed out at the height of apartheid, "I ... welcome the participation of all, both Black and white in the struggle for a new South Africa. The leadership of the struggle must be firmly Black hands. ... whites must be willing to follow (Tutu, qtd in Gordimer, 266-267). To ensure that the need to expiate for the past does not overlook differences created by a long history of institutionalized racism, white South Africans need to abandon the active desire to make good. Tutu asks the white population to play a secondary, more passive, role because their knowledge and resources, while necessary, are the result of their privileged status in a racist society. By focusing on the unique position of white South Africans I draw attention to the importance of letting victims dictate the terms of reconciliation. The victims as the guiding force reverse the old dynamics and allow new connections to be discovered.

I argue that reconciliation in South Africa is a postcolonial project, as well as a racial project because the present racist ideologies, institutions and identities date back to South Africa's colonial history. Reconciliation as process of marking the threshold to the other reads what would have been, conventionally, seen as failure in reconciliation as a positive step. By recognizing the melancholic nature of post-apartheid postcolonial South Africa as basis of action, reconciliation presents the much lamented postcolonial failure to reverse power structures as a realistic step to setting up new racial paradigms. Premised on the recognition that history is embodied differently, reconciliation offers the 
possibility of historically nuanced and ethical social relations that bypass racial animosity. Reconciliation as a process is not a step into pessimism, but a step towards a realistic future. Considered along these lines, South Africa's reconciliation efforts recognize the importance of settler indigene relations to settler identity. The definition of settler colonies as "self-governing dominions with tenuous ties with the mother country" elides the fact that the term "settler" is a euphemism to hide the violence and dispossession of indigenous people involved in the process of settling (Young, Postcolonialism 17). ${ }^{\text {viii }}$ Anne E Coombes points out that what differentiates settler colonies/countries such as Australia, South Africa, Canada and New Zealand from each other are not their relation to the mother country, but their relation with the indigenous people. ${ }^{\mathrm{ix}}$

Beyond Protest: Ethics of Racial Reconciliation in the Works of Post-apartheid White Writers compares the works of J. M. Coetzee, Nadine Gordimer, Antjie Krog and Andre Brink with the Truth And Reconciliation Commission Final Report, to argue that white authors adopt indirect narrative strategies such as magic realism and irony to negotiate their complicity with South Africa's racial history and the consequent problems of representing the racial other. The authors use indirect and ambiguous modes of narration to mark their complicity with apartheid and imagine alternate possibilities of inter-racial relations based on a positive relation with the past. The flamboyant play with different narrative strategies is a result of the ethical exigencies of post-apartheid South Africa, rather than an art-for-arts sake free play of aesthetic experimentation. This means that Brink's dream of literature free of politics is yet to be realized. Nevertheless, postapartheid literature is free of overdeterminism by politics, free to represent the complex 
relations between races and between the past and the present-connections that the new era must account for and engage with as it seeks to move behind the debilitating grip of racism’s long hostile history in South Africa. ${ }^{\mathrm{x}}$

\section{The Post in Post-apartheid and the Post in Postcolonial}

The problems with South Africa's reconciliation—entrenched racial and ethnic identity, fragmented body politics, continuing inequalities and absence of a common ground — come to the surface in a recent South African high court ruling reclassifying Chinese South Africans as “Black”. On June $15^{\text {th }}$ 2008, the Wall Street Journal reported that a South African High Court had ruled in favor of reclassifying South Africans of Chinese descent as "Black" so that they could benefit from the affirmative action policies set in motion to undo the wrongs of apartheid. ${ }^{\mathrm{xi}}$ The court ruling was because the Chinese Association of South Africa sued the government for discriminating against its members, who were classified as white and, hence, ineligible for affirmative action benefits. They felt that their community deserved to benefit from affirmative action because they faced discrimination during apartheid until the 1970s, when a trade treaty with Taiwan elevated their racial status. The Chinese South African demand for Black status brings up a number of points about the connection between South Africa's messy racial history and reconciliation, namely the shifting nature of race and the consequent problems with affirmative action.

The shifting racial identity of Chinese South Africans indicates that race has no transcendental value. The Chinese South African desire for Black status shows how a negative identity category from the apartheid has acquired coveted status, while the value of whiteness has declined. The fluctuating relative values of "Blackness" and whiteness 
suggest that race acquires its meaning from its context. Originally classified as

“Colored,” Chinese South Africans began to be treated as whites after a trade treaty with Taiwan in the 1970s led to Taiwanese South Africans being labeled as "honorary whites." While Chinese South Africans never attained full white status like the Japanese, South Korean or Taiwanese South Africans, they were protected from many of the discriminatory laws of apartheid since the 1970s. Their latest reclassification comes in the wake of China's increased investment in South Africa. The Chinese South African example suggests that race is based on social, economic, legal and political factors. The Chinese South Africa case highlights race as a "fluid ... historically specific concept parasitic on theoretic and social discourses for the meaning it assumes at any historic moment” (Goldberg, Culture 74). Yet, “traces of ... past significations” mark the present contours of race (Goldberg, Culture 81). The paradox of race in South Africa is that it colonizes discourses to fulfill its agenda, even though it is a "fluid, fragile and more or less vacuous concept capable of alternate theories” (Goldberg, Culture 81). While law was used to prevent Chinese South Africans from sharing resources with whites during apartheid, in post-apartheid South Africa Chinese South Africans effectively use the law to secure racial identity for themselves. The insinuation of race in legal discourses also ensures that only those Chinese residing in South Africa either in 2004 or earlier can benefit from affirmative action. By restricting the beneficiaries of affirmative action law divides the Chinese South African community. The Chinese South African example shows that race is not based on biological difference. It is "an imagined grouping” that “assumes content influenced by established political legal, cultural, scientific and social factors and relations, but is not reducible to them” (Goldberg Culture 82). The fluidity of 
race implies that though race doesn't seem to have a fixed form, it succeeds in perpetuating its agenda through various discourses that define it at a given point in time.

The Chinese South African example makes it clear that race is a reading of the body inflected with current social, political, religious, economic, and other discourses circulating in a particular context. As a representation strategy for embodiment, race is an almost empty signifier, dependant on social and political discourses for definition, even as it defines social forces. The shiftiness of race, its paradoxical ephemerality and persistence, is the result of its basis in changing ideology. The absence of an apriori essence makes Anthony Appiah claim that race is fiction since it based on biological claims that are spurious, while Paul Gilroy defines race as “imaginary” blackness in Against Race (270). But, as the Chinese South African demand for redress for past wrongs shows, this imagined system has very real consequences, consequences related to the distribution of and access to resources, quality of life, and opportunities for development. These consequences cannot be wiped away with a change in name. Indeed, the rising cache of Black identity vis a vis white identity in South Africa has not been accompanied by a corresponding improvement in the circumstances of a majority of the nonwhites. The gap between the value of racial categories and the lived circumstances of actual members of a particular racial group is the result of structural inequalities created by the nation's long racist history that continue in the present. Race thus has a duality: it is an ideologically-motivated representation strategy and it is lived experience. Changing the representation, under the circumstances, does not create a corresponding change in the lived experience of the other. 
The Chinese South Africans dependence on law to secure justice for its past suffering is ironic because law is embroiled in racial politics and informs racial meaning. The paradox of law is that it pretends to dispense justice on the basis of rights distributed evenly among its subjects, yet it protects and acts for special parties. In short, law's claims of being based on universal humanity are fiction. The principle of equivalence within which law theoretically operates makes the newly reclassified Chinese South Africans equal to other consistently Blacks groups such as the Africans and Indians. But it ignores the fact that Chinese South Africans, who were exempt from the worst effects of apartheid since 1970, had a very different experience of apartheid from that of other "Black” groups like Africans, Indians, etc. In the transformation of racial reconciliation into a battle of rights, in the reduction of a historically loaded racial term to an empty category of rights, the traumatic history of the African community is foreclosed. The Chinese South African case reveals how the universal premises of law actually serve private interests. One of the consequences of dependence of law as a means to reconciliation, according to Jean Comaroff, is that "in the pursuit of legal rights, as in the politics of special interest, history is in danger of being made into a commodity, into evidence of entitlement, a charter for stakeholders" (134). ${ }^{\text {xii }}$ Comaroff cautions that litigation encourages "assertion of even less tolerant sectarian differences, of an incorrigible plurality irreducible to common social denominators or collective narratives, indeed, irreducible even to a common argument save through such 'universalizing media as law or money'” (134). ${ }^{\text {xii }}$ Affirmative action, which defines equality in terms of opportunity i.e. equal "opportunity to compete" and "equal treatment before the law," instead of equal opportunity of development, misses the connection between equality and 
fairness (Goldberg Culture 20). Fairness refers to the distribution of resources so that everyone can have equal access to them to develop their talents. Equality of opportunity, on the other hand, is a matter of “opportunity," not “outcomes” (Goldberg State 252). Without opportunities for development affirmative action ends up in perpetuating the systemic inequalities of a historical context..

The example of Chinese South Africans illustrates the challenges of reconciliation in South Africa. It brings into focus the different issues at stake if reconciliation in South Africa is to succeed. The changing racial identity of Chinese South Africans and the concomitant access to resources highlight the shifting and deceptive nature of race, its intangible presence and its very tangible effects. This duality of race-race as representation and race as lived experience-makes reconciliation challenging. Yet this duality needs to be accounted for in reconciliation efforts. After all, if race is regarded only as representation based on spurious ideology it is possible to dismiss it and imagine common humanity as a way to move beyond race as Gilroy does. Gilroy’s concept of "planetary humanism" is a "new way of being at home in the world through an active hostility towards national solidarity and national culture and their privileging one over other more open affiliations” (Gilroy, Melancholia 68). However, as the experience of Chinese South Africans prove, race as lived experience means that the entrenched identities cannot be discarded for more open connections very easily. Thus reconciliation must account for both these aspects of race. Law and affirmative action fail because they only address the representative nature of race, ignoring its structural element.

In order to conceive of reconciliation as a process that accounts for the duality of race I draw on David Goldberg's theory of race as discourse. By race as discourse 
Goldberg means that it includes “descriptive representation of others" and "a set of hypothetical premises about humankind ... and about the differences between them” (Goldberg, Culture 47). The premises, which include ethical choices, institutional policies and rules of interaction, are "manifestations of power relations vested in between historically located subjects" (Goldberg, Racist 48). Race is thus a "socio-discursive praxis in determinate historical circumstances” that is integral to subject formation (Goldberg, Culture 59). The two aspects of race as discourse suggests that changing representation will not change the premises and practices that inform race. Thus changing the racial identity will not improve the lived experience of Chinese South Africans. The fluid nature of race, its dependence on other factors and its own goals mean that the practice of race perpetuates and changes its meaning. When race is used for the "exclusion of people in virtue of their being deemed members of different racial groups" it is institutionalized (Goldberg, Culture 98) Thus the practices and fictions of race are sustained and perpetuated by the discursive practices of racism, which is a "product of economies of power, reflected in the interrelation of bodies produced and refined in practice” (Goldberg, Culture 2). However, once initiated, "they pass onto the practicoinert, ready to be passed on, inherited, reproduced and reformed” (Goldberg, Culture 57). These exclusions include "actual or intended, effects or affects of racial and racialized discourse" (Goldberg Culture 2). The discursive nature of racism implies that there is no transcendental racism. As an instrument of social formation and naturalization of group relations, race itself is not violent (even though it is not ethical). It becomes violent when it is used by the agents, in particular historical contexts, to violent ends. 
Since race includes representation of subjects and social practices, and is the conceptual basis of racism, racism can be eliminated by attacking its racial foundation. Changes in racial patterns can be effected through "changes within a discourse and changes of a discourse" (Goldberg Racist 10). The former involves "local changes in some constitutive feature or element of the discourse," while the latter refers to "shifts from one discursive formation to another" that involve "changes in whole ways of world making” (Goldberg Culture 10). This means that changes in one strand sets off a chain reaction of changes in other strands that, ultimately, reconfigure and reorder racist expression. Thus there is no way of transcending race. But it is, however, possible to create opportunities for new positive dynamics between groups through change in practices. In short, reconciliation seeks to end racism, not race.

To put it in another way, South Africa's reconciliation efforts need to aim for an anti-racist society, rather than an anti-racial society; a post-racist state, rather than a postracial state. ${ }^{\text {xiv }}$ By "anti-racist” Goldberg means the acceptance of multiple formations of racism and adopting strategies to root them out individually. Antiracism actually roots out racist culture, not race. It is not based on assimilation or integration, which are both controlling, but on incorporation. ${ }^{\mathrm{xv}}$ It is not looking at simplistically replacing white rule with black, but at creating a society where whites and blacks are treated with humanity. As Goldberg puts it, the problem is not with eradicating race, but with the way it is used to define the body politic. If racism used race to perpetuate a culture of violence and terror then anti-racism uses it to perpetuate harmony. Because there are many different racisms and each kind of racism is tied to the specific context there is no fixed formulae for anti-racist practices. Harmony here is not static, but contingent, provisional and 
always fragile. Goldberg's strategy of tackling the shifting nature of racism is useful because it highlights the need for reconciliation to be fluid and flexible, guided by context, rather than a universal theory.

As much as I draw on Goldberg's analysis of race as discourse, its main drawback for reconciliation is that it focuses on resisting racism. However, reconciliation is not limited to resisting racism. Reconciliation also builds new connections to rupture existing patterns. Since racism is informed by power relations, the role of the different parties involved in preventing racism and building positive relations differ according to their position in the power structure. By focusing on the role of white South Africans I point out the need for the beneficiaries of power to relinquish control, however wellintentioned, and allow themselves to be directed by the wishes of the victims of racism. In short, the white South Africans need to be guided by respect for differences and understanding of history, instead of their ability or power.

Given the deep significance of the spurious claims of race in modern life, and the entanglement of racism in the practices and institutions of modern society, developing newer patterns of racial interaction need to move beyond established prescriptions of interaction, beyond preexisting norms. Transforming old patterns of interaction in a way that focuses on the racial other requires recognizing the singularity of the other. It involves moving beyond the realm of knowledge and active control to a world of reflective recognition and affective understanding, according to Emmanuel Levinas. Levinas describes this process of recognizing the other as alterity as a move from politics to ethics. For Levinas, the encounter with the other forces the self out of its solipsism into a relation and a rupture, for it forces the self into acknowledging the other. This 
acknowledgement results in a "responsibility for the other," which is "love beyond concupiscence” (Levinas 103). It is, thus, a movement from the quest for knowledge about the other to a desire to understand the other. Responsibility, for Levinas, rests on the premise that "being is not accomplished in the triumph of man over his condition, but in the very tension in which that condition is assumed” (Levinas 2). Instead of realizing the self by moving outside of the self to know the external world, the Levinasian self seeks to understand. Knowing or acquiring knowledge is a form of control, as colonial history has proved more that once. Understanding, on the other hand, attempts "not to define ... but to be in an affective state .... to be engaged, merged with what we think, launched - the dramatic event of being-in-the world” (Levinas 3). Levinas is not talking about negating oneself by identifying with the other, because he observes that responsibility for the other, born of face-to-face encounter with alterity, is asymmetrical and egoistic. Recognition, for Levinas, is followed by the need to connect and bridge the gap. In order to connect with the other Levinas recommends turning to language, instead of political measures such as law and government, because through language one "overlooks the universal being" that the other incarnates to focus on "the particular being that he is" (7).

But Levinas's substitution of language for law as the means to capture the singularity of the other is not a viable option for South Africa because of its fractured body politic as well as the post-structuralist gap between language and reality. By using language to connect to the other one is attempting to describe an "allegedly uncommon 'situation'” through a medium "whose generality takes on a value that is in some ways structural, universal” (Derrida Monolingualism 20). South Africa’s complex racial and 
ethnic situation complicates the postmodern gap between language and reality because there is no universal language in South Africa. During apartheid Afrikaans, the official language, divided the Afrikaners from the English South Africans, who spoke English. One of the points of alienation between the Coloreds and the Africans, who had their tribal languages, was that the former only spoke Afrikaans, the language of the whites. The absence of a common language is the result of a long and violent racial history. ${ }^{\mathrm{xvi}}$ The absence of a common medium of communication with the singular other in South Africa does not mean that reconciliation is impossible. It simply means that reconciliation should be based on the acceptance of irreconcilable differences as the foundation for an ethical relation with the racial other. Instead of wishing away differences through the rhetoric of shared humanity, reconciliation should negotiate through these differences, which are testimony to the way history is experienced and embodied differently across time. The irrevocable differences that are the basis of reconciliation resemble the “abiding alienation” between language and reality that is “constitutive” (Derrida Monolingualism 25). Derrida observes that this “inalienable alienation is not only the origin of our responsibility, it also structures the peculiarity and property of language” (Monolingualism 22). As a result, there is "some objectification in progress” in transcribing reality into language (Derrida, Monolingualism 22). The paradoxical relation between language and reality corresponds to the double bind of reconciliation and history. Language is alienated from reality because language cannot cover the complex heterogeneity of the real, the field of the signified. By extending Derrida's concept of the gap between language and reality to reconciliation we can say that history is the alienated sign of reconciliation. To put it differently, the idea of 
reconciliation seeks to deviate from the past, but the underlying premises of that history (identity categories, ideologies behind colonial and apartheid racism etc) constrain its expression. Reconciliation cannot be understood without acknowledging history: it seeks to alienate/differentiate itself from that history, yet that history marks the limits of reconciliation.

The challenge for white South Africans is to find a way to offer assistance that honors the differences, that never assumes an identity between the white self and the nonwhite other it seeks to represent. As Alfred Noyes astutely observes, reconciliation needs to abandon the illusory quest for a perfect correspondence of the speaking subject and the spoken object. What must be retained is the difference embedded in case, the difference between the nominative subjectifying case (who) and the accusative, objectifying case (whom). It is the question of how to speak against the hegemonic force of a universalizing theory while at the same time sustaining a theory in a way that enables not only a politics of reconciliation, but also of redistribution (275).

The goal of reconciliation, according to Noyes, is the vexing problem of discovering a way to offer redress that does not trivialize history under the rhetoric of universality.

Reconciliation as abdication of agency does not mean that it is unrealistic or impossible. Instead, the seemingly passive task of relinquishing control and letting the other dictate the terms of reconciliation allows for hitherto unexamined connections to emerge. These connections may fall short of perfect accord, but they are grounded on a reality that makes such accord illusory. Reconciliation based on a notion of agency that relinquishes active control heeds Gayatri Chakravorty Spivak’s caution against idealistic 
conceptions of agency in the real world, where justice is forever differed and deferred. Instead of speaking for the native, or projecting our desires onto them, Spivak advocates understanding that the "desire to help the colonial has a threshold” (Spivak Postcolonial 292). This “experience of the impossible," which she describes as the position where the "historical and national elite does not abdicate responsibility upon the easy road of call to arms by way of vanguardism that must of course never be acknowledged," avoids the trap of cultural relativism or pluralism in the name of humanism (Spivak, Postcolonial 292). Respecting the threshold to the other reveals a "commitment not only to narrative or counter narrative, but also to the rendering impossible of another narrative” (Spivak, Postcolonial 292). She describes this as a process of “active marginalization,” a self conscious acknowledgement of the limitations of one's position, while accepting that the boundaries are porous and the end is inclusive (Postcolonial 292). Spivak's politics of limitation provides a sense of agency that acknowledges the conditions of its creation even as it criticizes it. ${ }^{\text {xii }}$ As a model for possible action amidst deep global imbalances of power, Spivak’s concept of the “experience of the impossible” offers white South African a model for interaction with the racial other that bypasses romantic notions of agency. In acknowledging the "threshold" to understanding the other white South Africans highlight the narrative that is not to be-complete understanding between the two hostile groups. Reconciliation as a process of building an imperfect relation with the other is "a ... relationship without relationship, with one guarding itself from the other, in the waiting without horizon for a language that only knows how to keep people waiting” (Derrida Monolingualism 71). 
Spivak’s materialist deconstructivist postcolonialism and Goldberg's Foucauldian concept of race present reconciliation as a dynamic and fluid process of negotiating history by marking the limits to knowledge of the other and the ability to speak for the other. The combination draws attention to the correspondence between the "post" in postcolonial and the "post” in post apartheid. Moving beyond race, like moving beyond colonialism, is a constant process of negotiating the relation between the past, present and future, instead of temporal closure. ${ }^{\text {xviii }}$ It also reminds us that for South Africa the postcolonial situation did not just mean negotiation between Europe and the white settlers, but also between the white settlers and the African majority that they disenfranchised in the attempt to gain control over South Africa's land.

My exploration of the ethics of reconciliation in a settler colony like South Africa makes the case for the importance of reconciliation as a strategy for negotiating the legacies of colonialism, despite the skepticism of many postcolonialists regarding reconciliation. Postcolonial theorists such as Simon During and Benita Parry, among others, identify the postcolonial agenda with utopian projects like freedom for the disenfranchised, and justice as reversal of past wrongs. They are, therefore, critical of reconciliation, which is associated with compromise, as a postcolonial practice. For instance, in his essay "Postcolonialism and Globalization: A Dialectical Relation After All?” During writes that postcolonialism's embrace of concepts of cultural negotiation such as ambivalence, hybridity, etc., have turned the field "reconciliatory rather than critically anti-colonialist” (31). For Benita Parry reconciliation is a strategy to serve the perpetrators, rather than victims. Despite my emphasis on the possibility of reconciliation and the critical role of white South Africans in the process, I do not regard reconciliation 
as a strategy to maintain the status quo. My definition of reconciliation as a reflexive and ethical concept can be described as critical reconciliation. I use the term "critical” in the same spirit that Rebecca Walkowicz uses the term in her concept of "critical cosmopolitanism.” Walkowicz defines critical as "critique of critique” and "reflection about reflection” (3). It involves demystification of the neutral categories and investigation of objective concepts alongside the critique of conditions that make critique possible (3). It is thus about persistent self-reflection, and the "self-reflexive position of the self” vis a vis the other (2-3). Reconciliation as a critical and dynamic process of interracial relation is important for South Africa because, given the entangled racial structures and the complex negotiations involved in dissolving apartheid, South Africa can neither discard its settler population, nor disregard the need for their wealth and expertise in rebuilding the nation. In such a complicated historical context, as a process of reflecting on the assumptions of reconciliation and its methods, critical reconciliation lays the foundation for a more just society.

As a dynamic process of negotiating the difference between the self and the other to develop positive relations with the other, that are grounded in history, my conception of reconciliation challenges the assumptions of the melancholic school of postcolonialism. Despite its entrenched position as an academic discipline in the West, postcolonialism is apologetic about its failure to recover the subaltern or reverse the injustices of the past so that progress becomes possible. Its lack of triumphalism can be attributed to the gap between the messy and complicated reality of postcoloniality and the utopian projects it aligns itself with. Postcolonial theorists often regard these values as theoretical endpoints. Even as postcolonial theorists acknowledge strategies to tackle 
messy historical reality, they continue to remain nostalgic about the ideal. A case in point is Spivak’s essay “Can the Subaltern Speak.” In this essay Spivak argues that the subaltern cannot speak because class divisions prevent the subaltern's voice from being recorded in history. It, therefore, remains out of reach of the critic and historian. Spivak's strategy to circumvent the inaccessibility of the subaltern is to emphasize the importance of critical reading. The task of the critic is to mark the absence of the subaltern, rather than attempt to create or recover her. But, through careful and critical reading the critic can, at best, mark the absence of the subaltern. Spivak's nuanced understanding of the subaltern and the impossibility of recovering the subaltern is a perfect example of postcolonialism as an “ironic project,” where one mourns the loss and marks its absence (Seshadri 66). ${ }^{\text {xix }}$ While Spivak's strategy does not recover the subaltern, it, at least, offers a way of recognizing the existence of the position of the subaltern, which would otherwise have remained unnoticed. Yet, despite Spivak’s strategy to tackle the impossibility of recovering the voice of the subaltern in historical discourse there is a persistent melancholic tone in her essay. This is evident in her insistence that the subaltern cannot speak, since readers can only retroactively identify the position of the subaltern, in all her revisions of the essay. Spivak’s essay is marked by a sense of loss because, despite its recuperative strategy, she continues to regard justice as a theoretical endpoint, rather than a process of negotiating a positive relation between the past and the present.

I regard the ironic reality of reconciliation, of creating common ground through acknowledgement of differences, of accepting that history is embodied differently in its subjects, as the beginning of a possible and realistic future. While this notion of 
reconciliation is not a return to triumphalism, it, nevertheless, offers a more positive reading of the historical reality of postcoloniality. I argue that the complexity and paradoxes, the gaps and silences, and the imbalances and residues of earlier power relations that characterize postcoloniality should be the starting points for dreams of justice, freedom, and reconciliation, instead of utopian concepts. Reconciliation, as I imagine it, perceives South Africa’s post-apartheid and postcolonial state as a process of negotiating historical power imbalances through time. Implicit in the concept of reconciliation as process is the awareness that negotiations are the site where power dynamics shift through time, rather than steps to an end goal.

\section{Literature}

What is the role of literature in this racial system, a system which is the cause and the consequence of a network of all discourses of modern life? Since "the formidable manifestations of history continue to define various and interconnected cultural, economic and political landscapes” (Ernest 474), "the inscription of the Black voice” preserves "those very cultural differences to be repeated, imitated and revised in a separate Western literary tradition, a tradition of black difference” (Gates 12). ${ }^{\mathrm{xx}}$ If the discursive nature of race means that there can be only different expressions of race, then literature cannot escape from race. The objective of literature, therefore, is not to “demystify race itself, but to develop counter-projects that destabilize the link between representations of racial difference and the structure of the racial state” (Germana 3). Thus literature offers a counter-discourse to the institutional measures. Literature as a counter-discourse does not offer a way out of race, nor can it give voice to the other. 
Instead, literary counter-projects must factor in the author's racial identity and the resultant limit of identification.

Beyond Protest: Ethics of Reconciliation in Post-apartheid White Writing suggests that white authors experiment with postmodern self reflexive strategies such as open endings, irony, magic realism, and narrative tropes like archiving, metacommentary on narratives, and fragmented narratives, to signal their critique of and complicity with South Africa's post-racial present. The shift from realism to postmodern narrative modes is ethical because the latter prevents the formation of narrative empathy through identification with characters or narrators. These narrative strategies used by white writers indicate that literature is "not the bridging of gaps through the creation of empathy, but the articulation and keeping alive of intractable ethical questions about the asymmetrical relation between the self and the other" (Travis 232). Travis's comment alerts us to the fact that creating identification with the other through narrative gives rise to multicultural ethics that seeks to transcend differences. Indirect representation strategies, which inhibit readerly empathy, as intrinsic to the ethics of reconciliation dissociate ethics from empathy in literature. ${ }^{x x i}$ In Disgrace irony decenters the protagonist Lurie, while the absence of an authoritative narrator prevents concrete representation of the racial and gendered other. In Country of My Skull Antjie Krog's invention of an extramarital affair discounts her narrative authority to show the limits of empathy. The narrative ethics of reconciliation as a process thus demonstrates the limits of empathy. In the process it suggests that literature intervenes in discourses by forcing the reader to confront the aporias of imaginative empathy. 
I focus in the rhetorical aspects of reconciliation, which Walkowicz calls “postures,” such as irony, magic realism, fragmented narrative, and withheld autobiography, rather than different experiences of reconciliation (29). That way I draw attention to the critical models writers use to present and understand reconciliation, even as I acknowledge the way experience of reconciliation influences writing. The strategies used to present reconciliation in the text reflect this duality: they describe the specific practices of reconciliation such as the refusal of legal redress, respect for differences between the self and the other; at the same time, they demonstrate how limits to understanding the other prompt narrative strategies that confront readers with the boundaries of their imaginative empathy. These rhetorical strategies differentiate postapartheid literature from apartheid literature. For authors like Coetzee, who evaded the realistic discourses of protest literature, indirect representation is a continuation of their anti-apartheid practices. For others like Andre Brink there is a shift in strategy and theme from their apartheid novels. Brink switches over to magic realism from realism. For others such as Antjie Krog, the new era compels experimentation with a new genre and in a new language: non-fiction, instead of poetry, and English in addition to her native Afrikaans.

Recognizing reconciliation as a narrative practice and lived experience draws attention to the social nature of reading and writing. If creative writing, according to Derek Attridge, is inspired by the writer's encounter with the other that challenges established conventions, then reading forces the reader to encounter possibilities elided by politics and other discourses. I seek to explore how the imagined world of literature "furthers our commitment to the other and allows us to look to the future" in a way that 
other discourses fail to do (McGonegal 9). In the post-apartheid milieu, which encourages grand conclusive visions of reconciliation, literature outlines the problems and the promise inherent in its historical context. Peter Halliard, in Absolutely Postcolonial, points out that literature offers new ways of seeing because it can "step back from representation, suspend its natural flow and pay artificial attention to 'how it works'”(335). Thus literature can involve us in scrutinizing ideas. Spivak rightly describes literature as “our teacher as well as our object of investigation” (Spivak, Death 28).

I analyze the possibilities of literature as a counterdiscourse by comparing literary texts with the Truth and Reconciliation Commission Hearings and Final Report. The political and fictional texts challenge the idea of reconciliation as closure, or recuperation of power. These texts imagine and invent alternate ways of conceiving justice, history and, consequently, reconciliation. Instead of regarding justice as impossible, these texts dedicate themselves to exploring the possibilities of reconciliation, even as they acknowledge the difficulties of translating this vision into practice.

I examine the paradoxes of racial reconciliation by, first, analyzing the foundational event for racial reconciliation in South Africa, the Truth and Reconciliation Commission. The TRC sets the tone for reconciliation as a dynamic ethical project through its conception of narrative truth, restorative justice and its open public hearings. These conceptions of truth and justice enable narratives that reveal apartheid to be a period of complicity and resistance that challenge easy associations of Black and white with goodness and evil respectively. The open hearings forced the victims and perpetrators to enact new identities: the whites were forced to listen, while the hitherto 
silenced populations, the non-whites, presented their experience of the horrors of apartheid. It gave both groups the scope to inhabit their new identities. The performative aspect of the TRC hearings emphasizes reconciliation as a process that has to continue beyond the venue of the TRC hearings. It is, however, ironic that an institution that highlighted the need for narratives to understand the past and move beyond the destructive grip of history remained silent on the role of literature in reconciliation. In addition, the limited time span under its review neglects the deep roots of South Africa's racial problems. Viewing the TRC in this way prepares me for the significantly more complex cultural reflections and ethical meditations presented in the literary texts I examine in subsequent chapters.

Discussion of the importance of narratives in a political document sets the stage for a discussion on how narratives participate in and complicate reconciliation. J. M. Coetzee’s Disgrace challenges readings of South Africa’s racial problem as the result of only the apartheid. The novel has been panned by South African critics for the presence of negative stereotypes of the non-whites and a protagonist who rapes a Colored woman. I focus on the way novel uses irony and multiple narrative threads to criticize of South Africa’s post-racial politics, which cover the deep roots of the country’s racism and enable racial amnesia. The novel's subtle and sophisticated use of irony, I argue, undercuts its racist protagonist and his stereotypical representation of the other. In the end the novel suggests that racial reconciliation is achieved by acknowledging the impossibility of completely understanding the other, especially in relations marked by power imbalance and violence. 
Since the past inflects present identity, the ethics of reconciliation is concerned with creating a positive relation between the past and the present. Reconciliation must not only acknowledge the past, but it must also abandon the desire to search for an authentic past or valorize counter histories. Andre Brink’s shift to epistemic magic realism to represent the imagining of history, as opposed to his earlier efforts to recover history, attends to the critical role of history in reconciliation. In Chapter 3, I examine the ethical imperatives of Brink’s magic realism to argue that magic realism mocks the desire to recover an essential past by presenting historical accounts as ideological constructs. Exploring the ideological subtext of the different accounts of the past allows Brink to present South Africa's racial history as a chaotic system. The chaotic structures of race and its shifting, yet lingering, effects cannot be addressed through legal measures alone. It requires us to envision reconciliation as a process of active engagement with the past. For the protagonists of Brink’s post-apartheid novels reconciliation becomes an endless process of attempting to connect to the other.

Closely connected to reconciliation is the desire for forgiveness. Forgiveness offers white South Africans an opportunity to be integrated into the new nation space, where they are no longer in a privileged position. Forgiveness by the racial other also reaffirms their new self. But, not only is the demand for forgiveness from the non-whites egoistical, it does not address the structural basis of racism in South Africa. The uncertainty of forgiveness from the racial other poses a problem in white autobiographies, where the formation of a new self depends on affirmation from the racial other. In order to examine the relation between forgiveness and reconciliation, in my final chapter, I examine how autobiography, the most egoistical of genres, negotiates 
between the focus on the self, the responsibilities of being a witness to the other's narrative and the need for the racial other as an empathetic listener. I compare Nadine Gordimer's None to Accompany Me with Antjie Krog’s memoir Country of My Skull to argue that Spivak's notion of "withheld autobiography" offers a model for autobiography that privileges the listener, even as it narrates the white autobiographer's transformation. Gordimer's novel, which incorporates the structure of an autobiographical address in the interaction between characters, and Krog's memoir, which includes a fictitious extramarital affair to create the space for her experiences, erases differences between fiction and non-fiction in autobiographies.

In a brief epilogue I consider how reconciliation as a dynamic process forces us to reconfigure conventional ideas of hope, justice and friendship. Magic realism, withheld autobiography, and irony envision the possibilities of reconciliation as well as its problems in South Africa. In the process, literature transforms our ideas of forgiveness, hope, history and advocacy to show how critical reconciliation, based on an acknowledgement of unbridgeable differences, does not negate possibilities of justice, harmony and change, all values integral to the postcolonial project.

Ultimately, the following chapters will show that literature is a place where the thorny issues of South Africa's reconciliation are thrashed out and represented. By exploring the way racial reconciliation influences literary conventions I seek to affirm that literature is a site where the negotiations of reconciliation are enacted. The reflexive strategies of white authors are an attempt to negotiate between their privileged positions as white South Africans and the need to respect the singularity of the racial other. The 
negotiations require that visions of historically nuanced relations must be matched by narrative strategies that identify and demonstrate differences in experience of history. 


\section{Chapter 1}

\section{Truth and Reconciliation Commission of South Africa: An Event that Launched a Process}

In 1976, Archbishop Desmond Tutu, then the Anglican Dean of Johannesburg, wrote an open letter to Prime Minister John Vorster with several grievances against apartheid policies. He ended the letter with the fear that injustices against Africans were making them desperate and would result in a "point of no return when events will generate a momentum of their own” leading to a "bloody denouement” (qtd in Bell 86). The "bloody denouement" Tutu feared was averted by a miraculously bloodless transfer of power through universal suffrage that put Nelson Mandela’s ANC into power in 1994. Despite the peaceful transition of power, post-apartheid South Africa continues to be marred by racial violence. The murder of Eugene Terreblanche, the white Supremacist leader, by his non-white farm workers, on April $12^{\text {th }}$ 2010, is one of the most recent instances of continuing violence. Attempts by Terreblanche's group to appeal to the UN for a separate white homeland and fears of racial violence raised by his murder suggest that reconciliation remains a pipe dream more than a dozen years after the end of apartheid. ${ }^{\text {xxii }}$ The continuation of violence is not surprising because interracial relations in post-apartheid South Africa are still inflected by structural inequalities surviving from apartheid. Face to face interracial encounters in the post-apartheid era thus risk remaining embroiled in the discursive patterns of the past.

The continuation of racial violence in the post-apartheid era raises questions about the success of the Truth and Reconciliation Commission (henceforth referred to as the TRC or the commission) in achieving reconciliation. The TRC was formed for the 
express purpose of helping to realize the Postamble to the Constitution's vision of a new South Africa committed to the "recognition of human rights, democracy and peaceful coexistence and development opportunities for all South Africans irrespective of race, class, belief or sex" (qtd in TRC 6: 3). The Commission's task was the "pursuit of national unity, the well being of South African citizens and ... reconciliation between the people of South Africa and the reconstruction of society" (qtd in TRC 6: 3). The sociopolitical realities as well as the constitutional mandate defined the TRC's conception of reconciliation as requiring "understanding but not vengeance ... reparation but not ... retaliation, ubuntu but not ... victimization” (qtd in TRC 6: 3). ${ }^{\text {xxiii }}$ The need to move beyond violence implies that reconciliation needs to be grounded in an understanding of the past. In other words, as the TRC put it, reconciliation has to be premised on truth. In order to find a true picture of apartheid it is necessary to give space to the stories suppressed by the state-sponsored apartheid history. The Human Rights Hearings were developed to allow the victims to present their account of the past. However, utopian dreams of correcting the prejudiced apartheid history through these hearings need to be revised in the light of the fact that memorial reconstructions of the past are affected by failures of memory as a result of trauma and fear, resulting in contradictory accounts of events by victims and perpetrators. These contesting accounts reveal their different experiences of history. The hearings thus reveal truth to be an equivocal, and shifting (sometimes shifty) process of reinventing individual and national identity.

Critics have pounced on the ambiguous nature of truth that emerged from the hearings as a sign of the TRC's failure to correct history and deliver justice. For example, Geoffrey Robertson describes the TRC "less as truth substituting for justice than a form 
of plea bargaining in which truth is traded for leniency" (247). Richard Wilson feels that the TRC subordinated rights and law to the expedients of nation-building. As a consequence, he fears justice became the first casualty. Mehmood Mamdani has pointed out that the Commission's focus on extraordinary acts made apartheid seem like a rogue regime, foreclosing everyday injustices of the system. ${ }^{\text {xxiv }}$ Benita Parry points out that "no government or leader or officially constituted commission has the moral authority to grant a people's acquittal of their erstwhile oppressors, since in this situation the consent and co-operation of neither party has been solicited or procured” (183). Amy Gutman and Dennis Thompson claim "a post-apartheid state that forgave these crimes could not credibly claim to be committed to the most basic democratic principles” (32). The critics seem insistent on the need to unearth the full story of the past and deliver retributive justice because they feel that discovering the truth will permit them to undo the past through punishment and reparations. Their criticism is based on two premises: 1 . that the past can be put to rest, and 2. that retributive justice is justice par excellence. But, reconstruction of the past from memory is complicated by the position of the person remembering and psychological issues like trauma, paranoia, fear etc. Punitive justice can neither reverse the loss suffered by the victims, nor undo apartheid or the racism persisting from the colonial times. The impossibility of reaching the past means justice is always deferred. ${ }^{x x v}$

In this chapter I present a counter thesis to the previous readings of the TRC. I argue that the lacuna in truth that emerged through the hearings do not signal a breakdown in the TRC's reconciliation efforts or a failure to unearth history. Instead, the factual inconsistencies reveal the blind spots around which narratives construct 
themselves. The hearings reveal reconciliation to be a process of negotiating a relation with the past that moves beyond pathologies of amnesia and monumentalization to acknowledge the impossibility of transcending the past. It, thus, suggests that relation with the other needs to be open to the opacity of the other, to differences. Reconciliation as a process reveals South Africa's dream of a democracy free of racism to be in a state of constant realization.

Conventionally "process" implies action in progress, action directed towards a definite goal. The presence of a telos binds process to a time frame. This view of process is possible only in an ahistorical context. In reality, no goal is static because every goal is located in history, where it is subject to pressure of events and forces around it. Under these circumstances, process doesn't lead to a goal, but is an endless cycle of upholding a principle amidst the flux of history. Even if the goal remains the same, under the pressures of history, it will be realized differently in different contexts. In the real world, process as a dialogue between history and ideals is itself a goal. I therefore regard the TRC as an intrinsic part, but not the end, of the reconciliation process. It marks a shift in the racial dynamic of South Africa and opens up possibilities just as it forecloses others. This shift involves negotiations that took place before it and the actions taken by the state and individuals thereafter. Reconciliation as a process is akin to Jacques Derrida's notion of "democracy to come." xxvi In democracy to come Derrida describes democracy as a promise and injunction to equality, rather than a fait accompli in any historical context. xxvii Like Derrida's view of democracy, my definition of reconciliation as a process includes the promise and injunction of future respect for the singularity of the other, 
justice and harmony. Like "democracy-to-come," reconciliation is an "endless process of improvement and perfectibility” (McGonagal 8).

Attending to this understanding of process, I shall examine the historical background to the TRC to show that it was a part of the evolving racial dynamic of South Africa. Its specific historical context determines the TRC's unique format and accounts for its most innovative feature: the public hearings. The hearings, which explode the monolithic racial and historical discourse on apartheid, serve as a model for interracial interaction that moves beyond revenge and friendship to open up possibilities for recognizing the unique humanity of the racial other. However, the limited life-span and power of the commission mean that the onus on responding to the possibilities it opens up depends on the state and the citizens of South Africa. In short, I read reconciliation as a top-down approach, where the state plays a mediatory role in promoting and fostering reconciliation.

\section{Reconciliation as Political Compromise}

The most remarkable aspect about South Africa's journey from apartheid to democracy, according to Martin Murray, was not the demise of apartheid. The demise was expected, but the bloodless transition to democracy, given the violence that characterized apartheid and its resistance movements, surprised everyone. Signs of the end of apartheid had been evident from the eighties, when its exclusive policies and the international boycott brought the economy to near bankruptcy. An attempt to diffuse the black militant movement by devolving authority to the Black middle class saw violence spiral into a civil war, where unrestrained black militancy devoured itself as ethnic identities complicated the linear black/white racial dynamic. The emergency declared by 
President Botha in 1985 failed to curb the civil war. Under the circumstances, according to Murray, it was surprising "that the sudden denouement of the once invincible apartheid system was not accompanied by the kind of violent civil war pitting Black revolutionaries against an entrenched white establishment” that happened in neighboring Zimbabwe (1).

The non-violent transition of power was the result of circumstances. Apartheid's inability to protect the economic interest of the whites, and the rising militancy of the MK, the militant wing of the ANC and the Azanian People's Liberation Army (APLA), the militant wing of PAC, split the NP into conservative and reformist factions. The reformist faction gained voice when F.W. de Klerk took over. De Klerk granted more power to the Blacks at the local level. Consequently, the local Afrikaner councilors were replaced by Black councilors, who started their own corrupt regime in the townships to line their pockets. But leading non-white parties like the ANC and PAC rejected reforms. They wanted democracy and their militant wings launched guerilla warfare against the white establishment, targeting security forces and paramilitary forces that terrorized townships. Since the ANC was banned and operated from abroad, it had no control over its young cadres, who went on an unrestrained rampage, attacking not just white power, but non-whites of other ideologies. Black councilors, members of rival non-white political organizations and members from other townships and classes became targets of their wrath. At the same time, tribal chiefs in the various homelands set up vigilant forces to bring the Blacks in their territory under their control and fight the APLA and MK. Simon Skosana organized private armies for the independence of Kwa Ndebele, while Buthelezi, the Zulu chief, distanced himself from the ANC, in an attempt to portray himself as a moderate black. The fractured black identities meant that there was no 
cohesive non-white opposition. It comes as no surprise that the non-white resistance was unable to overcome the white establishment.

At this juncture—when the Afrikaner-majority party National Party (henceforth NP) government was brought to its knees by international boycott and collapse of law and order, but the resistance was not strong enough to capitalize on the momentnegotiations were in order. The NP originally planned to share power, securing minority rights and veto power over major decisions for the Afrikaners. The process of negotiations, initiated in the eighties through a series of secret meetings between the ANC and the ruling white NP, was carried out through the Groot Schmur Minutes (May 1990) and the Pretoria Minutes (August 1990). The result was the unbanning of the ANC and the release of Nelson Mandela. As exiles returned and many political prisoners gained freedom, there was backlash against the whites. The National Peace Accord was formed at the encouragement of the national human rights movement and the South African Council of Churches with the triple aim of (a) eliminating violence, (b) promoting democratization, and (c) reconstruction and development. Side by side, the Convention for a Democratic South Africa (CODESA), the first multi-party meet to discuss South Africa, was formed. Nineteen parties participated. CODESA1 and CODESA2 failed in the face of unabated violence. In fact, the ANC withdrew from CODESA2 because of the Boipotang killings. From this point of no return negotiations began anew. The NP was forced to agree to a democratic election, while the ANC agreed to an amnesty policy that would provide indemnity from civil or criminal prosecution in return for disclosure of crimes. Finally, in 1994 the elections were held. 
The historical events preceding the end of apartheid suggest that the postapartheid era did not end white supremacy. The non-white ANC government functions in a situation where, even though it has political power, the economic power remained under white control. This meant that the whites would want to maintain status quo, while the non-whites would prefer redistribution of resources. Nor could the ANC count on the support of the entire black community since they inherited a fractured community, where racial and class divisions were complicated by ethnic identities reinforced through the creation of Homelands. The ensuing divisions imply that ethnic and racial identities are so deeply imprinted that they continue after the end of apartheid. One example of the problem created by ethnic ties cutting across racial ties is evident in Zulu chief Buthelezi identification of Zulus as "Zulu South Africans." He further claims that "The State of Kwa Zulu Natal is a sovereign member of the Federal Republic of South Africa. It recognizes its obligations towards the Federal Republic ... in so far as they do not infringe upon the rights, powers and liberties guaranteed by this constitution” (qtd in Barber 75). ${ }^{\text {xxviii }}$ The Zulus, along with other tribes, forged an alliance called the Freedom Front that practices secessionist politics by demanding separate tribal enclaves. South Africa’s polity resembles Ernest Gellner's “eastern nationalism,” where, in the absence of "an already existing well defined and codified high culture which had as it were already marked out and linguistically pre-conceived its own territory,” competing cultures struggled for power "in ferocious rivalry with similar competitors, over a chaotic ethnographic map of many dialects, with ambiguous historical or linguo-genetic allegiances, and populations which had begun to identify with these emergent national high cultures” (100). In the light of South Africa’s complex ethnic and racial divisions, 
the movement from apartheid racism to post-apartheid democracy was not linear, but complex.

The brief history of the events leading to the TRC reveals that it was a compromise born out of a political impasse. As a political strategy the TRC sought to establish reconciliation so that the different groups could work in harmony. According to Rajeev Bhargava, political reconciliation ensures the "cessation of hostilities” so that "a minimally decent society” can be set in place. Political reconciliation is different from personal forgiveness or personal reconciliation, both of which need "profound change in ... identities” of victims and perpetrators (Bhargava 61). Nevertheless, political reconciliation creates the groundwork for a "radical restructuring of those economic, social, political and cultural circumstances which would render the wrongs of the past as properly transcended" so that "recall of ancestral and recent adversity may be contemplated if not in tranquility, then, perhaps with pain but without rage” because “only then can ... the descendants of the injured extinguish their urge to retribution” (Parry 183). Therefore, like all interim organs of justice, the TRC had a finite lifespan: it covers the time from 1960-1994. But as an organization responsible for building the foundation of a democratic society, the TRC sought to change the discourses and create a more open society, rather than magically transform the society.

\section{Truth as Narrative and Justice as Restoration}

The TRC drew upon the models of earlier organs of transitional justice ranging from the Nuremburg Trials to the Argentinean and other Latin American Truth Commissions. However, it was different from these models in its recognition of the complexity of truth and the importance of narrative truth in healing a fractured 
community. The TRC identifies four kinds of truth: factual or forensic truth, personal or narrative truth, social truth and restorative truth. Forensic truth refers to "factual corroborated evidence” obtained through “reliable (impartial, objective) procedures” (TRC 1: 111). Narrative truth, on the other hand, "keeping in mind the value attached to the 'oral tradition' in South Africa," refers to the stories told to the TRC. These stories were not presented as “claims to a court or arguments” but provide “unique insights into the pain of South Africa’s past”(TRC 1: 111). It validated the “individual subjective experiences of the people who had previously been silenced or voiceless”(TRC 1: 112). Social truth is "truth of experience that is established through interaction, discussion and debate" in order to understand the "complex motives and perspectives of those involved (TRC 1: 113). The final truth category highlights the importance of acquiring truth in a manner that acknowledges and affirms the pain of others. The different kinds of truths emphasize the singularity of each experience and present truth as a multi-faceted phenomenon that emerges through dialogue and openness to difference. The value of narrative truth lies in its ability to include narratives from the excluded groups and open the monolithic discourses of history to the unacknowledged voices. In the process, narrative truth challenges our understanding of apartheid as merely a racist regime to draw attention to the fractured body politic and the gender violence across race. ${ }^{\text {xxix }}$

The importance of transparency and dialogue in the TRC's conception of truth draws attention to the role of the listener in allowing narratives to exist. Jean Francois Lyotard points out that a narrative involves a listener, a narrator and a subject. Its meaning is, therefore, not "limited to the moment of enunciation," that is in the authority of the speaker, because "speech acts relevant to this form of knowledge [narrative 
knowledge] are performed not only by the speaker but also by the listener” and involves “know-how, knowing-how to speak-and knowing-how-to-listen” (Lyotard 21). The threeway circuit involved in narrative communication creates and affirms social bonds. The presence of a listener implies that the effects of narrative are not restricted to the moment of enunciation. The impact of narratives cannot, thus, be predicated and is not always immediate. The importance given to narratives draws attention to reconciliation as a long and fragile process that places signal demands on the listener. Thus, narrative truth raises questions about the ethics of listening or being witness.

In the TRC hearings, where the structure of the law court was adapted to enable narratives and privilege the victims, the listener was not just the perpetrator, who was invited to be present, and the general public, who could hear and watch the hearings being aired, but also the TRC, which was proxy for the new state. In order to ensure that these disclosures did not result in more bitterness the TRC set itself as a buffer between victims and perpetrators. The victim's lawyers or the victims themselves addressed their questions for the perpetrators to the three judges presiding over the hearings. The judges repeated the questions to the perpetrators. The perpetrators directed their replies to the judges as well as to the victims' lawyers. This ensured that the animosity between the groups was regulated. The TRC as mediator sets itself up as a virtual perpetrator according to Sanders. As a virtual perpetrator in the human rights hearings, the TRC opens itself to the testimony of the victims without questioning their veracity. By acting as the buffer between the victim and the perpetrators, the TRC mediated between hostile parties, still locked in the Manichean apartheid discourses, to offer an alternative mode of voicing difference. Since the ultimate perpetrator during apartheid was the state, the TRC 
as virtual perpetrator stands in for the erstwhile apartheid state and assumes its responsibility for reparation. The TRC as a virtual perpetrator reminds us that listeners do not just enable narratives; they have a responsibility to respond to the affective call of the narratives as well. The complex role of the TRC in the hearings highlights the critical role of the listeners in narratives.

TRC's narrative truth is based on the principle of restorative justice, which is a “victim-centered vision of justice,” which "affirms that in societies emerging from a period of repression justice requires an inclusive remembering of painful truths about the past and a commitment to allow victims to tell their stories," so that their experiences are acknowledged and their dignity restored (Kiss 73). Restorative justice enables the state in transition to bury the past "as seeds, rather than as corpses ... not dead and forgotten, but something from which the future can grow” (Phelps 128). Retributive justice, where the perpetrators of human rights abuses are punished in a court of law, in contrast, is based on "the Enlightenment principle that human rights accrue to individuals”(Barkan xix). However, Elizaar Barkan argues that group identities are crucial to identity formation and rights that accrue to individuals also accrue to groups. By failing to account for group identity retributive justice cannot always restore the victims' dignity or validate their experience.

The pragmatic goal of restorative justice views responsibility as a two-way process, even if the burden is greater for one group. Restorative justice “doesn’t need each victim to forgive each perpetrator. It needs a shared understanding of the terrible things that happened ... of how it happened and what the context was” (Sachs 96-97). Restorative justice places severe ethical demands on the perpetrators as well as the 
victims. For the perpetrators it involves "acknowledging, however haltingly, in whatever limited way, at least something of what they did” (Sachs 97). The victims, on their part, had to eschew revenge. This doesn't guarantee forgiveness in the ethical sense, but it creates the seeds of a civil order that allows for the transformation of both parties.

It might appear that narrative truth veers away from the empirical basis of law. However Sanders points out that narrative truth manipulates the ambiguity between law and narrative to challenge facile equations of law with facts and literature with fiction. The ambiguity in law refers to the fact that "while the words of the witnesses can themselves be ambiguous in meaning and effect, any such ambiguity is underwritten by an ambiguity in the law itself that comes into play when it solicits and elicits testimony” (Sanders 5). According to Sanders, when the court "elicits evidence through questioning, it calls forth a story. The questioner may think that he or she knows the answer in advance, but, since nobody knows what the witness will say, he or she is structurally in a position of ignorance” (Sanders 6).Consequently, law often ends up “facilitating both a narrative and counternarrative” (Sanders 9). Even though law depends on the verification of evidence, testimony cannot be verified at the moment of articulation. Law is, thus, forced to become host and hostage to its other. The statement that is accepted without verification is described as fiction by Sanders because it is neither false nor true, but "unverifiable” (Sanders 6). By being open to the unverifiability that lurks at the core of all testimony law exists as "the differance between fiction and truth" (Sanders 6) The doubling in the testimony, which makes law open to the unverifiable, often forces the TRC to revise its goals and expectations as we shall see in the case of the women's 
hearings later in this chapter (Sanders 8). This structural ambiguity in law makes truth less a matter of verifiable fact, than a fractal phenomenon.

\section{Performance and the Enactment of Reconciliation in the Amnesty Hearings}

The TRC hearings were structured to maximize reconciliation. The hearings were of two kinds: amnesty hearings and the human rights hearings. The amnesty hearings, held behind closed doors, allowed perpetrators to appeal for amnesty. The human rights hearings were formed to balance the perpetrator-focused amnesty hearings. The human rights hearings gave victims space to narrate their terrible experiences under apartheid. The human rights hearings, which brought hostile groups into contact with each other, marked a new era of interaction that was a clear departure from the segregation, terror and violence of apartheid. In the hearings after the victims finished telling their stories the judges stood up to commend them. This gesture ceremoniously distinguishes the TRC's ethos from that of apartheid. As a legal step that marks the new beginning, the TRC can thus be classified as an operative act, which refers to ceremonial actions that bring about a change in existing patterns and relationships, because it seeks to symbolize the new era. ${ }^{\mathrm{xxx}}$ But an operative act presumes on a community, on a set of beliefs that is common to the population it addresses. Since racial interaction in South Africa has no prior state of harmony to fall back on, the TRC is not bringing about re-conciliation as much as conciliation. It is attempting to build a fragile community on untried soil. Thus, unlike other operative acts, it cannot presume on the sense of community that gives meaning to ceremonial actions. Since the TRC is not a "part and parcel of the regular institutional arrangement of 'normal' democracies," but "part of historical founding projects” like “constitutional authorities, which are interim organizations that launch a 
new era,” it had to enact the values it represents (du Toit 124-125). It thus has to state its values as a performative utterance. ${ }^{\mathrm{xxxi}}$ Through its gestures, the TRC figuratively gives birth to a community, to that recognition of the other that will pave the way for a future. ${ }^{\text {xxxii }}$

The performative element of the human rights hearings has invited criticism. Richard Wilson argues that the hearings were a "theatricalization of the power of the new state, which compelled representatives of the former order to confess when they would rather have maintained their silence” (20). Wilson’s theatre metaphor equates performance with play acting. But his analysis ignores the fact that the arena for exhibition of state power was simultaneously a site for the enactment of a new racial drama - one where the two racial groups come face to face under the aegis of the TRC. In this context, it is necessary to distinguish between performance and acting. Acting in a theatre is different from performance because the actors remain conscious of the difference between their identity and that of the characters they are portraying. Performance, however, refers to action defined by prescribed norms that express identity. ${ }^{\text {xxxiii }}$ Through performance one is projecting one’s desires and identity to the outside. It implies involvement and commitment and is individual as well as communal. In the process of enacting desires performance realizes historical possibilities. That is why it is regarded as crucial to identity politics. In Cities of the Dead, Joseph Roach identifies performance as an expression or actualization of desire, as well as an attempt to restore. He further elaborates: “performance offers a substitute for something else that pre-exists it. Performance in other words stands in for an elusive entity that it is not, but that it must vainly aspire both to embody and to replace”(Roach, 3). Judith Butler 
emphasizes the element of absence in performance by describing performance as constituting identity through "stylized repetition of acts" that is often "internally discontinuous”(92). This suggests that identity is unstable. Merleau Ponty adds that body performances enact “cultural and historical possibilities” (qtd in Butler 902). Hence, performance is way of "dramatizing and reproducing a historical situation” (Butler, 902). Performance assumes that identity is without an apriori essence and defined by the context in which it is taking place and the possibilities inherent in that context.

By defining the individual, performance also adds to collective identity. Victor Turner describes social action as requiring "performance that is repetitive.” The absence of stable essence and the dialogic nature of identity, whether it is individual or collective, make performance a form of substitution. As substitution, performance has to be repeated i.e. carried on beyond the site of performance and individually replicated in order to represent the community and self. The importance of performance in national identity is reiterated by Homi Bhabha in "DessemiNation,” where he identifies two axes that constitute national identity—-pedagogical and the performative. The former is the ideal of a nation built around myths and symbols; the latter is the enactment of those ideals in everyday life. These two may not coalesce as the performative often does not embody the pedagogical. In South Africa, the pedagogical, in terms of ideals rooted in symbols of collective identification, is absent. So, the performative becomes crucial in embodying the nation. The TRC uses performance to create identity in two ways. First, the hearings embody in its structure and performance a different ethos from apartheid. Second the TRC's use of mass-media to broadcast the hearings creates an imagined community of "horizontal" solidarity through temporal "simultaneity" that is "traverse, cross-time, 
marked not by prefiguring and fulfillment, but by temporal coincidence, and measured by clock or calendar”(Anderson 24). However, the fragility of performance and the realities of truth finding make both truth and community ambiguous terms.

Theatricality has been an intrinsic part of racial relations in South Africa. ${ }^{\text {xxxiv }}$ Under the colonial regime and apartheid South Africa resembled a theatre of racial discrimination, where conventions and strict laws scripted the movement and interaction between racialized subjects and determined the architecture of the nation space.

Interaction in this theatre was marked by oppression, violence, secrecy and distrust. Since the theatre of racial segregation created polarized racial, ethnic as well as class identities in South Africa, one way to break the deadlock is to change the theatre. Transforming the theatre means changing the content of the theater as well as its form. So the closed and secretive apartheid theatre was replaced by the transparent and egalitarian theatre of the TRC hearings, which were public and broadcast by the media. The hearings created a theatre in which the state, citizens and courts were participants in the reconciliation process. In the TRC hearings the victims could tell their story and the perpetrators confess their crimes in front of a panel of three judges, and a public audience, which often included the victims or his/her kin, and the mass media. Despite being victimcentered, the victim's story was not the last word. Perpetrators were given a chance of rebuttal. At the same time, if the victims did not agree with the decision of the TRC they could take recourse to law as Steve Biko’s family did. The hearing allowed free expression of emotions and respected individual choice. The TRC theatre introduced a new mode of interaction that respected conflict, instead of suppressing it. Commenting on the functioning of the TRC, Patricia Valdez writes, "permitting the dynamics of conflict 
to evolve and the actors of civil society and democratic institutions to express themselves freely is one of the best ways of preventing all types of authoritarianism, thereby building a truly democratic political culture” (57). Alex Boraine reiterates this when he defines reconciliation as "exchange of ideas in a climate of mutual respect and peaceful coexistence" (77).

This new theatre created opportunities for enacting new identities. Teresa Phelps has described the hearings as carnivalesque. Drawing on Bakhtin’s definition of the carnival, she points out that in carnivals, unlike official feasts, where the power of the state was reinforced, restraints of the everyday world are lifted. Moreover, the carnival is also a space which brings together diverse groups of people together. In the hearings, for the first time, apartheid rules of racial interaction were lifted as victims and perpetrators confronted each other with their roles reversed. The victims were given a voice and the perpetrators were forced to listen. The hearings thus forced victims and perpetrators to enact roles discordant with their historical identities. Enacting a different script, in a different theatre, enables them to imagine the possibility of a different relation with the other than the one they are used to. It is hoped that acting out ethical choices will, in time, lead victims to forgive the perpetrator or create remorse in the perpetrator. While it is true that the perpetrators were generally known in many cases, the public confession implied acceptance of their responsibility in the violence and recognition of the singularity of their victims. At the same time, victims suppressed by the apartheid state got to narrate their story. The act of narrating their loss and suffering in a public forum validates the victims’ experience and restores their dignity because, according to Phelps, apartheid silenced the victims and denied them language, thus conveying a sense of negative self- 
worth. Because narratives have an immediacy and poignancy that facts lack, the act of narration transforms victims to individuals, while perpetrators morph from embodiments of evil to flawed human beings. Through narratives that remember the past, society was “re-membered” according to Phelps (71).

The public confessions set up a model of conduct and worked to create a community that didn't exist through recognition of the singularity of the racial and/or gendered other. It brought together hostile camps, whether it is the opposing Black groups like ANC and IFP, or the Whites and Blacks in a same place and forced them into an act of remembering and articulation. The audience and the performers were given the scope to look beyond the determinism of race to engage in mourning the loss of humanism, life etc. Through the process of interacting, remembering and reliving, a community was being built. The fragile community that emerges through performance at the TRC is similar to Saidiya Hartman identification of spontaneous community that formed during the communal dancing sessions of the African American slaves at the command of their masters, in Scenes of Subjection. Hartman points out that in the absence of an "apriori community” communal bonds were created through “interaction”(60). Hartman notes that communities formed this way were not seamless, despite the shared sufferings. Instead, community created through the dancing sessions was brought into existence through performances and was marked by antagonism and betrayals. Hartman's observation indicates that the formation of community in the absence of an apriori core is unstable and fluid, and needs to be reiterated constantly through repetition. Since the South African polity, like the slave communities of USA, is 
a fractured and fragile set up, any community created during the hearings has to be realized in the real world through performance.

Despite the carefully considered structure, the TRC's textbook model of reconciliation and truth-finding was often jeopardized by memory lapses, differences in the account of the victims and perpetrators, rejection of the TRC's mediating role, or its inability to be hospitable to the victims. The hearing of the five former Umkhonto weSizwe(MK) cadres and the police chief Jeffrey Benzien reveals many of the problems to community building that arose in the hearings. In the 1980s Benzien, a member of the Anti-terrorist unit of the Security Branch of Cape Town, had arrested Tony Yengeni, Ashley Forbes, Gary Krusner, Peter Jacobs and Bongani Jonas and tortured them. Benzien's account was marked by lapses in memory, memories that would have helped implicate higher officials who had not applied for amnesty. Benzien’s seemingly strategic loss of memory and breakdown at the hearing has been open to radically different interpretations. Some see it as sincere apology, while others read Benzien’s lapses in memory as a result of post traumatic stress disorder. ${ }^{\mathrm{xxv}}$ Ria Kotze, a psychiatrist, diagnosed Benzien with post traumatic stress disorder, marked by symptoms of auditory hallucinations and memory loss. His trauma was brought about by the fact that during his time with the Security Branch he was "torn by his belief that he was saving the lives of the public ... and the disgust that he felt in the measures he had to take” (qtd in Graham 26). The traumatic effects of violent regimes such as apartheid on both perpetrators and victims, so effectively exposed by the Benzien case, compromise truth-finding and present truth as indeterminate and ambivalent. 
The Benzien hearing was also marked by the victims’ request to the judges to question Benzien themselves. It was a departure from the ordinary proceedings because usually, in the hearings, the judges mediated between the victims and the perpetrators. When the victims decided to question the perpetrator directly the mediating function of the TRC was removed, and the victims and perpetrators confronted each other again. This confrontation creates the chance for a new violation according to Sanders. Sanders points out that the tone of Benzien's victims, as they began questioning him, revealed that they wanted to extract from him more than a confession: they expected him to "submit to them”(Sanders 105). That did not happen as Benzien effectively turned the table on them, repeating the original moment of torture. The Benzien hearing shows how traumatic experiences frustrate reconciliation and the recovery of the true past.

The special hearings for women reveal that the community envisioned by the TRC was gendered. Women occupy a particularly vulnerable position in South Africa. Not only were the indigenous women victims of the racist apartheid policies, but they were marginalized within the patriarchal structures of their community. In the hearings it was observed that, while women came to testify for their family members, they rarely spoke about their own experience of discrimination. The commission realized that even though it was not a part of their agenda, the women needed a forum to be able to speak freely of the injustices they had suffered. Therefore, special hearings were held for the women. In the hearings a lot of the women mentioned the abuses suffered in the liberation camps. However, none of them identified their perpetrators or the political organizations. The TRC, surprisingly, made no move to commiserate with the women as they shared their experiences of the abuses at the liberation camps. The TRC's failure to 
be host to the gendered other reveals the subordinate position of women in the postapartheid patriarchal order. The position of the women exposes the continuing connections between apartheid and post-apartheid South Africa.

The significance of the women being denied hospitality by the TRC lies in the complicated relation between customs and law in South Africa. In South Africa there have been two kinds of legal systems since the colonial times: the customary laws that were dispensed to the non-whites by the tribal chiefs, who were proxy for the colonials and modern justice, which was dispensed among the whites by the whites. The customary laws were, therefore, not really customary, but a part of indirect rule. The customary laws were codified as Natal Code in 1878. Even after the end of apartheid those customary laws remained, though they are subordinate to the national laws. So when the Bill of Rights included, in addition to the equality clause, the right to "use the language and to participate in the cultural life of their choice, but no one exercising these rights may do so in a manner inconsistent with any provision of the bill of rights," it brought the customary into the fold of the legal system and the non-whites into the nation space (qtd Sanders 71). For women inclusion of the customary into the legal system, however, did not automatically ensure inclusion into the nation-space. In fact, the Rural Woman’s Movement tried in vain to include the clause that "not only should equality apply to all groups but it should trump claims to culture and custom that justified discrimination against women”(qtd in Sanders 71). Since women occupied a subordinate position under the patriarchal system, the failure to include women in the constitution left them in a position no different from the one they occupied from the colonial times or under the rule of the chiefs. In fact, the women make it evident that end of racism needs to be 
accompanied by democratization in the rural areas and homelands so that they become privy to the same rights as men.

While the promises of community offered by the hearings were often thwarted by things beyond the control of the TRC, the use of mass media like radio, television and print to broadcast the hearings helped create a community despite the racial, ethnic and economic inequalities. Unlike the hearings, which built community through encounter with singularity and affective bonds, the broadcasts create bonds through sense of synchronous time. In order to explain this point Benedict Anderson's concept of the nation as an imagined community is important. According to Anderson the nation is an imagined community built on the notion of “deep horizontal comradeship”(7). This horizontal comradeship developed after the demise of monarchy and the theocentric universe in Europe. Temporal simultaneity was made possible in earlier times through religion or monarchy, both of which connect the past, present and future in messianic time. In the secular era, after the disappearance of religion or monarchy as cohesive forces, temporal simultaneity moved from messianic time to "temporal coincidence" that is “measured by clock and calendar”(Anderson 24). This sense of simultaneity, this awareness of other strangers inhabiting the same geographical space in time, is created through the novel and newspaper according to Anderson.

South Africa's entry into the imagined community of modern nationhood plays out dramatically in the shift from the apartheid concept of national community and to the post-apartheid concept of national community. The main difference between apartheid and post-apartheid ideas of imagined community is that during apartheid the nation was conceived in terms of allegiance to apartheid racial ideologies. The dream of a racially 
pure nation united the community across space. In the new nation, where there are 11 national languages and many ethnicities, community is imagined in terms of temporal simultaneity, rather than ideological or linguistic allegiance. The sense of simultaneity is replicated in South Africa by the various media broadcasting the hearings. The South African Broadcasting Corporation (SABC) transmitted the hearings and had special programs every Sunday, summarizing the plans of the commission and the schedule for the week ahead. The radio transmissions were in all the eleven official languages. The broadcasts conjure up a space occupied by a number of individuals who, despite being unconnected to each other, are engaged in listening to the radio or television broadcast. In that sense the broadcasts effectively help to "invent” community amidst deep inequalities (Anderson 6). ${ }^{\mathrm{xxxvi}}$

Creating community through the broadcast has been ambiguous process because the media seized on certain images of the hearings as emblematic of the past. Graham points out that Benzien's demonstration of the wet-bag technique and his breakdown at the hearing, the cry of Nomonde Calata, and Lucas Skewepere declaring that telling his story to the commission made him feel like he got back his sight were seized upon by the TRC and the media as signs of reconciliation. Tony Yengeni’s protest against Benzien’s accounts in the hearings as well the decision of the Biko family to file charges against Biko's murderers suggest that the paradoxes of truth resulted in monumentalizing the past, and a certain version of the past. In the process the everyday abuses and connection between apartheid and colonialism was lost.

\section{Reparations as Imperfect Gesture}


The women's hearings, the Benzien case, and the dependence on horizontal solidarity to form community reveal reconciliation and truth-finding to be marked by deep-seated ambiguities and indeterminacies. While the victims are so traumatized that they remember an incident vividly, the equally traumatized perpetrators were often unable to remember the incident or remembered it differently from the victims as the Benzien case shows. The indeterminacy of the past made the TRC refer to its task in the final report as a "story of South Africa”. By describing itself as a story, as opposed to a history, the final report offers itself as "a roadmap" for those "who wish to travel to the past" and "critique this [the commission's] perspective" and not the "whole truth" as Tutu puts it in the Foreword of the Final Report (TRC 1: 2). Therefore judging the TRC's story of South Africa in terms of history brings it into the realm of facts, truth and lies. Sanders points out that, while it is necessary to avoid falling into the trap of rejecting facts for narrative truth, we should be aware that "facts and the subsequent division between truth and lies, depend on originating, instituting 'lies' to which we give names such as 'telling'”(167). In the politics of fact and fiction, the emphasis on facts that can be empirically verified can result in rejection of testimonies that do not corroborate with “instituting lies” (167). Tutu's invitation to debate draws attention to the multivalent nature of South Africa's past. By inviting responses it encourages a new relation with the past: one that moves beyond the pathologies of amnesia and fetishization to engage with the past in a matter that does not paralyze progress. ${ }^{\text {xxvvii }}$ The TRC, at best, initiates the process of recovering suppressed histories.

The main means of redressal available to the TRC was reparations. The Committee of Reparation and Rehabilitation observes that "the work of the commission 
would be unbalanced” if the “exposure and exploration of past experiences” was not accompanied by “reparation and rehabilitation-related services and the meeting of financial and other needs” (TRC 1: 96). Reparations took the form of symbolic gestures to commemorate the victims in public and private memory such as exhumation of missing bodies, construction of memorials, renaming streets and boulevards, and issuing death certificates and rehabilitative measures. Rehabilitation includes measures to improve conditions in Black townships, resettle the displaced, and offer medical and psychiatric care for those affected by the violence. Special attention was given to psychological assistance for victims because "the mental health of many victims of apartheid ... depends on the ability of the new government to work towards provision of adequate services” (TRC 5: 371). The TRC also suggested monetary reparations to the victims identified during the hearings. It recommended that the state force businesses that benefited from apartheid policies to make reparations in terms of taxations.

When the past is so contested, so frustratingly ambiguous, reparations as the means of addressing past wrongs are inadequate. Reparations as the sole means of undoing the past are problematic because they are symbolic gestures. Just as the connection between a sign and its referent is not logical in a symbol, the relation between reparation and the wrongs it seeks to atone for is, also, arbitrary. According to Sanders, this is because reparations are retrospective actions that seek to restore what has been damaged or destroyed. But the attempt to restore originary wholeness is fraught with problems because it is hard to identify origins. The wholeness that reparation seeks to restore is, therefore, often "a retrospective construction of an aristocratic and magisterial past” that has been lost (Sanders 129). Since the basis of reparations is a phantasy of 
wholeness its motivations are egotistic. The object of reparation is not in the picture except as a beneficiary or recipient of the reparations. Moreover, as Sanders argues, in South Africa, where relations are marked by violence and memories are distorted by trauma, the perpetrator's perception of suffering will not match the victim's perception of the loss. The symbolic nature of reparations means that they are always incomplete, and always inadequate. In the case of TRC there is the added complication of the TRC as a phantasmagoric perpetrator. However, without any power of execution the TRC cannot do more than recommend reparations.

Reparations are an act of double inscription. On one hand gestures of reparation for past crimes symbolize the end of the past and a new beginning. But reparation also draws attention to the incommensurable gap between suffering and compensation, law and loss. In the process, the act of making reparations reinscribes the history it unsuccessfully seeks to address. Reparations remind us that for the victims of historical crimes justice is fugitive as Stephen Best and Saidiya Hartman point out. Although Hartman and Best use the term in relation to the African American hope for justice during slavery, "fugitive justice" offers a nuanced understanding of the politics of redressal. Fugitive justice recognizes the difference between "grievance and grief" in "the necessity of legal remedy and the impossibility of redress”( Best and Hartman 3). It recognizes that "justice is beyond the scope of law, and redress necessarily inadequate"(Best and Hartman 1). For terrible crimes and events such as slavery "forms of legal and social compensation available are less a matter of wiping the slate clean than of embracing the limited scope of the possible in face of the irreparable, and calling attention to the incommensurability between pain and compensation” (Best and Hartman 
1-2). If justice is fugitive, the past cannot be erased. Yet, efforts for compensation have to be made even though words cannot capture the sufferings of the victims, and money is a poor substitute for historical wrongs. Reparation as failure to recover the past, rewrite history and repair historical wrongs ultimately doubles back to reinscribe the history it seeks to erase, a history beyond means of redressal.

According to Best and Hartman's concept of fugitive justice, reparations by the TRC underscore the insurmountable gap between state gestures based on the rhetoric of human rights and liberal discourses of freedom, and the psychological effects of apartheid that exist beyond any strategy for remedy or reversal. The TRC, which embodies fugitive justice, does not reverse or redress the crimes of apartheid, but signals the death knell of apartheid. The TRC presents the beginning of democracy and the end of apartheid as a moment of political interval between "the no-longer and the not yet, between the destruction of the old world and the awaited hour of deliverance" (Best and Hartman 3). It speaks for a pragmatic politics of working through the injuries of the past within the limited scope of the possible, rather than reversing a right, restoring the past or returning what was taken. By taking on the responsibilities of absentee perpetrators, which includes individuals and the erstwhile apartheid state, the TRC acknowledges and commemorates the violent history it cannot reverse. As a measure it is more successful in marking the past than other measures such as land rights. The former doesn't reject history while the latter gives the impression that land rights reverse the past wrongs.

Reparations are pragmatic measures that seek to build a new relation with the past. Building new relations with the past involves, among other things, transforming the signs of the past. The TRC made recommendations for infrastructural changes to remove 
the deleterious material effects of apartheid so that the past would not distort the present. Without the recommendations for compensation, truth would aggravate divisions and foster bitterness and violence. The recommendations imply that the commission is a part of a process of negotiating a healthier relation with the past, rather than a solution for past injustices.

In this new relation with the past, a past that remains elusive despite the openness of the TRC's process, the state and citizens have to be equal participants. The report's claim that "the commission has done its share to promote national unity and reconciliation" and its "achievement is up to each one of us" draws attention to the role of citizens in the process (TRC1: 23). Sharing responsibility with other entities presents the TRC as working in tandem with "organs of civil society -such as faith communities, nongovernmental organizations (NGOs), community based organizations (CBOs) and ordinary citizens" who "will need to continue to work towards unity and reconciliation long after the closure of the commission” (TRC1: 49). The Final Report makes it clear that reconciliation is a shared task that extends beyond the timespan of any organization. By deferring action to other institutions the TRC undercuts any closure to locate itself as part of a larger process and recognizes reconciliation as a personal choice of the state, the citizens and the leaders. The report reminds us that the TRC is an evanescent moment of unity among victims and perpetrators in what is a long ethical process.

Despite offering a historically nuanced idea of hope in moments of transitions, the TRC's representation of the post-apartheid moment as marked by indeterminacy of truth and deference of justice give an elegiac tone to the Final Report. This elegiac feeling does not indicate weaknesses in the structure and goals of the TRC as much as it exposes a 
lack of clear divisions between apartheid and post-apartheid era. The post-apartheid moment that comes out in the document is melancholic, rather than ecstatically optimistic. The TRC's larger processes bring home the fact that South Africa's dreams of the future remain firmly tethered to its past. The criticism that has greeted the TRC for failing to accomplish reconciliation is a result of this contrast between the new beginning it promised and the melancholia it exposed. This melancholia, resulting from the breakdown of the illusion of newness of the post-apartheid era, tempers hope and transforms reconciliation into a dynamic and pragmatic process. Instead of unambiguous assertion of healed ties, the TRC reveals fleeting possibilities of community that cannot ensconce themselves in the society.

\section{TRC and Literature}

Despite its lofty goals, the TRC's hearings prove that finding the truth is a frustrating process that belies the enthusiasm and hope that marks its inception. The result is the postponement of justice and monumentalization of the past. Instead of reading the TRC's inability to find the truth about apartheid as a symptom of its failure, it is possible to read the larger processes of the TRC, particularly the hearings, as pointing to the blind spots and contradictions that accompany rewriting history. The ambiguities of truth that emerge from the hearings point to the paradoxes that make the past unnarratable. At the same time, strategies of remembrance adopted in the hearings offer imaginative and productive ways to engage with the past (Graham 28). I am suggesting that what was said and what was not is less important than probing and understanding the visible gaps in the narrative as signs of the historical situation that perpetuated such trauma in both victims and perpetrators. The TRC is a call to move beyond holding these narratives to the 
category of facts and understand them as a process of individual and collective reshaping of identity in a new context.

The need to represent the unnarratable and the inaccessible confronts the TRC with the same issues that literature has to contend with. Graham claims that the TRC proves that "some truth cannot be spoken, only pointed to ambiguously"(34). It is, therefore, necessary to bear witness and represent "without sensationalizing it, fixing it, foreclosing its meanings, monumentalizing it or consigning it to the archive of oblivion” (Graham 34). Literature addresses these problems by moving away from dependence on factual reasoning to an imaginative reconstruction. In inviting alternate histories and counter narratives the TRC provides a space for literature because only literature can imaginatively mark the silences and dramatize the paradoxes and predicaments of truthfinding, bypassing simplistic dreams of closure. The TRC has underlined the importance of narratives and indirectly alluded to the need for storytellers and stories to recover counter narratives and imaginatively construct both the past as well as the future. The TRC's dependence on narrative truth and its recognition of the indeterminacy of truth point to the centrality of narrative in its process. Yet, the TRC remains silent on the importance of literature in representing the ambivalence of the post-apartheid moment. Sanders points out that the TRC's failure to elaborate on the importance of storytelling implies a devaluation of the role of literature in the post-apartheid context. ${ }^{\text {xxviii }}$ The silence on storytelling is unfortunate because, even as the state fails to fulfill its injunctions, literature, through its formal innovations and imaginative vision, offers ways to reach out to the other without nullifying differences. The versatility of post-apartheid literature, as it moves beyond the determinisms of reportage and realism, offers visions of 
reconciliation that account for the messiness of history and encompasses the difference between the self and the other. In the following chapters I shall examine how prominent white South African writers like J. M Coetzee, Andre Brink, Nadine Gordimer and Antjie Krog respond to the challenges of representing the other to envision racial reconciliation. 


\section{Chapter 2}

\section{Speaking With a Forked Tongue: Disgrace and the Irony of Reconciliation in Post-apartheid South Africa}

The Truth and Reconciliation Commission of South Africa’s (TRC) open and public hearings and inclusion of both the victims' and perpetrators' perspectives on the apartheid set up a model of representation that is open, inclusive and eager to embrace the heterogeneity of South Africa. The TRC thus represents the other as complex and singular historical beings, intersected by and differentiated into race, gender, ethnicity, sexuality, class and religion, existing beyond the racist and exclusive stereotypes circulating during the apartheid. The unique aspect of the TRC's representation is that it did not exclude other groups, not even the perpetrators, in the effort to give voice to the racially disenfranchised. Excluding the perpetrators would have repeated the same violence that it sought to end. But how might this ideal be extended into literature, given that literature must account not simply for an imagined historical turn but for a complex historical process? How is one to represent the other as an embodied being in history, when the long and messy history of racism precludes identification with and understanding of the other in South Africa? More importantly, how does one ethically represent the racial other without excluding or simply demonizing the perpetrators?

In South African literature, in recent times, the question of ethical representation of the other has centered on the debate about the viability of literary realism, deployed by resistance and dissident writers, over the anti-realist mode. As a way of representing the horrors of the apartheid, realism was regarded as an ethical imperative by some of its practitioners such as Alan Paton, and Nadine Gordimer in her pre-The Conservationist 
novels. Realism was seen as replacing the compromised historical documentation controlled by the apartheid state. The problem with realism in South African writing is that in the effort to present a true picture of the apartheid it often objectified the other into a spectacle. ${ }^{\text {xxix }}$ Anti-realist literature, on the other hand, was criticized for its attention to formal experimentation, instead of the moral exigencies of the apartheid. But as the nation entered the postapartheid phase, realism lost its status as an ethical imperative; accordingly, the move from apartheid to post-apartheid literature was seen as a leap from the bondage of realism to the freedom of literary experimentation. ${ }^{\mathrm{xl}}$ Just as descriptions of South Africa's political transition from apartheid to democracy as a smooth and linear movement from racism to freedom ignores, what Dorothy Driver calls, the "stealthy survival of apartheid discourses” and the continuation of white supremacy in the post-apartheid era, the movement from realism to anti-realism does not present a true picture of South African literature, nor does it account for the demands of South African history. ${ }^{\text {xli }}$ Continuation of racially asymmetrical social structures means that neither the urgency nor the need to speak for the other has ended. But how does one represent such realities without falling into spectacular objectifications of the other?

Such questions highlight the importance of J. M. Coetzee’s work. As Derek Attridge has argued, Coetzee's anti-realist mode of narration demonstrates that formal innovation is more than apolitical aesthetic play. ${ }^{\text {xlii }}$ Formal experimentation, Attridge clarifies, is the result of an author's attempts to recreate the experience of an encounter with the other that challenges existing representational paradigms. In his apartheid-era novels Coetzee avoided both the objectifications associated with realism and the 
apolitical shortcomings of anti-realism. Coetzee's metafictional strategies in the novels subvert and critique conventional genres to suggest that the violence involved in the discursive construction of self through narratives like fiction, travelogues, and historical documentaries is similar to colonialism and the apartheid. ${ }^{\text {xliii }}$ For example, in Foe Coetzee juxtaposes different genres, like travelogue, feminist fiction, and realist fiction, to show that the organization of events into narratives privileges a particular discourse or perspective by excluding others. ${ }^{\text {xliv }}$ In Dusklands placing Eugene Dawn’s documentary about Vietnam War before the account of $17^{\text {th }}$ century Dutch explorer Jacobus Coetzee's travels reminds readers that the violence of historical accounts lies, beyond the text, in the marginalization involved in crafting a self within a discourse. Coetzee thus gestures towards a more complex understanding of what might be understood as realism in South Africa, an understanding of an absurd social world that could be documented only by extending beyond the boundaries of literary realism.

To examine the possibilities of this approach, then, it is useful to look at Coetzee's first post-apartheid novel Disgrace, in which he confronted the challenge of representing post-apartheid realities. In this chapter, I argue that Disgrace grapples with and raises questions about the ethics of representing the other through a narrative that insets a 50-year-old Afrikaner's struggles to write an opera about Lord Byron and his last great love Teresa Guicolli within the larger narrative problem of representing the racial other in post-apartheid South Africa. Coetzee's subtly crafted and nuanced use of irony reveals the contradictions of ethical representation to be rooted in the historic contradictions of racial interaction in South Africa. In effect, the novel argues that in South Africa ethical representation can be successfully achieved through irony because 
the other can only be addressed indirectly. It therefore speaks, I argue, with a forked tongue, a deliberate avoidance of the priorities of literary realism by which Coetzee suggests that reticence about the other--and acknowledgement of the failure to capture the other as a complex being in time and space--is more ethical than realistic portrayal. The novel's deliberate and reflexive refusal to present the other as a concrete entity, ironically, points to the other's presence as a being in history. Irony in South Africa, the novel implies, is not just a rhetorical concept but the existential and philosophical condition of its racial history. ${ }^{\text {xlv }}$ Irony’s forked tongue enables Coetzee to decenter the novel's racist protagonist as well as explore the complex historical roots of the protagonist's racist perspective. Irony, then, empowers Coetzee to critique contemporary racial politics and their effects on reconciliation, and extend the inclusive politics of the TRC in the process.

\section{Critical Reception of Disgrace}

J.M. Coetzee, twice Booker Prize winner and 2003 Nobel laureate, is a controversial literary figure in South Africa. It is easy to understand why. During the apartheid, when realism and overt opposition to state racism was considered the responsibility of art, he insisted that literature "operates in terms of its own procedures and issues its own conclusions" and is a rival to "history, not a supplement" (Coetzee 23). Rejection of political determinism during the apartheid may have allowed Coetzee to produce some of the most formally innovative novels of his time that cemented his international reputation as one of the best novelists of the later twentieth century. But, the same formal experimentation made him unpopular at home because his works resisted appropriation by any political agenda. When Disgrace was published, in 1998, one 
expected his work to finally find appreciation in South Africa. After all, the apartheid was finally over. With it, one hoped, the need for literature to take a political stand through realistic depiction of violence had disappeared as well. This meant that literature, at least in theory, was finally free of political determinism and could, according to Andre Brink,

not simply ... escape from the inhibitions of apartheid, but ... construct and deconstruct new possibilities; ... activate the imagination in its exploration of those silences previously inaccessible; ... play with the future on that needlepoint where it meets past and present; ... be able to risk everything in the leaping flame of word as it turns into world (27).

In the new era, Coetzee could follow his "allegiances ... with the discourse of novels and not the discourse of politics” without apology (qtd in Penner xiv). He need no longer feel coerced into becoming a "South African Novelist," someone obligated to "produce works that can be adapted to political uses”(qtd in Penner xiv).

Disgrace, one of Coetzee's rare realistic novels, won 2 international awards: the Booker Prize and the Commonwealth Writer's Prize. Declaring Disgrace the winner of the Booker Prize 1999, the British Labour MP Gerald Kaufman praised it as "an allegory about what is happening to the human race in the post-colonial era” (qtd in McDonald 321). Announcing it the winner of the Commonwealth Writer's Prize, in 1999, Shashi Deshpande described it as "a complex story” that "embraces with remarkable skill the politics of a new nation” (qtd in McDonald 321). But for a novel that won 2 international awards, its reception in South Africa has been largely negative. The novel owes its notoriety to ANC's trenchant criticism of its depiction of non-white characters. In an oral report to the South African Human Rights Commission (SAHRC), the ANC reported that Disgrace enabled the persistence of racism among white South Africans because it portrayed the Black as a "faithless, immoral, uneducated, incapacitated primitive child" 
(qtd McDonald, 323). The ANC’s criticism was echoed by others like Aggrey Klaaste, who wrote, in the Sowetan, that the novel was the perspective of a "disgruntled Afrikaner" and that the story of "black men raping white women” was "offensive” (qtd in McDonald 325). Jakes Gerwel, professor and Director General of the President's office under Nelson Mandela, in the Afrikaans weekly Rapport, in February 13, 2000, was dismayed by the novel's "almost barbaric post colonial claims of black Africans," its representation of "mixed race characters as whores, seducers, complainers, conceited accusers,” and its “exclusion of the possibility of civilized reconciliation” (qtd in McDonald 325). The common point between the very different responses is that they regard the novel as a direct and transparent signifier of reality. The international awards, which praise the novel for its verisimilitude to South Africa's contemporary racial situation, distance themselves from the nation's complex problems by reading them as historical indicators. ${ }^{\text {xlvi }}$ On the other hand, the criticism from South African reviewers is premised on the belief that literature needs to reflect the political aspirations of the state. In both case, the assessment focuses on the narrative surface of the novel.

If we examine the novel in terms of its realistic narrative surface it will appear that the truculent critics have reason to protest this time. The narrative revolves around two rapes: David Lurie’s rape of his colored student Melanie and the gang-rape of Lurie's daughter Lucy by a crowd of black men. The violent storyline is complicated by the fact that the narrative perspective is on Lurie, a 50-year old Afrikaner and university professor, who is responsible for the racist utterances in the novel. The racist stereotypes uttered by Lurie become a problem because there is no authoritative third-person narrator as witness and judge of Lurie. Without an authoritative narrator to provide a concrete 
moral compass, the novel appears to endorse Lurie’s racist views. The absence of an authoritative moral focus in the novel means that the other never acquires a concrete shape, either as a character or a source of knowledge in the novel. The narrative focus on the racist protagonist, the absence of an authoritative moral voice, and the other as an absent presence has contributed to the novel being labeled as racist.

But the narrative surface, however realistic, is never a reliable indicator of Coetzee's intentions. The absence of a moral compass is a common theme in Coetzee's novels. For example, in Foe there are competing narratives without the privileging of any one. In Dusklands the juxtaposition of two novellas in reverse chronological orderEugene de Klerk's account of the Vietnam Project and the eighteenth-century explorer Jacobus Coetzee’s account of colonial polices in South Africa -forces readers to draw their own conclusions about the connection between contemporary practices and colonialism. Rosemary Jolly points out that the absence of a judging centre enables Coetzee "to represent the acts of violence that constitute a recurring subject in his fictions, without participating in the process of violation these acts exhibit.”(Jolly 110). It also helps Coetzee to "counter history as a prison, one in which we are doomed to repeat without difference the contours of a violent past” (Jolly 110).

If we take into account the ironic relation between the two strands of narrative as well as the play with narrative perspective, it becomes clear that in Disgrace the language of racist discourses is ironically mediated and turned against itself so that the other can be recuperated as an embedded, material presence in history, instead of an object of racist discourses. Through misreadings prompted by the presence of a larger-than-life racist Afrikaner and the lack of moral focus, the novel effectively confronts readers with the 
limits of their interpretive authority and biases. Coetzee's play on racist discourses in the novel recognizes that literature's participation and intervention in racist discourses differs from that of political manifestos and historical chronicles. On the basis of Coetzee's earlier works, the absence of a moral center and the other as a spectral presence can be read as a deliberate parody of various discourses to highlight the violence of discursive representation and expose the limits of the reader's knowledge of the other within the present discursive set-up. I begin by examining Coetzee’s representation of the new South Africa to analyze the changes that separate it from the past. The novel's context is important because it sets the ground for the racial representations that the characters engage in. The relation between contemporary racial discourse in South Africa and the racist past gives rise to two specific modes of representing the other: stereotypes, and the law based on a philosophical commitment to universal human rights. In the final section, by comparing Coetzee’s ironic representation of the other as an absent-presence with Lurie’s stereotypical representation of the non-whites, I argue that Coetzee offers an alternative mode of representation that can bypass the ideological impasse created by the nation's racist ideology that still continues in the post apartheid era.

\section{Post Racial Politics and Private Racism}

Disgrace proclaims its post-apartheid context from the opening paragraph, where the protagonist Lurie proclaims that his Thursday visits to the prostitute Soraya has “solved the problem of sex” rather well (Coetzee, Disgrace 1). The seemingly unremarkable statement by a twice divorced, lonely 52-year old man, glad to find an outlet for his flagging desires with a prostitute, is extraordinary in South Africa because Soraya is non-white. In South Africa, where inter-racial sexual relations were strictly 
monitored under the apartheid, sex with a non-white prostitute is novel. The statement makes it clear that in this new South Africa the Immorality Act (1950-1985) and the Prohibition of Mixed Marriages Act (1949) are no longer in force. Therefore, Lurie, who would have been labeled a blood mixer and imprisoned during the apartheid for having sex with non-whites, now visits Soraya without fear. ${ }^{\text {xlvii }}$ I do not mean that miscegenation began in South Africa with the end of apartheid. Miscegenation was an important part of racial and colonial politics and the presence of the sizeable Colored population is testimony to that. Apartheid legislation sought to end that to maintain purity of the Afrikaners. This meant that in the post-apartheid era, after a long time, people could choose their sexual partner across race and without fear of legal action.

What is even more remarkable in the new South Africa is the absence of racial reference. The racial identity of the non-white characters is indicated through references to ethnicity, history and skin-tone. Soraya’s non-white identity is revealed through references to her religion and her "honey-brown body, unmarked by the sun" (1). ${ }^{\text {xlviii }}$ The escort agency, Discreet Escorts, eschews race as an identifier and lists non-white sexworkers as "Exotics," identifying them by their ethnicity: Thai, Chinese, Asian etc. Since ethnicity has been used by the apartheid to fracture non-white resistance, it serves as a synonym for race. Melanie’s race is signified by her Kaaps accent, Lurie renaming her as “Melani-the dark one,” and references to darkness and non-European ethnicity in her description (Coetzee, Disgrace 18). ${ }^{\text {xlix }}$ For instance she has “close-cropped black hair, wide almost Chinese cheekbones”( Coetzee, Disgrace 11). ${ }^{1}$ We know that Petrus is an African through Lurie’s reference to their relationship as “baas en Klass” (Coetzee, Disgrace 116). Lurie’s reference to himself by the old Afrikaner title of “master” marks 
Petrus as non-white. Petrus also speaks in Xhosa at home. Despite the lack of racial reference for the rapists, their non-white identity is evident through Lurie and Lucy’s constant reference to the history they are trying to correct. Even though Lurie's own racial identity is not explicitly identified, we know he is white from his attitude to Petrus. His nostalgia for the "old days", when as a white man he "could have had it out to the extent of ... sending him [Petrus] packing and hiring someone else,” reveals his racial identity (Disgrace 116). His ethnic affiliation as Afrikaner is revealed through his reference to his relation with Petrus in terms of the Afrikaner master-slave relations: “baas-en-Klass", as well as his description of his daughter Lucy as a "frontier farmer of a new breed” $(116,62)$. Coetzee’s description of Lucy as “frontier farmer” connects her to Afrikaner history, when the Boers moved to the interior and set up their farms, to escape the rising power of the British colonials, who controlled the mines. The indirect reference to racial identity is a result of the trend of replacing race with ethnicity and other signifiers.

The racial silence in Disgrace identifies the racial ideology and practice of "new South Africa” with David Goldberg's concept of the post-racial. Since "racial” refers to “the various designations of group differentiation invoked in the name of race," "post racial” implies the absence of race as a criterion of group identification (Goldberg, Culture 2). The post-apartheid fear of racial reference is a consequence of the use of race as a divisive tool to secure white privilege and fracture non-white resistance during the apartheid. The desire to erase racial reference and forge a community to prevent the country from splintering into numerous ethnic enclaves is, thus, understandable. Fear of ethnic nationalism, often a consequence of resistance movements based on racial identity, 
motivates Paul Gilroy to recommend moving beyond race. But Gilroy's alternative of "planetary humanism" is unrealistic in South Africa, where "in the wake of long and vicious racist histories the present cannot simply be a raceless state" (Goldberg, State 248). The internalization of racist practices "by their routine repetition" that "hints at their presumed naturalization" has resulted in their being "taken as given and therefore coterminously unalterable" (Goldberg, State 116). As a result, racial subjects continue to be created despite the end of racist regime.

Nonracialism as a mode of racial reconciliation thus poses serious problems. Goldberg points out that "nonracialism in South Africa," which is comparable to "colorblindness in the USA" or "racial democracy in Brazil," results in, first, the relative silencing of public analysis or serious discussion of everyday racism in the respective societies. Second it has made it more or less impossible to connect historical configurations to contemporary racial formations. And third, each instance of racelessness has displaced the tensions of contemporary racially charged relations to the relative invisibility of private spheres, seemingly out of reach of public policy intervention. (Goldberg, State 217).

Instead of ending racial classification, the imposed silence on racial reference "erase[s] the exclusionary experiences of racialised subjectivities, the effects of racist patterns of discipline and deprivation, and the marginalizations and periphraxes insinuated into the racial ambiguities of social practices” (Goldberg, Culture 207-208). The enforced silence on race in a country with a violent racial history turns "racially marked social orders into racially erased ones" (Goldberg, State 222). According to Goldberg, racelessness is "not 
a politics of recognition, but of reconciliation and defensiveness, tolerance and dismissal (personal and positional) at the middle and upper end of the social scale, and of desperate survival and reconstruction, but also sometimes of resentment at the lower class ends” (Goldberg, State 233). Racelessness or nonracialism is, therefore, “as much a refusal to address, let alone redress, deeply etched historical inequalities, racially fashioned, as it is an expressed embrace of principles of race-ignoring fairness and equal opportunity”(Goldberg, State 213). ${ }^{\text {li }}$ In essence, racelessness reduces race to an empty category, which is "nowhere and everywhere at once, useable and discardable to whatever productive purposes those in command of production and circulation of signification can sustain”(Goldberg, State 236).

The erasure of racial reference in South Africa encourages nostalgic recreations of the colonial period. It characterizes the apartheid as an extreme and aberrant inhumanism and effectively stymies public discussion about it as a metamorphosis of earlier practices, resulting in nostalgia among the white community. The result is an ebullient celebration of some aspect of the past that is not associated with it. Lurie's reading of the colonial practice of miscegenation as symbol of freedom is one instance of such nostalgia. Lurie identifies the sexual freedom of the post-apartheid period with the phantasy of miscegenation during the colonial period. He claims he has "solved the problem of sex rather well” because he can now engage in sex with non-whites (Coetzee, Disgrace 1). The sex industry transforms the phantasy of miscegenation into a money-spinning enterprise. The racial history of South Africa warns against idealization of colonial practices without caution. 
My reading of the revival of the colonial past amidst the white South Africans as nostalgic celebration of the past is aligned with Gilroy’s concept of “post imperial melancholia”. lii According to Gilroy, England's loss of her colonies and her global preeminence after WWII, coupled with the swelling number of immigrants, who were a constant reminder of her loss of power, precipitate an identity crisis. The liberal discourse current in England erased racial references from public discourses and represented the colonial period as reprehensible in an attempt to forget England's role in colonialism. The white Britishers were, thus, denied the scope to mourn their loss of global eminence and turned to the WWII era as a model for emulation. WWII England, unlike colonialism, where Britain's conduct was neither victorious nor exemplary, is associated with Churchill's inspiring patriotism, British military prowess and victory, and is untainted by the negative connotations of colonialism, even though England was still a powerful imperial presence. The nostalgic identification with WWII thus gives Englishmen an illusion of power. According to Gilroy, one reason behind this nostalgia was that it provided an escape route from the bewildering and serious demands of an increasingly heterogeneous Britain.

Even though South Africa is not an imperial nation, there are parallels between its post-apartheid state and late $20^{\text {th }}$-century Britain. In South Africa, the postcolonial whitesettler-indigene dynamic acquired imperial undertones as the apartheid polices sought to wrest land from the indigenous population through land laws and reduce them to second class citizens. Therefore, the end of apartheid and the imposition of liberal post-racial policies precipitated a similar identity crisis among white South Africans, particularly Afrikaners, which manifested itself in melancholic idealization of colonial practices as a 
result of being denied articulation in the post-racial milieu. For the white South Africans, particularly the Afrikaners, who lost their preeminent position in the state along with special privileges, aligning with the colonial period, an earlier period of white glory in South Africa, which is less obviously racist than the apartheid, creates the illusion of importance. $^{\text {liii }}$ Just as in Britain, nostalgia for the colonial period among the whites in South Africa is a misrepresentation, motivated by rising sense of loss and insecurity. It is a strategy that prevents the white community from facing up to the demands of the postapartheid context. For instance, Lurie can visualize happy domesticity with Melanie, yet he is unable to apologize to her. He can imagine a cozy intimacy between himself and Soraya, but is unable to picture Petrus beyond the stereotype of a wily peasant.

This nostalgia for miscegenation is a misreading of the colonial past. Mark Sanders notes that the decimation of local population in settler colonies was followed by repopulation by the settlers. In South Africa, however, repopulation took place "not only through increase among the settlers and their descendents. It also took place between settlers and remnants of decimated subject populations of the Cape of Good Hope, and between settlers and slaves and servants” (Sanders 174). The commodification of miscegenation by the sex industry, with their special category of "Exotic" sex workers, repeats the racist colonial phantasy of miscegenation. The apartheid, which tried to suppress miscegenation to preserve the purity of Afrikaner blood, thus is an extreme configuration of colonial racism. The complex history behind sexual dynamics in South Africa connects its post-racial present, the long colonial history and the apartheid in complex loops. Consequently, the temporal movement from apartheid to post-apartheid is not linear and progressive; it is complex and chaotic. By locating the presence of earlier 
racist practices in the post-apartheid present the novel does not imply that the colonial racist patterns are replicated in the present. Instead, it draws attention to the fact that present racial patterns of representation are, in part, based upon earlier patterns that remain sedimented in the social structures and inform present perceptions. But repetition of these patterns in the post-apartheid era can jeopardize the new country's tentative steps towards reconciliation. Racelessness, which makes it difficult, if not impossible, to detect these patterns, does not aid the cause of inter-racial ethics.

The complex connection between race and sex in South Africa presents the postracial celebration of freedom from apartheid's sexual laws in a new light. The sexual problem in South Africa is not a matter of mere intercourse, as Lurie thinks; instead, it is deeply political. The intersections of race, sex and gender in South Africa's long colonial history ensures that in South Africa sex is never a personal matter or a physical impulse. Consequently, a sexual act, particularly rape, cannot be glossed over as an act by the “servant of Eros” (Coetzee, Disgrace 52). Nor can miscegenation be commodified by the sex industry in blithe disregard of the dark and violent history of the Colored population. "Eros” is loaded with historical significance in South Africa, where desire is connected to white phantasy and Black revenge. To ignore this history and rape a woman is to commit a crime more serious than a sin of desire; just as rape of a white woman by a Black man is more complex than simple rape. Given this history, Lurie’s belief that his visits to a Colored prostitute solves the problem of sex is ironic because it perpetuates the use of sex to assert power in a country whose long and bitter racial history is intertwined with sexual exploitation. This violent history that racelessness erases, resulting in the 
insensitive commercialization of the non-white women by the sex industry, is embodied in the child Lucy conceives after being gang-raped by Africans

The complicated relation between the post-racial present, colonial history and apartheid gives Lurie a more complex identity than that of an old racist Afrikaner stuck on older values. Lurie claims "His temperament is not going to change, he is too old for that”(Coetzee, Disgrace 2). He identifies himself with the old apartheid order and rejects the post-apartheid present. But, the roots of apartheid in colonial history and the reiteration of that history in post-apartheid South Africa, through practices such as miscegenation, locates Lurie at the juncture of a far more complex history than that of the apartheid. His adherence to the apartheid ties him to the long colonial history and the presence of colonial racist practices in the post-apartheid, post-racial times makes him as much a child of the post-racial present as that of the apartheid. This deep and messy history of the post-apartheid context, in the end, identifies Lurie's acts as racist because the value of any practice is not so much in its apparent intention, but in "what sort of ends we would achieve by our social practices, in what sort of values we have committed ourselves to in understating the practices themselves” (Goldberg Culture 213). By sleeping with Soraya and raping Melanie, Lurie is unconsciously repeating the patterns resonant in South Africa's colonial history of gender and racial exploitation. By participating in the commodification of racial and ethnic difference, Lurie is engaging in racist behavior.

Just as nostalgic revival of the WWII as the best period of British glory has resulted in attacks on immigrant communities by skinheads in Britain, revival of the colonial practice of miscegenation also results in violence on the gendered racial other, 
whose most terrible consequences are Lurie’s rape of Melanie and Lucy’s gang-rape by Africans. For Lurie, raping Melanie is not so much abuse of power as it is an act of animal impulse; for the Africans rape is a calculated act of revenge. In the post-racial state, justice for the victims of this kind of racial violence can only be attained through human rights based law. Law, which represents individuals as rights based citizens, irrespective of gender, sexuality, race and religion, erases differences to create uniform subjects. The problems with the uniformity imposed by law in South Africa are evident in the university enquiry to investigate Melanie’s accusation of rape against Lurie and determine possible disciplinary action. When Lurie’s lawyer learns Lurie is guilty of rape he advises him to admit his guilt and negotiate some form of counseling as punishment in lieu of losing his job. Manas Mathabene, the chairman of the enquiry, asks Lurie if he is willing to commit to counseling. The enquiry's insistence on a confession and public apology in return for pardon and job security tries to create a narrative of guilt, confession, apology and reformation. The attempts to pressure Lurie into counseling represent Lurie’s rape of Melanie, a Colored student, as individual pathology that can be cured. By making a scapegoat out of Lurie and establishing themselves as reforming agents, the law and the new nation-state establish their legitimacy. This narrative of racism as pathology presents time as linear and progressive and ties in with the representation of the transition from apartheid to post-apartheid post-racial ideology as clean break from the inhumane past.

The enquiry's efforts seem to be directed towards reaching a compromise rather than determining the reasons behind Lurie's action and finding a way to dispense justice. Lurie pleads guilty at the start of the enquiry, but refuses to accept their terms. Yet, the 
members valiantly try to cajole him into accepting their terms so that he can keep his job. The desperate efforts to prevent Lurie from losing his job and to negotiate a punishment suggest that law seeks to restore status quo rather than serve justice. In order to restore status quo law carries out a series of quantitative substitutions between legal processes and internal transformation, between contrition and confession, apology and repentance, and between Lurie's punishment in the form of a brief suspension and the emotional and psychological effects of rape Melanie suffers. All of these equivalences are premised on and perpetuate the axiom that Lurie, a 50-year old white Afrikaner man, is equal to a 20year old Coloured woman, who is also his student. However, the history of sexual exploitation of and discrimination against women by both whites and Blacks and the connection between race and sex in South Africa's racial history of does not support such a premise. Status quo can only be restored by law through willful erasure of the historically specific subject. As Lurie reminds Mathabane, chair of the enquiry, “repentance belongs to another order of discourse” (Coetzee, Digrace 55).

The enquiry finds Lurie guilty and fires him because he refused to participate in the narrative it sought to elicit from him and sanction. He refuses to accede to a public confession and apology. Against their narrative of pathology Lurie presents his narrative of desire when he claims that he was a "servant of Eros” (52). Lurie’s narrative of desire illustrates how a rights based legal system creates more conflict than it resolves because “one person’s liberty may conflict with another's and one’s liberty or claim with one’s entitlement and power” (Goldberg, Culture 37). Lurie presents the rights of desire as timeless and beyond law. However, he forgets that rights of desire are not simple matters in South Africa. The problem with Lurie's narrative of the rights of desire and the 
enquiry’s narrative of deviance is that, while they present competing interpretations of the same event, both their interpretations are ahistorical. The rights-based legal system equates Lurie and Melanie without considering their differences in gender and race and its history in South Africa; Lurie’s reading of his action as Eros dismisses the interracial sexual politics of South Africa’s history.

It is not that the university enquiry remains silent about history. . Protesting against Lurie’s elision of history, Farodia Rasool exclaims “all of a sudden it is not the abuse of a young woman he is confessing to, just an impulse he could not resist, with no mention of the pain he has caused, no mention of the long history of exploitation of which this is a part” (53). Desmond Swarts, another member of the enquiry committee, alludes to this history when he explains that for "good of the whole we have to deny ourselves certain gratifications" and feels that there should be "a ban on mixing power relations with sexual relations” (52-53). However, these allusions are not explored in the enquiry, which quickly gets mired in negotiations. At the enquiry, as grief is turned into grievance, deep equality was bypassed for civility, and liberty for litigation. In the ensuing process, justice became a battle of contesting rights and the opportunity for turning a messy event into social change was missed.

Historical amnesia of the legal system destroys Lurie’s daughter Lucy’s faith in the law. She refuses to report being raped by a group of Africans because she feels that her rape is “a purely private matter. In another time and in another place it might be held to be a public matter. But in this place at this time it is not. It is my business, mine alone” (112). She clarifies "this place” as “Africa” (112). By declaring her rape as a private matter she rejects nonracialism, which transforms the long history of racism behind the 
Black violence on whites, particularly white women, into deviance. Without taking into account the history of racial relations in South Africa, Lucy’s rape in the hands of a group of African strangers is liable to be read as personal dispute, a one-off incident by deviant men or a settling of personal score, just as Melanie’s rape was reduced to a case of ordinary sexual harassment. But the racial history of South Africa makes settling personal scores a historical one because the inter-racial power struggle uses women as the ground for asserting control over the racial other. Prosecution of the rapists will not change the underlying premises that support racism in South Africa; instead, it creates a sense of entitlement and guilt in the whites and desire for revenge in the non-whites. Nor will it address the basic gender premises in South Africa, where women are a currency in the interracial battle for power between men in nationalist, religious and patriarchal discourses. Until there is a metamorphosis in the governing principles of racial and gender relations in South Africa the position of the racial and gendered other will not change. Racial erasure and dependence of law as the means of solving the historical problem of race in the post-racial state "delimits the gap between those represented and those representing, to efface, diminish or overlay it with representable subjects (through education and cultural socialization) into political representatives” (Goldberg, State 250251). ${ }^{\text {liv }}$ The emphasis on law enables the non-white government to avoid responsibility for the complex structural changes necessary to transform the condition of the nonwhites.

The ahistoricism of rights-based law is reflected in the cavalier use of history. History is reduced to a narrative strategy. Lurie claims that in the creation of his daughter, whose attitude to race is different from his, "history had a larger share” 
(Coetzee Disgrace 61). He tries to explain to Lucy why the gang of Black men raped her by pointing out that "it is history working through them, a history of wrong” when attempting to explain the motivations of her rapists (Coetzee, Disgrace 156). Yet, when Lucy tells him that being raped was a price she had to pay for her history as a white Afrikaner, he dismisses it, saying, "I am sure they tell themselves many things. It is in their interest to make up stories to justify them.” (Coetzee, Disgrace 158). His comment reduces history to a narrative strategy. The commodification of history turns it into an empty signifier, there but not there, capable of being used whenever needed by those in power.

The post-racial milieu, which denies the complex connections between the past and the present, and enforces a silence on race even as racial practices continue to persist, splits discourse at the moment of enunciation. The post-racial era forces Lurie, who identifies with the apartheid, to conceal his racist views, resulting in guilt. Sanders writes that the novel's suppression of race and its long history presents “racism ... in terms of the projection and acting out of guilt ridden phantasies of violence” (144). The enforced “taking up of any one position, within a specific discursive form, in a particular conjuncture is ... the site of fixity and fantasy” that results in stereotypes (Bhabha 77). The ambivalence produced by the post-racial state is similar to the splitting in colonial discourse that Homi Bhabha identifies as the source of the creation, enunciation and perpetuation of stereotypes. In “The Other Question” Bhabha argues that stereotypes are a result of the colonial economy that seeks to construct the colonial as a "population of degenerate types on the basis of racial origin in order to justify conquest and to establish a system of administration and instruction” (70). The goal of the colonial economy is a 
contradictory one, based on display of power and aggressiveness and a desire for similarity, because the colonial space is a "space of disruption and threat from heterogeneity of other positions” (Bhabha 77). Confronted with this heterogeneity, the colonial power was forced to engage in the politics of "recognition and disavowal" (Bhabha 70) that indicate "the desire for origins which is threatened by differences of race, sex and class" (Bhabha 75). In short, stereotypes are a "strategic maneuver," in the Foucauldian sense, to avert the threat posed by heterogeneity to the goal of gaining power by establishing western culture in the colonies. Thus, in colonial situations, both colonizer and the colonized, are "constructed with an apparatus of power which contains ... a knowledge that is arrested and fetishistic and circulated through colonial discourses as that limited form of knowledge of otherness ... called stereotypes”(Bhabha 77-78). The "arrested and fixated form of representation" of a stereotype "constitutes a problem for psychic and social relations”(Bhabha 75).

The arrested representation that marks stereotypes is most dramatic in Lurie's response to Petrus, the Black tenant farmer on Lucy's farm who has become a landlord after buying some land from her. Petrus is simultaneously "[a] man of patience, energy and resilience. A peasant, a payasan, a man of the country. A plotter, a schemer and no doubt a liar too like peasants everywhere. Honest toil and honest cunning” according to Lurie (Coetzee, Disgrace 117). Later, when Lurie helps Petrus with the plumbing, he reveals a similar inconsistency: "Petrus is a good work man...it is Petrus himself he has begun to dislike” (Coetzee, Disgrace 137). In these insights into Lurie’s mind, we discover that Petrus is an object of both desire and derision. Confronted with a Black peasant, whose presence defies the conventional representation of Blacks, Lurie seeks to 
dissolve his anxiety by trying to transform Petrus into something familiar. This limited economy of knowledge within which racist discourses function creates a flat and menacing representation of Petrus. Stilted representation is also evident in Lurie's characterization of Melanie as either a Madonna or a whore. When he first encounters Melanie, she is a sly siren with an "evasive and perhaps coquettish smile” (Coetzee, Disgrace 12). After she accuses him of rape Melanie morphs into a helpless girl coerced by her father, cousin, and boyfriend into charging him. "Melanie would not have taken such a step by herself ... she is too innocent for that, too ignorant of her own power.... They must have talked her into it,” he reasons (Coetzee, Disgrace 39). For a woman who destroys his life, Melanie remains bafflingly silent. In Lurie’s attempts to construct Melanie, Melanie the living individual, who can think and act on her own, is foreclosed. The post-apartheid context of Disgrace maps out the conditions imposed on South Africa’s racial reconciliation efforts by its post-racial politics. It underscores the fact that individual acts of racism cannot be dismissed as pathology or deviance from the social norms, particularly when past racist structures persist in society. The post-racial politics in post-apartheid South Africa enable us to locate the root of continuing racist practices in current social polices. By placing Lurie’s actions in the post-racial context it is possible to see how his racist actions locate him at the intersection of private racist practices and public rhetoric of racial equality. As a result, Lurie is represented as a far more complex character than a one dimensional racist Afrikaner. At the same time, the novel does not excuse Lurie’s private racism as a consequence of social malaise. The narrative’s ultimate discrediting of Lurie's perspective ensures that we do not read the role of the social context as an excuse for the protagonist's racist practices. 


\section{Stereotypes and Problems of Reparations.}

The stereotypical representation of the other that results from guilt, ultimately, sabotages possibilities of ethical relations because guilt creates "ambiguous and confused impulses to make good” (Sanders 169). The desire to repair or restore is an act "to undo in retrospect” (129). Sanders elaborates that reparations are based on a phantasm of a wholeness that the act of guilt tries to repair. Reparation is, thus, based on a sense of “phantasized omnipotence,” a belief that one has the power to restore and repair the object of phantasy (134). Sanders' analysis of reparations reveals two things. First, he points out that phantasy serves an "agent of reparation without doing anything for the object”(133). It signals the limit of responsibility and its “setting to work”(Sanders 133). In short, reparations motivated by guilt are essentially egoistic: the object remains outside the egoistical circuit of the self. Second, Sanders indicates that, since reparations involve phantasy, the task of restoring also involves the act of “making”(Sanders ). ${ }^{\text {lv }}$ He therefore connects reparation to restoration as well as to creative acts. He claims reparation "takes manifold forms ranging from Coitus to the production of works of art and the intellect” (Sanders 134-135). In Disgrace Lurie resorts to art as well as restoration to undo past wrongs

Lurie's initial guilt about being a bad role model for his daughter escalates when Lucy is raped by a crowd of Africans while he is visiting her. Overcome with guilt at being unable to protect Lucy, Lurie confesses, “I did nothing to save you” (Coetzee, Disgrace 157). In this instance, paternal guilt for failing to protect his child is coupled with guilt at being complicit in a racist system through his historical position and actions. His first attempt to alleviate this guilt is to identify with her. However, both Bev and 
Lucy remind him that he was not in the room when Lucy was raped; therefore, he cannot imagine her experience. Lurie’s failed attempts to identify with Lucy are followed by attempts to make reparations to her. He makes plans to send her to her relatives in the Netherlands and even engages Petrus to work as farm manager without Lucy's consent. But his solutions do not respect Lucy's belief that escaping from the farm will be a defeat. The gap between father and daughter is evident in Lucy's refusal to report the rape. He reads her refusal to report the rape and leave South Africa as an attempt to "humble” herself "before history" to atone for the role of the whites in South Africa’s racist past (160). In frustration, Lucy points out that his actions make her a "part of the story" of his life, where he is the "main character" and she is a "minor character" (198). However, in her life she is "the one who makes the decisions" (198). Lurie seems unable to go beyond the expectations of him as a white man and a father to address Lucy the individual.

Lurie’s reading of Lucy as a passive woman, who seeks to atone for the past by accepting rape as a price for historical wrongs against the Africans, reads her within the historical expectations defined by racist discourse in South Africa. The portrayal of a white Afrikaner woman as a passive suffering figure has a history in Afrikaner history, according to Anne McClintock. In her essay “No Longer a Future Heaven,” McClintock points out that the concept of Volksmoeder is memorialized in the statue of the Vrouemonument as homage to the female victims of the war. McClintock observes that the monument of the Afrikaner woman as suffering mother with a baby in her arms removes the "militant potential” of Afrikaner women and "enshrines Afrikaner womanhood ... as suffering, stoic and self sacrificing” (McClintock 105). The white 
woman as a "weeping victim of African menace” elides the woman’s own complicity in racial history and can overlook the "mighty embarrassment of male military defeat" (McClintock 105). Reading Lucy as a woman who passively sacrifices herself to history places her in the tradition of the suffering Afrikaner woman and enables Lurie to overlook his failure to protect her from the non-white rapists. Lucy, however, is hardly passive. She has followed her dream of farming, and despite being abandoned by her friends, who fled the country, she stayed on.

Parallels between Lurie’s rape of Melanie and Lucy’s rape reveal complex interracial connections. The Black rapists display the same indifference towards Lucy, the object of their lust, as Lurie when he claims that his rape of Melanie was an act of instinct. When Melanie and Lucy are raped, they are reduced to mere appendages of the rapists. Describing her rape, Lucy observes that it was "so personal. It was done with so much personal hatred. ... But, why did they hate me so?’(156).Within the generalized discourse of race in South Africa, Lucy represents the white woman, a symbol of colonial and apartheid history. Race binds Lucy and her rapists in a sick familiarity that elides the other as a singular being, beyond racial discourse. Similarly, when Lurie rapes Melanie he is inadvertently repeating a history where it was acceptable for a white man to sexually use a non-white woman without her consent. As an object of Lurie’s desire, Melanie is stripped of her singularity and racial history. Despite his ignorance of its historical precedence, Lurie’s act is as historically loaded as the African men's deliberate rape of Lucy. The parallel between the two rapes reveals the complex racial history of South Africa, where the end of apartheid does not free the country from the deeper history of racism, of which the apartheid was an extreme form. Lucy’s question to Lurie-- 
“you are a man, you ought to know ... when you have sex with someone strange, when you trap her ... put your weight on her... doesn’t it feel like murder?”( Coetzee, Disgrace 156)—-makes Lurie realize that "he can if he concentrates ... be the men”. (Coetzee, Disgrace 158).The recognition of the parallel makes him question: "are she and he on the same side?” (Coetzee, Disgrace 157). In the complex cross currents of race and gender in South Africa, Lurie has more in common with the racial other than with his own daughter. Lucy has more on common with Melanie, than with her father.

The inadequacy of guilt-driven reparations is also evident in Lurie's hilarious attempt to apologize to Melanie’s parents. This apology has been read as a sign of his internal transformation. Mike Marais points out that it leads Lurie to sympathize with the Issacs since, like them, he is now a father whose daughter has been raped. However, Marais forgets that Lurie visits the Isaacs at George soon after his conversation with Lucy leads him to recognize the connection between his act of rape and that of Lucy's rapists. The egoistical basis of his action is evident from the fact that he arrives at dinner with his preferred wine when the Issacs are teetotalers. This action belies the sincerity of his extravagantly staged apology. Since his action is based on guilt and a desire to separate himself from the rapists, rather than remorse or concern for the Isaac family, his actions receive lukewarm response. Not surprisingly, his apology doesn't restore the others, nor does it cancel his guilt. Therefore, in response to Mr. Isaac’s questions——what lessons have we learned? ... what are we going to do now that we are sorry"-_Lurie says he is being "punished and punished. ... I live in disgrace” (Coetzee, Disgrace 172). To live in disgrace is to live "like a dog," without dignity (204). As long as his efforts to reach out are rooted in the egoistic fears of the other, there is no end to his state of disgrace. 
Lurie’s interpretation the phrase "like a dog”contrasts with his daughter's take on it. Lucy’s rape and her sense of insecurity make her seriously contemplate marriage to Petrus and handing over her land to him in lieu of security. It is a sad end to her dream of living on the land she loves and making a living from its bounty. Yet, she sees being "like a dog” with nothing, "No cards, no weapons, no property, no rights, no dignity” as “a good point to start from again” (Coetzee, Disgrace 205). Lurie and Lucy’s vision represent two extremes of the dilemma of post-colonialism, which careens between the risk of a new beginning and the "collapse of civil societies”(Spivak, “Ethics” 22). The difference between Lurie's and Lucy's response to the loss of privileges in the new era suggests that stereotypes circulating in a particular culture may be enabled by certain aspects of that culture, but they are, in the end, created by individuals. Individuals, the novel implies, are not just products of a time and place, but agents operating within a context. Disgrace highlights the role of the singular subject in enacting and resisting the potentials of a given space. ${ }^{\text {lvi }}$

The lack of a correspondence between Lurie’s efforts to make good and the expectation of others doesn't mean that ethical reparations require the wishes of the victim and the actions of the perpetrator to match. Lurie's relation with animals reveals how reparations can be open to the other despite being rooted in the self. Unlike his interaction with Lucy or Petrus, where Lurie assumes his actions coincide with their wishes, he recognizes that saving animals would require tremendous resources that the nation is unable to spare at present for animal care. Nor is it possible to transform the human-animal hierarchy that informs the basis of a society where killing animals once they become too many is humane. So, instead of the "quick-fix frenzy of doing good 
with an implicit assumption of cultural superiority which is legitimized by unexamined romanticization,” Lurie seeks to ensure that, within the constraints, he is able to provide the animals with dignity and love (Spivak, Reader 293). Consequently, when Bev inserts the lethal injection into the dogs, Lurie holds their paws and soothes them so that their last moments are happy. Even though he doesn’t need to, he goes one step further: he bags the corpses for the incinerator and, instead of just dropping them off to be dumped in the incinerator, takes them home, brings them back the next day, and carries them into the incinerator himself. He makes all this effort because if the corpses are left overnight rigor mortis sets in and the attendants have to break the bones by beating the corpses so that they can fit them inside the incinerator. As Lurie puts it, he "may not be their savior, the one for whom they are not too many, but he is prepared to take care of them once they are unable. Utterly unable to take care of themselves, once even Bev Shaw has washed her hands off them” (Coetzee Disgrace 146). His actions ensure that the dead dogs are treated with the dignity that is denied to them in life. In doing so, Lurie resists the discursive structures of the human world. His action, however, remains local and interventionary, rather than revolutionary.

The motivation behind Lurie's action is narcissistic. He confesses that he takes care of the corpses because in his world "men do not use shovels to beat corpses into convenient shape for processing.”(Coetzee, Disgrace146). By locating the motivation for action in himself Lurie admits his failure to account for the consciousness of the dog and draws attention to the position of the dog as a being outside human discourses. The dog here exists as a trace. A trace, according to Spivak, is at once a sign of the position of the other vis a vis discourses, as well as the threshold to knowledge about the other. A trace 
of the other is more ethical than a full-bodied realistic description of the other if we consider Spivak's notion of the subaltern. The other in the extreme sense is the subaltern, who lies beyond dominant discourses. According to Spivak, "Finding the subaltern is not so hard, but actually entering into a responsibility structure with the subaltern, ... is the hard part” (Spivak, Reader 293). The subaltern is difficult to represent because his consciousness is "the place of difference rather than identity" (Spivak, Reader 213). Since it is "subject to the cathexis of the elite, ... it is never fully recoverable, ... it is always askew from its received signifiers, ... it is effaced even as it is disclosed, ... it is irreducibly discursive. (Spivak, Reader 212). The real subaltern is always an absence and recognizing him involves recognizing the subject position retroactively, as an absence. While I am not suggesting that the racial other is a subaltern, I draw attention to Spivak's concept of the subaltern because it helps explain how Lurie’s silence about the other transcends romantic notions of altruism. By self-reflexively indicating the egoistic basis of his altruism Lurie draws attention to the dog as a living being, beyond the lop-sided human-animal discourse.

Lurie's interaction with the animals is a departure from his reparative efforts with Melanie and Lucy. His motives for both actions are egoistical: he apologizes to Melanie's parents to expatiate his guilt and he physically dumps the dog corpses onto the incinerator because he believes even dead dogs should be respected. The difference is that, in the first instance he assumes that his acts to make good coincides with Melanie’s parents’ expectation of him. That is, he does not acknowledge that there is a gap between himself and Melanie or Lucy. With the dogs, however, he remains pointedly conscious that his 
views have nothing to do with what the dog wants. In acknowledging this difference he marks the position of the dog, a spectral presence, beyond anthropocentric values.

The aesthetic possibilities offered by representing the other as an absent presence is outlined in the secondary narrative that centers around Lurie's efforts to compose an opera about Lord Byron and his last great love affair. To escape from his sense of failure as a father Lurie focuses on his opera about Byron and his last mistress, the Italian Countess Teresa Guicolli. When his car, with the research material on Byron in the trunk, is stolen he is forced to imagine Byron and Teresa, based on the letters exchanged between the couple, Byron’s letters to his friends in England and numerous Byron biographies. The recognition of the complex connection between him and Lucy's rapists compounded by the disappearance of his materials on Byron transform the opera about Byron and his last love into an opera about the act of imagining the other. Lurie represents Teresa and Byron at a point where they disappear from history. His Teresa is a middle aged widow, looking after her aged parent; Byron is dead. Teresa's efforts to imaginatively reach out to the dead Byron parallels Lurie’s attempts to capture the historical Teresa, hidden in the cracks of patriarchal representations of her as an amorous coquettish adulteress. His intimation of Teresa is faint and vague, rather than full-bodied; just as her intimation of Byron is faint. The attempt to imagine Byron to life is futile because Byron remains beyond the human realm, just as Lurie’s attempt to represent Teresa is doomed because imagination and language can only represent the shadow of the actual person. The failure to capture the embodied other through imagination is symbolized by Byron’s daughter Allegra’s futile cry for her neglectful and dead father. Byron’s ghost cannot answer her call because Byron is dead. Byron’s resistance to 
Allegra's call and Teresa's imperfect attempts to reach Byron reveal that the other remains resistant to discourses. The opera thus enacts a failure of imagination. This failure is not an indictment of Lurie's imaginative abilities; it reveals the disjunction between the other as an embedded and heterogeneous presence in time and the other as representation in art. ${ }^{\text {lvii }}$

The metatextual implications of a novel staging Lurie's opera about imagination's limits to envisioning the other, through the trope of a woman trying unsuccessfully to give voice to the dead lover, indicates that ethical representation of the other is possible. The opera, which draws attention to itself as an imaginative representation of Teresa, does not claim the authenticity that is attached to the historical documentation of Teresa. By presenting itself as artifice, the opera draws attention to the absence of the real Teresa and points to her as a presence beyond language. The opera thus demonstrates Attridge's observation that the act of inventive writing involves an encounter with the other that challenges the writer's world view and, by extension, the prevalent discourses through which the world is expressed. ${ }^{\text {lvii }}$ It demands that the writer manipulate existing discursive codes to express the singularity of an experience. Thus, Lurie's opera, which began as a traditional opera involving lush music and a young Byron and Teresa, in the end becomes a very streamlined text about a middle-aged woman and a ghost against the monotone of a banjo. The secondary narrative thread indicates that the central issue for an ethical representation of the other in art encompasses being open to the singular presence of the other, rather than realism. If the other remains resistant to appropriation by discourses, no representation, however realistic, can capture its embedded complex being. 
The transformation in Lurie's creative vision and his newfound empathy for animals has been read as an indication of his transformation. Sanders claims that the novel suggests that we can relate to the other outside language, in the wordless medium of music. He consequently reads Lurie's ability to envision the gendered other in the subplots as an indication of his ability to envision the other. While I agree that the novel questions the ability of language to read the other, I do not think that moving from the linguistic medium to another medium of representation, music in this case, allows for a better representation of and interaction with the other. In fact, Lurie's opera shows how representation is incapable of capturing the other. It is also presumptive to read Lurie's attitude towards animals and his opera as signs of his transformation. If we compare the events in the last chapter of the novel we realize that Lurie's awareness of the limits of representation in art do not translate into an ethical relation with the racial other.

In the final section of the novel, Lurie decides to sell his apartment in the city and move into the country. Soon after he moves to Grahamstown, Lurie hears that the boy accompanying the rapists is staying with Petrus, next to Lucy's property. When he learns that the boy's name is Pollux, he remarks sarcastically, "Not Mncedisi? Not Nqabayakhe? Nothing unpronounceable, just Pollux!” (200). He calls Pollux “a jackal... mentally deficient. Morally deficient” (208). The connection between mental and moral deficiency echoes the colonial racist terms for Africans. His animosity towards Petrus and Pollux leads him to physically attack Pollux when he catches him peeping into Lucy's room. This section is followed by the final episode in the novel, where Lurie gives up his favorite dog in the shelter to be euthanized. This juxtaposition of his treatment of the Pollux with his treatment of the animals creates a glaring contrast, 
suggesting that Lurie is unable to extend his compassion for animals to his non-white countrymen. The diegetic gap between the main narrative and the secondary narrative testifies to the gap created by racist history and denies a transformative or prescriptive role to art. ${ }^{\text {lix }}$

\section{Irony as Mode of Representation, Representation as Irony}

Coetzee's exploration of the post-apartheid situation in Disgrace reveals that the novel's post-racial politics enables stereotypes, impairs reparation, and, ultimately, results in a ridiculous situation where the protagonist can empathize with a dead dog, but is unable to show compassion for a living African man. The consequent narrative gap poses a problem because it identifies Lurie as a static character. The narrative focalization on a static racist character, at a time when the nation is trying to move beyond apartheid, gives the impression that the novel endorses Lurie's stereotypical representation of the

other. ${ }^{\mathrm{lx}}$ However, the association of stereotypes with a particular context and consciousness—Lurie in post-racial South Africa— and framing of Lurie through the optics of irony ensure that the novel is open to the "utterance of the other" (Sanders 148). The manipulation of narrative perspective is more effective in disrupting the circulation of stereotypes than positive images of the other because the problem with stereotypes is "not so much the bald concern with the racial reference and invocation, but the purpose to which race is invoked” (Goldberg, State 244). The novel's narrative strategy challenges the reader to move beyond identification of racial references and focus on the complicated mode of representation at work. The indirect and often ambiguous address of irony in the novel is a response to and a demonstration of the deceptive and entangled terrain of racial relations in the post-apartheid context. 
The almost relentless narrative focalization on Lurie counterintuitively locates the stereotypes in the novel in a particular context and consciousness. Lurie as the focalizer and his relation to the post-racial context reveals that the stereotypes in the novel are "not the setting up of a false image which becomes the scapegoat of discriminatory practices”(Bhabha 81). Instead, they are a “much more ambivalent text of projection, introjection, metaphoric and metonymic strategies, displacement and determination, guilty aggressivity, the masking and splitting of 'official' and phantasmic knowledge to construct the positionalities and oppositionalitites of racist discourse” (Bhabha 81-82). Therefore, to judge a stereotype on the basis of prior political normativity is to "dismiss it, not to displace it” (Bhabha 67). Coetzee’s location of stereotypes in Lurie’s mind effectively exposes how post-racial politics breed and keep stereotypes in circulation in the post-apartheid context.

The identification of post-apartheid politics and post-racial ideologies as the source of stereotypes in the novel goes against the conventional wisdom of tackling negative stereotypes through substitution. Apart from the fact that the postmodern subject is interpellated by multiple, internally discontinuous discourses, and therefore exceeds representation, the substitution method is ineffectual because it does not move beyond the discursive paradigms governing production and circulation of stereotypes. Goldberg analyzes three distinct elements of stereotypes: (1) the "objects to which the discursive representations refer;” (2) “the styles of reference to be found in figures of speech, and metaphors as well as in categories and expression;” and (3) "the underlying ... preconceptual plane or set of primitives”(Goldberg, Culture 46). Changing stereotypes only changes the expression and brings about a change in the terms, rather than in the 
foundational principles. Moreover, replacing a negative stereotype with its positive substitute raises ethical questions. It presumes an identification with and knowledge of the other that negates differences between the self and the other. The act of replacing a stereotype with a positive one also "assumes that the other is homogenous and unable to speak for himself” (Spivak, Critique 256). In addition, it raises the danger of imposing one's own voice on the other. Representing the other in such instances becomes an act of appropriation. The possibilities of representation across racial lines become limited and community is unimaginable if we turn the other into the self. If literature cannot imagine the possibility of a community in which differences in identity and history are respected, then, chances of historical representation along political lines become remote. Without the ability to recognize the singularity of the other, or identify others outside ourselves advocacy cannot take place. To disable stereotypes literature needs to expose the politics that enable racist stereotypes in particular historical moments.

Coetzee's strategy of disabling stereotypes by using Lurie as focalizer enables him to reveal the effects of post-racial discourse on individuals. By looking beyond the representative surface and into the underlying premises of stereotypes Coetzee presents stereotypes as symptoms of deeper social problems. His strategy is a literary demonstration of Homi Bhabha's suggestion that in disabling stereotypes the "point of intervention should shift from the ready recognition of images as positive and negative to an understanding of the processes of subjectification made possible and plausible through stereotypical discourses" so that one can engage "with its effectivity, with the repertoire of power and resistance, domination and dependence that constructs colonial identification subject” (Bhabha 67). Instead of asking if a stereotype is positive or 
negative, Bhabha suggests that the question be about "the mode of representation of otherness” (Bhabha 68). By emphasizing the politics behind stereotypes, instead of their truth value, Bhabha's strategy breaks the signifying chain that keeps stereotypes alive to offer an alternative mode of representation.

Since the narrative focalization on Lurie raises questions about the novel's values, Coetzee dissociates the novel from Lurie's perspective by framing it with a third-person narrator. The difference between Lurie and the narrator is made explicit from the first sentence, where we are informed that "For a man of his age, fifty two, divorced, he has to his mind solved the problem of sex rather well” (Coetzee, Disgrace 1). The phrase "to his mind” indicates the disjunction between Lurie’s perception and reality and that between the narrator and Lurie. This free indirect discourse makes it clear that later sentences like “To some degree he believes his affection is reciprocated” reveal Lurie’s perspective, rather than the actual state of affairs (Coetzee, Disgrace 2). Lurie’s unreliability as a narrator is manifest in the diminished role of the father figure. As a father he is unable to understand his daughter and her goals. He also fails to protect her from being raped. Lucy's refusal to file a police report after being raped brings their estrangement to a head, resulting in Lucy asking him to stop “being a father.” His place is supplanted by other protector figures in Lucy’s life, like Bev and her husband Dave, Ettinger and Petrus. The failure to be a father is repeated in his failure as a father-surrogate in the novel. Like a father he renames Melanie, “Melani: the dark one,” yet he violates his role as her teacher and protector by raping her (Coetzee, Disgrace 18). ${ }^{\text {lxi }}$

While the narrator discredits Lurie, his views are never grounded in concrete assertions or positions that qualify Lurie by providing a counter meaning. Marais points 
out that our awareness of Lucy does not arise from more information about Lucy as much as our awareness of Lurie's inconsistencies. He notes that we do not know if Petrus is really devious because he is presented through Lurie's eyes. The narrator does not tell us what Petrus is either. Petrus exists between Lurie’s racist stereotypes and the narrator's implicit criticism of Lurie. Without an authoritative narrator Lucy or Petrus cannot become concrete presences that provide a counter-perspective to Lurie: they exist in between the said and the unsaid, their meaning endlessly deferred. The absence of concrete representations of both these characters underlines the distance between Coetzee and the other. In the process, it pays homage to the history behind that distance. Coetzee's refusal to represent the racial and gendered others is a deliberate strategy that draws attention to the novel as a representation of the other, rather than a "representation”. lxii

Discrepancy between the third person narrator and Lurie creates a structural irony because it informs the reader of the true state of affairs, while Lurie remains ignorant. The entente between the narrator and reader that can arise out of this conceit is, however, nicked because the dual poles of the irony are not resolved. The reader is, thus, left without a clear idea of the other, who remains a spectral presence framed between Lurie's racist perspective and the narrator's implied knowledge. By leading the reader to the brink of knowledge about the other, only to deny that possibility, the novel confronts the reader with the threshold to understanding the other, the ridiculous situation, created by a messy and complex history, where reconciliation involves interacting with the other with a haunting awareness of difference. In short, the novel's irony does not resolve the divided poles of the narrative through rhetoric; instead, it reveals a "higher actuality" 
(Kierkegaard 323). Irony in the novel emphasizes representation as an experience of the impossible, split between the said and the unsaid, between the positive and negative, a presence and an absence, an absent presence. As a consequence, reconciliation is fractured and doubled between connection and difference, an act of bonding and a failure of identification.

In the novel irony is more complex than rhetorical legerdemain. The novel's structural irony points to deeper paradoxes in the post-apartheid context. Irony in the novel therefore refers to an existential condition. Such irony, where the dualities of irony don't synchronize — so that the twin perspectives aren’t merely juxtaposed, but are in a relation of antagonism, or at the very least disharmony — is described as "irony of irony" by Friedrich Schelegel and ““irony sense eminentiori’” by Soren Kierkegaard (254). .xiii $^{\text {. }}$ Both philosophers refer to this irony as a philosophical "position,” rather than a mode of expression. Philosophical irony or second order irony locates the instability of meaning in the gap between the finite and infinite, according to Schlegel, and is a result of the difference between phenomenon and essence, according to Kierkegaard. As a result, this irony is not directed "against this or that entity but against the entire given actuality at a given time and under certain conditions” (Kierkegaard 254). Kierkegaard therefore claims that philosophical irony is "not the truth but the way" to truth (327). ${ }^{\text {lxiv }}$ Since higher order irony does not create a new entity, but only reveals what is already present, Kierkegaard describes irony "as the negative” and Jahan Ramazani calls it "subtractive” (104). The goal of secondary irony is different from rhetorical irony, which engages in "hiding what is actually the case; not however, in order to deceive, but to achieve special rhetorical or artistic effects” (Abrams 142). The existential negativity associated with 
philosophical irony results in an infinite regress into greater ironies in a text. The consequent textual anarchy made Schlegel exclaim in despair, "What gods will be able to rescue us from all these ironies?” (369). Instead of looking to the divine for an answer, Kierkegaard locates the answer in the text. He points out that, since irony is “omnipresent” in a poem, "the irony visible in the poem is in turn ironically controlled" (Kierkegaard 324). Kierkegaard's observations suggest that philosophical irony is selfreferential and doubles on itself to cancel its negativity.

In Disgrace irony appears to present post-apartheid South Africa as a dark world, with little scope for congenial inter-racial relations. This pessimistic picture is, however, reversed by the similarities between Coetzee’s narrative strategy and Lurie’s representation strategy in the secondary narratives. As a strategy, Coetzee's refusal to provide a concrete counterpoint to Lurie resembles Lurie's own nuanced representation of Teresa and the dogs. Coetzee's deliberate refusal to depict the other ironically registers the other as an embodied being outside discourses. Lurie may be unable to bring that insight in his interaction with Petrus, but by recuperating that same strategy for the representation of the other in the novel Coetzee establishes his mastery over the novel's protagonist. Coetzee's use of the third person narrator thus decenters Lurie's point of view to identify him as a function of the novel's deceptively realistic narrative strategy.

Coetzee's recovery of Lurie's representation strategy from the secondary narrative to represent Petrus and Lucy in the main narrative provides a model for advocacy that is fastidiously aware of the limits of a white male author's subject position. ${ }^{\mathrm{xv}}$ At the same time, Lurie’s inability to offer a nuanced representation of Petrus and Coetzee's use of the third person narrator to discredit Lurie forecloses equating Lurie 
with Coetzee. Irony in the novel thus doubles back on itself to reveal a "textual agency capable at once of reflecting on and dictating the terms in which it is read” (Roy 121). ${ }^{\text {lxvi }}$ By being alert to the rhetorical cues we find that the novel performs a different story from the one it professes. Disgrace professes that racial discourses make relation with the other impossible; it performs the grounding of the ethical in reading and writing to make a limited relation possible. The novel's silence on Lucy and Petrus, the focus on a racist Afrikaner, and the gap between the two narrative threads are, in the end, part of its rhetorical web, rather than a narrative failing.

The ability of higher irony to rescind its own negative energy and reassert authorial control is only possible with a skilled ironist. This ironic control, according to Kierkegaard, “yields truth, actuality and content,” and can be seen in the works of Shakespeare and Goethe (Kierkegaard 326). Skillfully used, second order irony enables the author to direct the reader and protect his text from being appropriated to fit the reader's expectation. But the author's textual control doesn’t imply superiority outside the ironic field. Kierkegaard points out that “just because a poet manages to be master over the irony at the time of writing" does not mean that "he is master over it in the actuality to which he himself belongs” (324). Instead, it suggests that the author's control over the irony in a text is a contrast to his lack of control over the existential and historical context he writes about. He is thus "related ironically to what he writes" (Kierkegaard 324). The fact that the author is embedded in the context he exposes offers the scope for “complicitious critique” that "works from within a power field but still contests it”(Hutcheon, Downspout 154). This is significant for the white writer in South Africa because s/he is complicit in the racist politics and cannot, by virtue of that history, 
understand the racial other. By this statement I do not imply that there was no common history between the whites and the non-whites in South Africa. The irony of South Africa's history is that racial discrimination ensures that history was experienced differently by the different groups. This differential experience of a common history makes identification with the other impossible. Coetzee's refusal to present concrete images of the other mocks at the ironist's power, even as it signals his complicity in South Africa’s history.

Disgrace creates an intensely affective experience that repeatedly frustrates readers' expectations to dramatize the limits of discursive paradigms in representing the other. The novel thus engages in the "staging of referentiality" to draw attention to itself “as event” (Attridge ,Singularity 96). As an event, Spivak points out, "literary reading teaches us how to play the game," whereas other discourses "describe the game” (Spivak, "Ethics” 22). Literature as an event creates an "experience of the discontinuities that remain in place in 'real life’”(Spivak, "Ethics” 18). However, Spivak cautions that as "an event literature is —an 'indeterminate sharing' between writer and reader, where the effort of reading is to taste the impossible status of being figured as an object in the web of the other. Reading in this special sense is sacred”(Spivak, "Ethics” 18). The active process of engaging with the form of the text makes the reader participate in the writer's act of resisting the conventions to represent his intimations of the other. Thus, through the experience of literature, the reader enters into the singularity of a text and is "constituted as a subject by the event of the performance” (Attridge Singularity 98). Attridge's and Spivak's emphasis on the active connection between meaning and reading assigns a transformative power to literature. 
Literature's ability to transform the reader through reading is tested by irony as a narrative device. Irony's ability to travel incognito makes its detection a power play between the author and his audience. Linda Hutcheon, however, denies such power play at work in postmodern irony because she claims irony does not bring a community into being as much as its existence signals the presence of a community of likeminded people. ${ }^{\text {lxvii }}$ Her notion is based on the postmodern notion of the subject as a heterogeneous entity, a particular inflection of discourses, circulating in a particular culture, rather than a "free floating signifier." According to Hutcheon, the inability to detect irony therefore does not indicate the reader's naiveté as much as a different ideological leaning. By the same token, being able to read irony doesn’t indicate intelligence as much as shared discourses between the reader and the author. The ability to read the linguistic and rhetorical codes of Disgrace makes one participate in the novel's resistance to post-racial conceptions of reconciliation in South Africa. Failure to read the rhetorical codes reveals the reader's allegiance to other discourses. The fact that the novel won international awards for non-literary reasons reveals the expectations of those award committees from literature. Similarly, the ANC's criticism of the novel because of the presence of African stereotypes reveals its allegiance to post-racial agenda.

While irony in Disgrace helps identify a preexisting community, it also tests Hutcheon's notion of postmodern irony because it does not eliminate power play between the reader and the author completely. In the novel irony is multidimensional. It is both a structural device as well as an existential condition. It is double edged because it is critical of the apartheid as well as the post-racial post-apartheid discourses. In the novel 
“irony's edge," as Hutcheon puts it, cuts both ways all the time. The novel makes a subtle political stand by using presenting Lurie through the lenses of irony. By identifying its protagonist as racist and dissociating the novel's ethos from the protagonist Disgrace criticizes post-racial values. Readers who are unable to decipher the complex levels of irony align themselves with the post-racial discourses the novel criticizes. It may not indicate their naiveté, but they are, nevertheless, the target of irony’s edge.

Coetzee's identification of the text's irony with its context ridicules the expectation that literature can provide an easy answer to complex historical situations. This is not to say that literature is apolitical. Irony may not resolve the narrative gaps; nevertheless, it offers restrained hope. By this I mean that it does not encourage false optimism by claiming that the rhetorical resolution of the ambiguities of irony in a text resolves the complexity of its context. This may not allow for ebullient optimism, but the sobering enlightenment clears space for a realistic appraisal of the situation. Kierkegaard aptly explains that through irony "we are not uplifted by the destruction of the great but are reconciled to its destruction by the victory of what is true”(322). In Disgrace irony creates a nuanced awareness of the impasses of interracial relations in South Africa. This realistic appraisal of the post-apartheid situation does not deny possibilities of reconciliation; instead, it envisions a more ethical inter-racial cordiality—one that accounts for the deep history and opens discourses to the other. Coetzee's deft use of secondary irony implies that literature functions in complex political situations by making us more aware of ground realities. 
Coetzee's ethical representation of the other, which underscores the impossibility of capturing the other through language deliberately fractures the realistic surface of the novel. His refusal to close the structural irony reveals the paradoxes of racial relations in contemporary South Africa and draws attention to the fact that rhetorical irony cannot resolve historical schisms. By representing the other as an absent presence and by refusing to close the novel's structural irony Coetzee uses realism and irony discursively. By describing Coetzee's use of irony and realism as discursive I mean that he shows that realism is one among many existing discourses. This ambiguity indicates Coetzee's complicity in the context he ironizes. In Disgrace Coetzee thus acknowledges that literature, particularly literature written by a white author, cannot solve racial hostility through a realistic portrayal of non-whites. In order to reverse the racial discursive order that perpetuates misrepresentation of non-whites, white authors need to adopt more complex strategies. Disgrace implies that while literature does not offer simple solutions that can be translated into legislative policies, it does, however, draw attention to the problems of its milieu, question prevalent codes and expectations of its times, and expose the existential contradictions that are the groundwork of interpersonal relations in any context. In doing so, Disgrace redefines advocacy as a way of acknowledging the singularity of the other that respects the distance between the self and the other. In literature, this kind of advocacy often means acknowledging the failure to represent the other and highlighting the absence of the historical other in a text. However, literature's advocacy tends to be surreptitious and precarious, without any guarantee of repercussions in the public sphere. In short, literature provides scope for individual intervention in the discourse. Disgrace draws attention to the importance of reading in understanding the 
relation between the self and the other and the self and history. Acknowledgement of the limitations of a relationship with the other is the ground of the interaction, rather than the beginning or end of reconciliation. 


\section{Chapter 3}

\section{Making Friends with Ghosts: Magic Realism and the Demands of History in Andre Brink's Post-Apartheid Novels}

The TRC’s hearings and J.M. Coetzee's Disgrace reiterate, in their different ways, the critical role of history in reconciliation. While Coetzee's analysis of the effects of post-racial politics in Disgrace warns us of the consequences of forgetting the past, the TRC hearings remind us that history is a polyphonous discourse. Counter-histories, which began trickling into South Africa with the lifting of state censorship, in the dying years of the regime, became a veritable flood in the early post-apartheid years because of the TRC hearings. These counter-histories challenge the apartheid version of history. The common theme among these widely divergent representations of apartheid are recurring patterns of violence across the racial divide as white and black violence was mirrored by black-on-black violence, white-on-white violence, and gendered violence. These multiple accounts of the past that surfaced after the end of apartheid raise questions about the representation of the past. How does one represent the past as a panoply of perspectives, some of which are radically opposed to each other? What is the responsibility of those who are witness to these alternate histories? The answers to these questions are crucial because in order to create a realistic vision of the future it is important to create a reasonably sound map to the present.

Emergence of suppressed histories creates the temptation to either fill the gaps in dominant history with the counter-histories, or privilege counter histories as the new authentic history. Substituting dominant history with counter-histories has been described by Keith Jenkins as a move from history in the upper case to history in the lower 
case. ${ }^{\text {lxviii }}$ Both tendencies repeat the totalizing desire of white historiography. In order to revise history it is necessary to move beyond dominant white historiography and the concomitant temptation to create a black historiography. Instead of regarding counter perspectives as corrective of existing history, it is necessary to see history as a synchronous and complex web of narratives. The best way to map this synchronicity is to relinquish the desire to fill in the gaps of official history. In essence, it means recognizing the different versions of history as narratives that arise from the demands of specific contexts.

One way to escape the totalizing gestures of apartheid history and its counter histories is to move beyond the desire to find a true essence of the past in historical records. It means reading history as a text, instead of a mirror to the past. This movement has been described by Jenkins as a movement from narrative history to postmodern history. The way to bypass the fallacies of authenticity is to "ideologize" attempts to reconstruct "the past on its own terms" and engage in postmodern critiques of history in the lowercase and history in the uppercase” (Jenkins 13). ${ }^{\text {lxix }}$ The difference between the two histories is that one considers language to be a transparent medium for facts, while the latter considers language to be an opaque medium marked by the discursive position of the historian. The premises of postmodern historiography make it similar to fiction. ${ }^{\text {lxx }}$ In this chapter, I examine the way Andre Brink, the Afrikaner anti-apartheid activist and novelist, has grappled with the connection between fiction and history in his novels. He regards language as the common point and the point of departure between the two discourses. He observes that since all "human experiences are embodied through language," it is the point where "story and history meet and mingle, where private 
experience (expressed in language) intersects the public, the social or the political (also expressed in language)” (Brink, Reinventing 142). Brink’s observation implies that by presenting primary experience, whether it is personal experience or public experience, through language, experience is turned into narrative. In short history needs to be a reflexive and recognizes itself as one among many ways of representing the past.

Brink’s preference for the self-reflexive nature of narrative makes him prefer literature to other means of recording the past. He thus observes that the "TRC is intent on effecting reconciliation through establishing ... the whole truth ... truth being equated with facts,” while fiction "reaches well beyond facts” (Brink, Stories 30). Fiction, according to Brink, "is concerned with the real, it presumes a process through which the real is not merely represented but imagined. What is aimed at is not a reproduction but an imagining" (Stories 30). Brink’s observation ties in with his belief that a "literary text is a reinvention” (Mapmakers, 143). Thus Brink warns that "unless the enquiries of the TRC are extended, complicated and intensified in the imaginings of literature society cannot sufficiently come to terms with the past to face the future (Brink, "Stories” 30), because "without the attempt to grasp, with creative imagination, the past and its silences, South African society as a whole may get bogged down in mere immaterialities, sterile rationalizations and the narrow mechanisms of retributions and amnesty” (Brink, Interrogating 25). Brink's focus on literature as an imagining of the creation of history draws attention to the need to understand the conditions that give impetus to certain versions of the past, rather than on the factual merits of the events described.

One of the modes that emerged to express the complex racial terrain of postapartheid South Africa is magic realism. In Brink’s post-apartheid novels we find a shift 
from the desire to recover the past to a desire to explore the discursive basis of different historical perspectives.

Brink uses magic realism in his post-apartheid novels to dramatize history as a process of reinventing of the past to suit present historical exigencies. Magic realism, which juxtaposes realist and supernatural elements side by side, without privileging either, enables Brink to present competing version of historical events: official history and unofficial versions in the form of myths and stories. The juxtaposition of two seemingly incompatible systems of representation locates truth in the tension between language and silence. The fantastic stories circulating in the underbelly of official discourses disrupt the monolithic official history to expose it as an invention that perpetuates the myth of a pure white Christian identity threatened by interracial relations. In Brink’s post-apartheid novels magic realism demonstrates the epistemological problems of seeking to connect to the nation through counter-narratives. In the process of witnessing the imagination of history the protagonists of the three novels I examine in this chapter-Kristien Muller in Imaginings of Sand, Flip Lochner in Devil's Valley and Ruben Oliver in Rights of Desire-have to forego their obsession with factual veracity in order to intuit the significance of the stories: the opacity of language and inability of history to capture the authentic past. Brink’s magic realism accomplishes two things: it draws attention to history as a linguistic construct, rather than a mirror to facts; second, it collapses differences in time and space to map the evolution of racial identities in South Africa as fractal patterns. Viewing racial history as fractal underscores the reiteration of racist patterns in the postapartheid era. This chaotic map of Afrikaner history makes complex demands on the individual confronted with this history and nixes dreams of easy redress. 
My position challenges previous analyses of Brink's magic realism as an attempt to set up an alternate cultural system. Brink has come under the critical scanner because his use of the trope of miscegenation and haunting to challenge the apartheid discourse on Afrikaner history, ultimately, represents racial reconciliation as a matter of unearthing the atavistic roots connecting the Afrikaner with Africa. ${ }^{\text {lxxi }}$ This, critics point out, conveniently glosses over the violent aspects of settler colonialism and indigenous land right claims. Dismissing the novels because of their allegiance to counterhistories, however, misses the fact that Brink doesn’t establish a particular counter history. Instead he focuses on the emergence of certain versions of the past at particular historical epochs. The novels narrate the imagination of the past in historical accounts to suggest that history is a process of defining and redefining identity (national and individual) under different circumstances.

I use chaos theory to read Brink’s magic realist novels because they represent race as a dynamic and fluid system that is a consequence and cause of complex social processes. Race thus resembles chaotic, rather than linear, conceptions of history. Chaotic systems are dynamical systems whose present states completely or almost completely determine their future, but do not appear to do so (Lorenz 8). Since chaotic systems are a kind of "dynamical system whose state changes over time. Systems such as these are multi-faceted, complex, and interdependent, they constantly push and pull against themselves to create sensuous irregularity and unpredictability that is a sign of our physical environment”(Briggs 15). As a dynamical system, chaos is not characterized by absence of information, but a glut of information. Consequently, the slightest change in one factor can transform the entire system. According to Briggs, this includes "even our 
attempts to gather the information itself” (16). Objects in this dynamic system are defined by sensitivity to initial conditions. Sensitivity to initial conditions means that the system is not dependant on the conditions at the beginning, but the conditions at any point of time. Because chaotic systems are dynamic, they are subject to feedback or information that loops back into it. The folding and refolding of feedback magnifies changes and results in convulsions. Unlike linear systems, which are progressive, incremental and, therefore, predictable, chaotic system are fractal and volatile. Fractals map the way “images fold and unfold, feeding back into themselves” (23). Fractals thus measure the irregular contours of chaotic systems. Therefore fractals have been used to measure weather, clouds and stock markets. According to John Ernest, chaos theory "offers a useful approach to cultural processes that follow general patterns without leading to absolute and unchanging results” (Ernest 63). Chaos theory helps us map the complex social terrain created by race, an unpredictable system that infiltrates other discourses, even as it is a product of the interaction of multiple discourses. Chaos as a metaphor for race presents reconciliation as a process of setting up a counter-discourse of racial interaction, rather than transcending race.

Representing the complexity of race and the intricate and entangled social world it engenders requires a more sophisticated representation strategy than realistic narrative. According to Brink such an opportunity is provided by literature, which is reflexive and can indicate the processes involved in the creation of each perspective. In Brink's fiction there is a shift from desire to present the other side or history with a small "h," as Jenkins puts it, to mapping the processes involved in the creation of different histories. This shift coincides with political change so that in the post-apartheid novels he becomes involved 
in mapping the complex social terrain created by South Africa's racial history. Magic realism, particularly epistemic magic realism, offers him the medium to map the chaotic currents of race.

\section{Magic Realism and Andre Brink}

Magic realism as a narrative mode is effective not just in presenting the polyvalent and synchronous discourse of history, but also in drawing attention to the epistemological politics involved in representing the real. The possibilities of epistemological critique inherent in a mode that marries the antipodal qualities of realism and fantasy lie in the deep history of magic realism. Magic realism as a narrative mode is associated with Latin America. Its origins, however, go back much farther to Europe, where Novalis, or Frederich von Hardenberg as he was known, first used the word in a cryptic diary entry. Novalis came up with two words: magical idealist and magical realist. But he didn't elaborate on the latter term at all. ${ }^{\text {lxxii }}$ The term magic realism was next used by Francis Roh in reference to post-expressionist art in the Weimar Republic. For Roh magic realism was a characteristic of art which had moved beyond the 1920s expressionist emphasis on subjectivity to focus on the ordinary. Roh's definition of magic realism veers away from the fantastic or marvelous to present the mystery inherent in reality. ${ }^{\text {lxxiii }}$ Roh's definition differs from the way magic is understood in literature. In literature magic refers to the irrational, fantastic or the supernatural. ${ }^{\text {lxxiv }}$

Because of its long and much traveled history, and the different contexts in which it has been used, it is hard to come up with a stable definition of magic realism. It has often been associated with marvelous literature and fantastic literature. In the attempt to differentiate the mode from marvelous and fantastic literature, most theorists agree that 
magic realism involves the simultaneous coexistence of magical and realistic modes, without any mode being privileged. Maggie Ann Bowers writes that it relies upon a “matter of fact, realist tone ... when presenting magical happenings” (34). She further explains that magic realism fuses the "two opposing aspects of the oxymoron (the magical and the realist) together to form one perspective” (Bowers 34). In their introduction to an anthology on magic realism, Wendy Farris and Lois Parkinson-Zamora observe that "in the magical realist texts ... the supernatural is not a simple or obvious matter but it is an ordinary matter, an everyday occurrence-admitted, accepted and integrated into the rationality and materiality of literary realism.” (3). Christopher Warnes says it is a "mode of narration that naturalizes or normalizes the supernatural... the real and fantastic, natural and supernatural are coherently represented in a state of equivalence” (3). The juxtaposition of two radically different systems in a single text has been used to achieve two very different goals at different times in its history.

While theorists agree that the intrusion of the fantastic in the ordinary without privileging either has a corrective function, they are split on how magic realism corrects the past. Zamora and Parkinson write, "it creates the space for interactions of diversity" (3) by drawing upon “cultural systems that are no less 'real' than those upon which traditional literary realism draws — often non-Western cultural systems which privilege mystery over empiricism, empathy over technology and tradition over innovation” (3). For Bowers, "its attack on dominant culture and its authoritarian version of the truth actually provides a more comprehensive mode or referentiality” (71). The first position perceives magic realism as creating space for previously silenced cultures. The latter position hints at epistemological critique. The first is identified with Alejo Carpentier and 
his association of the mode with the "baroque" American landscape. Carpentier aligns the intrusion of magical elements as a signifier of other modes of apprehending reality. The second mode is identified with Borges, who uses magic realism as a mode of defamiliarization that presents all representations as ideologically located. ${ }^{\mathrm{lxxv}}$ Despite differing on the mode of correction, both positions acknowledge magic realism's power to deepen the idea of realism by challenging the Western Enlightenment rationality that gave rise to realism.

The controversy deepens further as these two goals of magic realism are geographically politicized. For example, Durix claims that the magical realism that uses magical elements as a signifier of another culture is associated with postcolonial cultures, while magic realism as a mode of epistemological critique is associated with European magic realism. Jean Weinberger claims that there are two types of magic realism, "a scholarly type that constructs a speculative universe and is the province of the Europeans" and a "mythic or folkloric type mainly found in South America" (qtd in Farris165). Durix claims that in European literature the fantastic "serves to protest against the tyranny of 'fact'," while in postcolonial literatures it has a "social function" (81). He goes on to claim that in Africa a "return to the world of ancient deities and heroes does not constitute a reversal of codes; it is an attempt to reclaim alternative rules which may complement those in use in present times” (81). For Durix magic realism in the postcolonial context serves to incorporate "old values in the modern man's perception" (81). Farris and Zamora echo Durix in their claim that it helps "reestablish contact with traditions temporarily eclipsed by mimetic constraints of $19^{\text {th }}$ and $20^{\text {th }}$ century realism” (2). The claim that the anthropological and ethnographic function of magical realism is 
associated with postcolonial nations and that its ability for discursive and epistemological critique is associated with post-structuralism in Europe replays the binary its form denies. Such clear divisions are not supported by historical evidence. Christopher Warnes identifies two trends in magic realism: ontological or faith-based magic realism and irreverent or epistemological magic realism. The former associates discourse with being, while the latter treats it with epistemological skepticism. In the former the "supernatural event or present may stand synecdochically or metonymically for an alternative way of conceiving reality usually derived from a non-western belief system” (14). For the latter a supernatural event or presence "which is not rationalized or explained away, ... stands in place of an idea or a set of ideas ... about the way language constructs reality or about the incapacities of binaristic thinking”(15). The former uses magic realism to reveal its alliance to a set of cultural values to which the text gives access; the latter kind of magic realism “defamiliarizes a discourse without giving access to any particular world view as the best” (16). The first is anthropological in its approach and the latter is literary in its approach, according to Warnes. In this analysis, Warnes’ divisions correspond to Durix’s system of European and postcolonial magic realism. Yet Warnes shows that in Nazi Germany the anthropological magic realism had been used to create the Aryan myth by Spengler and others. Similarly, Salman Rushdie and Borges use magic realism in the discursive sense to raise questions about the politics of representation. Warnes shows that in the hands of expert postcolonial authors such as Marquez, Carpentier, Rushdie, etc, the mode has become a way of critiquing realism. While Rushdie uses the discursive mode and Carpentier uses the cultural mode, it is true that others like Marquez combine both the modes in their fiction like Autumn of the Patriarch. This is not to say that the 
epistemological magic realism doesn't espouse values. In Satanic Verses and Midnight's Children Rushdie exposes nationalist historiography as a discourse in order to argue for Indian identity as hybrid and complex. Magic realism has, thus, not always been liberating and the faith-based or ontological mode has been used for reactionary purposes by Europeans as well as non-Europeans.

The postcolonial affinity for magic realism can be attributed to the complex demands of its contexts. Realism is a vexed issue in the postcolonial context. Durix identifies three main problems with the use of western realism in postcolonial context. First, the search for authentic reality by counter movements repeats the totalizing tendencies of colonialism in the hybrid postcolonial ethos by creating a fixed indigenous identity. Second, the act of repossessing reality was a linguistic enterprise since the postcolonial writers were writing in a language that was often not their own as well as trying to overwrite the modes imposed by colonialism. This means that a language loaded with all the associations of the colonizer was used to represent a reality that was different from that represented in western realism. Third, since their books had a large readership in Europe, their audience was often not just the indigenous population, but Europeans as well. This poses a few problems: for the western audience the reality of the postcolonial context may appear fantastic. At the same time, presenting the indigenous life in a nonindigenous tongue has a distancing effect. Perhaps the most vexing issue as far as realism is concerned is that neither the colonial realism, nor the anti-colonial desire to return to the origins does justice to the reality of the postcolonial context.

The postcolonial context itself is deeply hybridized through cross-fertilization between European modes of representation and existence, and indigenous representation 
and modes of life. Magic realism captures the hybridity of the postcolonial context in the very ambivalence of its mode and embeds it in the narrative form. Farris and Zamora observe that magic realism’s “in-betweenness” and “all-at-onceness encourages resistance to monologic political and cultural structures, a feature that has made this mode particularly useful to writers of postcolonial cultures and increasingly to women” (6). This vision enables the postcolonial writer to reach the old modes of life and deepen the understanding of realism. Alternately, it enables the writer to critique the desire for an authentic past as well as reliance on western modes by demonstrating such modes and desires to be discourses with ideological underpinnings. The ability to undermine European realism without privileging another discourse makes magic realism mirror postcolonial ambivalence. It signals the author's complicity in the context he or she critiques and the language he or she uses.

In post-apartheid South Africa the postcolonial ambivalence is complicated by the fact that there is a need to recover the silent voices of history without engaging in presenting the recovered voices as the true past. There is need to expand the notions of history beyond facts and empirical evidence to include non-traditional, non-rational modes such as stories, myths, legends and folklore. Not surprisingly, magic realism has been adopted by many authors, particularly white authors such as Mike Nicols and Andre Brink. Brink’s magic realism engages in epistemic criticism. Through magic realism Brink juxtaposes patriarchal Afrikaner history with various counter-histories to highlight the omissions of official accounts. In Imaginings in the Sand, for example, the protagonist's family history, recovered though her grandmother's stories, is treated with lighthearted humor against the heavy weight of the official Afrikaner version. In Rights of 
Desire and Devil's Valley the search for answers from the past and the desire to record the true history of the past is gently ironized. The novels draw attention to the ideological subtext behind historical accounts and embed the opacity of language in their form.

At the same time, Brink perceives magic realism as a mode that is uniquely South African, a mode that enables the Afrikaner writer to touch the heart of South Africa. In “Interrogating Silence” Brink writes that openness to other perspectives would enable the Afrikaner to connect with the magic of Africa. This magic, of course, differs from black magic and witchcraft associated with Africans. Magic, Brink points out, is a part of Africa, where there is "free interaction between the worlds of the living and the dead, a rich oneiric substratum, and also ... historical commitment” (Brink, Interrogating 25). By adopting magic realism, which combines the European and African modes in its form, Brink represents in his narrative strategy the hybridity of Afrikaner identity. ${ }^{\text {lxxvi }}$ Brink's emphasis on magic realism as a narrative mode interlinks the past, present and the future to underscore the need to acknowledge the post-apartheid moment as melancholic.

Brink’s epistemic magic realism considers the seemingly inconsequential narratives, the ones that official history ignored, to present a racial picture of South Africa that defies the binary divisions of apartheid ideology and the belief in linear progression from racism to post-racial discourse in the post-apartheid era. These inconsequential details and deviations ignored by official history at the familial and national level do not establish an authentic past as much as expose the ideological and social forces at work in the creation of different accounts. Brink thus presents the racial system in South Africa as a disorderly and dynamic system where past racial structures continue into the present. 


\section{The Place of Magic Realism in Brink’s Canon}

The first Afrikaans writer to be banned under the strict apartheid censorship laws, Brink, along with a group of like-minded Afrikaans writers called the Die Seistigers, rebelled against the conventions of Afrikaans literature from the beginning of his career. With The Ambassadors, his first novel to be translated into English, Brink issued a direct challenge to the romantic-colonialist tradition of Afrikaner literature. Brink broke down taboos on the content of Afrikaner literature (particularly taboos on sex as a subject of literature) imposed by the repressive Calvinist Afrikaner nationalism to criticize social structures and encourage technical and aesthetic experimentation. Sue Kossew points out that "writing back” to Afrikanerdom involves “recognizing the restrictive imperialist/nationalist structure imposed on all the people of South Africa by the Afrikaner Nationalist government and its cultural, linguistic, political and social ideologies” because “attempts to subvert them or write back to them from within were couched in modernist terms emphasizing the writer's right to experimentation with form (Pen 6). Brink’s writing back was an attempt to redeem Afrikaans from being colonized. Commenting on the evolution of Afrikaans, Brink notes that this language was created as part of a political struggle for the emancipation of Afrikaners from Dutch and English oppression by appropriating the indigenous, partly creolized, language spoken mainly by the Coloreds. During the apartheid, in order to separate Afrikaner identity from the nonwhites, the African roots of Afrikaans were denied. Afrikaans was thus colonized by apartheid regime. Therefore, according to Brink, “writing back” means a "dual struggleagainst the hegemony of the apartheid state and for a new acceptance of its African origins” (qtd in Kossew Pen 6). "Writing back” to recover the messy and complex origins 
of Afrikaner identity and literature was a political enterprise that influenced Brink’s early experimentation and his later sense of the writer's political responsibility in a repressive state. In 1973, with Looking into Darkness, his first novel to be banned, Brink began to self-consciously address political issues in his work, instead of trying to exempt art from politics. Brink's overt political stance in his apartheid fiction contrasts with Coetzee's refusal to offer political closure through literature.

In his essays, Brink repeatedly presents an alternative history of the Afrikaners based on forgotten or erased figures who reveal Afrikaner identity to be hybrid and formed in collaboration with Africans to resist Dutch and British colonials. He presents the Afrikaner as a dissident. The myth of terra nullis and stories of racial purity, on which Afrikaner history is based, suppress the presence of indigenous population as well as events and perspectives that challenge official accounts of the past. Brink's novels seek to recuperate this forgotten history of the Afrikaners. In his post-apartheid fiction he dramatizes the process of writing history to present the Afrikaner's relation to the land as an imaginative kinship, rather than autochthony. His post-apartheid novels show that when the official history of the Afrikaners is considered from the point of view of women, Coloreds or Africans, as in Imaginings of Sand, Devil's Valley or Rights of Desire, connections with the racial other, gendered other, or between the past and present events emerge that were invisible in official accounts.

While preoccupation with recovering the entangled roots of Afrikaner history remains a concern in post-apartheid fiction, there is a shift in focus as well as in approach. In his apartheid era political novels Brink rewrites history by imagining historical events from alternative perspectives. For example, in A Chain of Voices Brink’s 
research about a failed slave revolt led him to try and decipher the slaves' voices from the official legal court documents and resulted in his imaginative narrative about the revolt. Similarly, in the First Song of Adamastor he rewrites the Lusiads, the first European text to refer to South Africa, by presenting the landing of the Dutch in the Cape of Good Hope from the perspective of the Hottentots. However, in his post-apartheid novels Brink moves from writing counter-histories of the past to narratives that foreground the discursive nature of history. In Imaginings of Sand, Kristein learns that the value of Ouma's fantastic accounts of nine generation of women in their family lies not in the veracity of the accounts, but with the conditions that governed their production and circulation. Baffled by contradictory accounts of the same event, Flip Lochner, in Devil's Valley, learns that the contradictory versions are testimony to the circumstances of their production. In Rights of Desire Ruben's comparison of the court documents on the conviction and execution of the Colored slave Antjie of Bengal with the accounts of her ghost, who haunts his house, shows how legal, cultural and social ideologies work together to allow certain narratives and suppress others. Through imaginative recreation of the emergence of official historical accounts, Brink’s post-apartheid novels dramatize history as a fluid and discursive construct. Brink’s post-apartheid novels call for a move beyond the desire for narrow factual veracity as the basis of historical authenticity to a critical examination of the conditions involved in recording history.

Brink effectively uses magic realism to mock the quest for an authentic past and underscores the impossibility of accessing the past. At the same time, the easy traffic between the natural and human worlds, spirits and humans, the past and the present reveals the history of racial identity in South Africa to be messy and fluid. The chaotic 
currents of racial classification in South Africa reject simplistic gestures of reconciliation to present it as a process of negotiating a relation with the past in the present.

\section{Magic Realism and History in Brink’s Post-apartheid novels}

The three novels analyze South Africa's racial politics at different points in the post-apartheid era. Imaginings of Sand is set in the eve of the first democratic elections in South Africa, a moment of transition charged with conflicting emotions. It is a time marked by the Afrikaner fear of a non-white government and consequent Black reprisals, the Colored despair of change, and the African desire for revenge coupled with hope. Kristien Muller, the protagonist, returns from self-imposed exile, to South Africa, a week before the elections, to a country beset by terror and fear, rather than hope. Her grandmother Ouma Kristina's house, the Bird House, a symbol of Afrikaner power and wealth, is burnt by African miscreants. Her sister Anna stocks up on essentials in anticipation of African attacks, while her brother-in-law Casper and his friends form a patrol to protect the neighborhood. In reality, in order to vent their rage and frustration they look for excuses to attack African or non-whites. The Colored servants Trui and Jonathan fear that, just as they were disregarded during apartheid for not being completely white, in the new era they will be forgotten because they are not pure Africans. The only hope amidst this fear and distrust is the ANC leader Thando Mukolo's assurance that “we can’t imagine the future by pretending to forget the past” (Brink, Imagining 264). In Devil's Valley we find that South Africa has abandoned Thando's philosophy for post-racial politics. Flip Lochner, along with most people, regards the Devil's Valley as a relic from the past in a new South Africa. According to him the inhabitants of the valley sequester themselves from the outside world and adhere to the 
racial mores of the nineteenth century. In the mean time the rest of South Africa has learned "to get along with others" and done penance for its racist ways by electing a “black president”(Brink, Devil’s 105). The reluctance of the inhabitants from the Devil’s Valley who have settled outside to talk about their roots for fear of ridicule, however, indicates a nation anxious to avoid its past. In this post-racial milieu, far from being an anomaly in South Africa, the Devil’s Valley, located deep in the ravines of Drakensburg Mountains, is a repository of the history and practices that the post-apartheid nation is anxious to avoid. Rights of Desire, set a decade into the post-apartheid era, presents an equally depressing picture. It presents a nation where rationalization policies privilege Africans over Colored and Afrikaners. As a result, Ruben is forced to resign as university librarian to make way for more Africans hires, just two years before retirement, while his Colored servant Magrieta finds that government housing is reserved for Africans. Not surprisingly, these measures have bred ethnocentrism, hostility, corruption and violence. The novels depict the post-apartheid era as a time of violence and disappointment, where continuation of past structures and liberal responses to the challenges of reconciliation has ossified existing racial divisions. The despondence, despite efforts to create racial equality, is because of the dependence on preferential programs and post-racial politics, all of which fail to tackle the historical problems at the root of racial animosity in South Africa. Preferential treatment programs are problematic because they see equality as a matter of “opportunity to achieve scarce social rewards,” rather than "equalizing opportunities to develop individual powers and talents” (Goldberg, Culture 231). Unless the potential of the disenfranchised races are nurtured preferential programs will increase competition for limited resources, instead of leading to better relations. 
The protagonists of the novels are marked by a sense of alienation from their milieu. In Imaginings Of Sand Kristien left South Africa, disgusted with apartheid politics, vowing never to return. Ruben Oliver in Rights of Desire has spent his life trying to make himself immune from all the racial politics. During the apartheid, eager to dissociate himself from his in-laws, wealthy vineyard owners from the upper echelons of Afrikaner society, he bought a house for himself in the suburbs and immersed himself in books and music. When post-apartheid rationalization forces him into retirement he seeks refuge from the deteriorating and violent racial relations in his books, resisting his family's efforts to persuade him to emigrate. Flip, in Devil's Valley, is a fifty-year-old jaded journalist who has failed to live up to his earlier potential. Kristien's exile, Flip and Ruben's sense of redundancy and irrelevance relate to the Afrikaner struggle to rediscover their relevance in a nation where they occupy an ambivalent position. The struggle to find their home in South Africa is a continuation of a longer struggle of the Afrikaners to make South Africa home. The Afrikaners historically regard themselves as twice exiled because they were neither European nor African. This sense of exile is exacerbated in the post-apartheid era by loss of privilege and political power and preferential treatment programs.

Despite their self-imposed exile or withdrawal from issues that beset South Africa, Kristien, Ruben and Flip suffer from deep guilt. Kristien’s decision to move away to London meant that she relinquished her role as her grandmother’s protégé, the keeper of the family's secrets and fantasies, and the opportunity to learn the real significance of the family’s fantastic stories. In Rights of Desire Ruben’s inability to recognize and help his friend Johnny Macfarlane, who was beaten by thugs and left on the road, builds guilt. 
This guilt escalates after his encounters with his beautiful and free-spirited tenant Tessa, who forces him to confront his complicity with South Africa’s racial history. Flip, in Devil's Valley, is filled with guilt for betraying the non-white cause during apartheid by not reporting the violence and injustice against them. At the beginning of his career, in a phase of “misplaced romanticism” about his role in the political events, he sought to expose the complicity of the police with the racist apartheid state (Brink Devil's Valley 16). However under an unsympathetic editor he was forced to submit to the state censorship rules and rescind his stories on state abuses. His silence made him complicit with apartheid state's censorship laws. Not surprisingly, Flip describes his life as one where "compromise is the name of the game, until you swallow your last lump of self respect like vomit from a bad hangover” (Brink, Devil’s Valley 15).

Guilt creates a concomitant desire to make amends in all three of the protagonists. When Kristien learns of her grandmother Ouma Kristina’s desire to see her before her impending death she immediately flies to South Africa "to return to older kinds of knowing, to withdraw again to that desert where Ouma and her spirits have roamed and where they are now in the danger of extinction” (15). She imagines that visiting Ouma's deathbed and recording her stories will compensate for her willful neglect of her role as keeper of secrets. In Devil's Valley, Flip believes that by writing a book based on his research on the inhabitants of the Devil's Valley, where the old colonial racist ways continue, he will atone for his complicity with apartheid. In the course of his research, as he gets involved with the people of the valley, he believes that saving Emma from them will atone for his past betrayals. In Rights of Desire Ruben's recognition of his culpability in Johnny’s death creates a desire to make good his negligence and leads him 
to focus on making life better for his trusted housekeeper Magrieta. All the three protagonists believe that the past can be amended by a single gesture. Kristien believes that she can record the stories and leave for London. Flip believes that a week of fieldwork in the valley will give him enough material to write a book that will atone for his complicit silence during the apartheid. Ruben believes that helping Magrieta find a house will be penance for his neglect of his wife Riana and his complicity with apartheid through his silence.

However, through their encounters with fantastic events the three protagonists recognize the complex connections between present wrongs and South Africa’s deep racial history that make simplistic notion of reparations as a means of reversing the past impossible. In Imaginings of Sand the inerasable vivid erotic painting by Ouma's mother Rachael — who was raped by the servant Salie to avenge his daughter's rapesymbolizes the violent history of rape and betrayal that binds their Colored servant Trui to their family. The spirits of the dead women hovering around the house as birds suggest the constant presence of the past in the present. Wilhelmina, one of their ancestors, is a spectral witness to the narration of her life story. In the Devil's Valley the past and the present are blurred as ghosts inhabit the valley. The dead of the valley come together on New Year and for church service. Flip observes that "the pews were crammed to capacity; not only by the living but... by the dead of the community as well”(178). Flip is greeted by the ghost of Lukas Seer, who had died in the $19^{\text {th }}$ century. The Seer's dead descendants keep reappearing. Flip sees Lukas Little’s ghost when he is about to hand over his ashes to Dalena. Ouma Lisbet Prune appears on her rooftop after she is dead. In the valley dream and reality merge to blur differences past and present. Flip’s vision of 
Mooi-Jaana, the woman with four breasts, swimming in the Devil's Hole as he enters the valley and Emma's vision of his arrival in her dream about swimming in the Devil's Hole sets Emma, the much maligned object of lascivious male fantasy in the valley, as an incarnation of the legendary Mooi-Jaana. In Rights of Desire the ghost of Antjie of Bengal, a slave woman who was executed on the charge of murdering her mistress, haunts the house. In the first paragraph Rueben informs us that "Two fixtures came with the house: The ghost of Antjie of Bengal and the housekeeper Magrieta Daniels” (Brink, Rights 3). Ruben's presentation of the two characters suggests the continuation of the injustices against the Coloreds in the present.

The connection between the past and the present is indicated by multiple references to palimpsests. The interweaving of the past in the present is symbolized by Gert Bush's paintings in the Devil's Valley. As Gert uses the same canvas repeatedly the painting resembles a palimpsest. In Imaginings of Sand Thando reminds Kristein of the presence of the past in his comment, "You have all your ghosts with you” (Brink, Imaginings 267). The present as a palimpsest is also evident in Kristien's description of Ouma’s dying moments when she observes "I see her sinking slowly, flickering ghost images of many faces passing through her as if she tries them on and merges with them; see her falling from body to shadow to ever-changing names, cascading though time in a present that never ends” (Brink Imaginings 323). No group is testimony to the continuation of apartheid trends in the post-apartheid era as much as the Colored women in the novels. Trui tells Kristen that things will remain the same for her because she will “still be taking orders” (Brink, Imagining 72). In Rights of Desire the rationalization policies have ignored the Colored population as they initiate programs for Africans only. 
The continuing violence in the non-white localities reveals that there has been little change despite the end of apartheid. Kristien's sister Anna, wife of one of the Afrikaner leaders, claims, “even if the country does change, what difference can it make to me? I live on a different level... its very basic. Man and woman. And that's not going to change” (Brink Imagining 313-314). Anna argues that the political change will not affect the fact that she is “not even a woman any more,” but "somebody’s wife, somebody's sister and somebody’s mother” (Brink, Imaginings 314). Her despairing words suggest that in some cases political change does little to end other inequalities.

The fantastic events have resulted in Brink's brand of magic realism being aligned with the post-colonial magic realism associated with Alejo Carpentier. For example Melanie Joseph-Villain in "Magic Realism in Two Post-Apartheid Novels by Andre Brink" writes that both Imaginings of Sand and The Devil's Valley "go back to the origins of the nation” through magic realism (30). Her comment refers to the fact that the fantastic events such as ghosts, spirits of ancestors as birds, disrupt the linear space-time continuum to connect the Afrikaners to the land. The Afrikaner connection to the land is established through the figure of the non-white woman. Kristien's family is connected to South Africa through Kamma/Maria, the Hottentot who bartered herself to the Boers in exchange of peace for her tribe and was renamed and civilized by her Boer husband Adam Oosthuizen. In Devil's Valley Billah, the Hottentot woman the Seer married and raped over her husband's grave, connects the Afrikaners of the Devil's valley to the land. Perhaps the most dramatic example of the connection between the past and the present is Antjie’s story. Antjie is not a native South African like Billah in Devil's Valley, or Kamma/Maria in Imaginings of Sand. However, her execution, which demonstrates how 
law is directed by "structures of inequality which bound the Cape’s Colonial society together,” connects her life to the racial history of the country (Brink, Rights 48).

The use of African and Colored women to connect the Afrikaner women to the land recolonizes African history for Afrikaners according to Sue Kossew. Kossew describes it as reinscription without the violence. ${ }^{\text {lxxvii }}$ Moreover, Kossew reads the use of non-white women in Imaginings of Sand as erasure of the Afrikaner woman's complicity in the racial history of South Africa. Kossew's comment refers to Imaginings of Sand, but it could also be applied to the two other novels as well. Moreover, according to the critics, miscegenation as a strategic device to connect the Afrikaner with the land glosses over the violence of settler occupation and the Colored history. The novels present miscegenation as a mutual decision. Kamma/Maria decides to offer herself to the Boers to preserve her tribe. Similarly, Antjie is a willing participant in Willem's plans to kill his wife because she loves him.

Even though magic realism offers alternate histories that reveal a different world order, the status of these alternate histories as authentic accounts is questioned in the novels. Brink cautions against uncritical acceptance of alternate histories presented by women, Jews, Colored, etc., as truth through reference to narratology. In Imaginings of Sand Ouma admits to possessing an "amazing memory" that "can remember things that never happened" (4). Commenting on the different stories circulating about the fate of her ancestor Benjamin, Ouma observes that "there are flaws in each of these suggestions, so why opt for one? ... The story doesn’t need him anymore, so we will drop him” (103). Ouma's observation implies that the difference between official accounts and stories is non-existent since writing history is a matter of "prophesying the past" and turning event 
into narrative. In Devil's Valley Gert disabuses Flip of the notion that the different accounts lead to the truth. He points out, "I am not saying it is true, I am just telling you what people say. ... You'll hear so many stories in this place you can never be sure what really happened” ( Brink, Devil's 157). In Rights of Desire Ruben notes that through retelling Magrieta’s ancestress, who they both arbitrarily name "Maria of Tuticorin,” became a contemporary of Antjie. He further notices that Magrieta seamlessly incorporates Khoisan myths into her family stories. Ruben's observations on the imaginative nature of Magrieta's story about her family indicate the fictional nature of historical accounts. References to the unreliability of narratives present those counterhistories as constructs and one among many competing accounts.

The references to narratology suggest that the past is accessible through language and mediated by individuals located in space and time. Since the attempt to present events turns them into narratives, the actual events remain inaccessible. Consequently every attempt at historiography is revisionary, according to R. Radhakrishnan. Even so, contemporary attempts to revise history are motivated by dissatisfaction with the existing accounts. Therefore, Radhakrishnan points out that the key questions when considering revisionism are "why return, return to what, who returns and what are the differences between return undertaken by different human subjects that occupy different human locations and positionalities”(70). Radhakrishnan’s observation implies that revisionary accounts do not access the true past as much as they reflect the ideological biases of the historian.

Despite his mission to challenge the narrow and destructive Afrikaner identity through alternative histories, in his post-apartheid novels, Brink uses magic realism to 
expose all history, even alternative histories, as artifice. Magic realism juxtaposes two different realities or versions of events to make revision of existing history "a matter of rubbing history against the grain and telling another story, along its grain as it were” (Radhakrishnan 75). This often results in a multiplicity of narratives that reveal the lacunae in history, rather than the essential truth about an event. For example, Ouma’s story of her trips with the Jewish trader's nephew changes often. However, its existence reveals a narrative that challenges the myth of a pure Afrikaner identity. In Devil's Valley Flip’s encounter with Smous' story of the valley and Dalena's story of the women in the valley destabilize the Lermiets's version of the valley as the last bastion of pure Afrikaner values. Ouma Prune’s creation story, which incorporates Hottentot myths, when contrasted with the narrative of the valley as terra nullis reveals a violent history of dispossession and miscegenation that is glossed over. In Rights of Desire the juxtaposition of court documents with the accounts from Antjie’s ghost makes Tessa observe, “I guess all historians were men” (Brink Rights 51). Her comment reminds us that Antjie was just an occasion for the discourse on race and power. The sheer impossibility of fantastic events in the novel such as the woman with four breasts in Devil's Valley, or Antjie's ghost in the Rights of Desire, or a woman turning animals into stones in Imaginings of Sand draws attention to their fictionality.

The juxtaposition of narratives, however, does not lead to a core event. We do not discover if Trui is really related to Kristien, nor do we learn the true nature of the events that led to Antjie's arrest. Instead, the cacophony of stories point to a lacuna around which narratives develop. The multiplicity of narratives juxtaposed against each other mark the past as an "active absence or a series of absences in the body of dominant 
historiography” (Radhakrishnan 75). The dream of reclaiming the past is symbolized through the impossibility of verifying the stories. In Devil's Valley Flip’s goal was to "write a little tract of history" (Brink 10) and iron out the wrinkles in the line between Monsieur L'Hermite and Lukas Lermiet (12). As he explains, "if I want to write anything that is worth its salt every fact must be checked" (Brink, Devil's 264).But his efforts at finding the facts is foiled at every step. First, his instruments for documentation fail him as his camera falls off a cliff and his tape-recorder mysteriously stops functioning. In the end, in frustration he rants, "All I have ... in the search of facts, is an impossible tangle of contradictory stories” (Brink, Devil's 396). In Imaginings Of Sand, it is impossible to verify the stories since they have been passed along orally. Moreover, the fire to Mount Sinai destroys half the house, including Louisa's diary. In Rights of Desire the court documents do not provide the whole story about Antjie's life and there is no way to verify the accounts of Antjie’s ghost since they are mediated through Magrieta or Tessa.

The juxtaposition of different narratives without privileging any in the end implies the impossibility of reaching the past, unless it is through narratives, whether it be state narratives or individual stories. The significance of the stories, in the end, lies in the contradictory function of asserting the presence of an event and the failure to present a determinate picture of it. Instead of worrying about whether the outlandish stories of Ouma and the people of the Devil's Valley ever happened, it is more important to consider why the stories came about. Brink claims that in his post-apartheid novels he is aiming for something more complex than presenting multiple perspectives. He is moving towards an intimation that "something may actually have happened, but that we can never be sure of it or gain access to it, and that the best we can do is fabricate metaphors- that 
is tell stories in which, not history but imaginings of history are invented” (Brink, “Stories” 42). Brink’s comment reveals that it is important to understand the impulse behind the production of narratives of the past. He further elaborates, what matters are not the specifics of the invention (a woman changed into a tree) but the fact that they are resorted to at a given moment in an individual life, or at a specific historical juncture. ... in other words the question is not what 'sense' metaphorical, political or otherwise the stories may have taken individually or in series, but what sense ... the telling of these stories by this person at this juncture could possibly make (Stories 40).

He reiterates in an interview that he is interested in the "mythology of history or the relationship between the two terms, history and story” (Higgins13). In a similar vein Radhakrishnan asserts, pace Fanon, that history "performs the metafunction ... of 'preparing the ground,' that is preparing a temporality that is already in emergence” (79). Brink's perspective is seconded by Emma, who functions as the author's mouthpiece in Devil's Valley, when she points out that just because there are no verifiable facts doesn't mean that nothing happened. Trying to explain the true worth of Ouma's fantastic stories to her more prosaic elder sister Anna, Kristen struggles to find a way to explain that Ouma’s stories suggest "that the very fabric of our fictions betrays the predicament of our culture” (Brink, Imagining 130).

In the novels magic realism doesn't present the atavistic roots of Afrikaners as much as it presents the exigencies of different historical accounts, which cumulatively point to the past as an absent presence. It matters little whether Ouma went to Paris or 
Egypt in a magic carpet, or if Louisa really met with the famous opera singers of Europe. The stories suggest the fortitude and resilience of these powerful women living in a racist order, which survived by imposing repressive roles on them. The surfacing of these stories on the eve of a new order enables Kristien to find her place in her country and recognize the need for structural changes in society. Similarly, it matters little whether Katrina turns into a white goat in Devil's Valley, or if an African servant raped her. What maters is the raison d'être of the stories. For the Smous, the story of Katarina turning into a goat reveals her love for her Jewish husband. For the Lermiets the story of the brothers wooing Katarina by bringing her gifts of goats establishes the superiority of the founder's family. Instead of regarding stories of the valley as terra nullis as fiction, it is more fruitful to see how the myth reveals the complicity of Christianity in racial differentiation. In Rights of Desire the different versions of Antjie’s story reveal the agendas of the different groups. The depiction of Antjie as a murderer in court is brought about by the pressures of cultural ideologies that made it impossible to accuse the master for the same crime as the slave. When the court convicts and sentences Antjie to death without convicting or punishing Wilhelm, who was equally culpable, it imagines a version of the past. The African and Colored slaves' depiction of her as a faithless blood traitor testifies to their vulnerability. Her own account of it reveals her hurt at being rejected by Wilhelm. All three versions reveal more about the pressures of their creations, rather than the actual events. Together they point to the messy nature of racial relations in South Africa and the interconnections between the political and ethical discourses in defining racial identity. 
Brink’s novels, which dramatize the impossibility of accessing the true past, can be read as metaphors for history as an endlessly receding phenomenon. Since we do not gain access to the true events, no new identity or new truth is asserted. Instead we are exposed to the messy currents of the linear official history. Ouma Kristina point out that “our story is different, it doesn’t run a straight line” (74). She again reiterates the nonlinearity when she points out that women's history is “much more complicated and more fluid than mere linearity”(Brink, Imaginings 246). In Devil's Valley Ouma Lisbet Prune presents the official history of Devil's Valley as a linear narrative, where

“Lukas Seer begat Lukas Nimrod, and Lukas Nimrod begat Lukas Up-Above and Lukas Up-Above begat Lukas Strong, and Lukas Strong begat Lukas Bigballs, and Lukas Bigballs begat Lukas Devil, and Lukas Devil begat Lukas Death and Lukas Death begat Lukas Small” (Brink, Devil’s 117-118). She points out that this represents only one of the lines since Lukas Seer had 17 children, 9 sons and 8 daughters. Ouma Kristina and Ouma Prune's comment proves that the linear chronological progression of patriarchal history is a construction that has little to with a far more complicated reality. Ouma Kristina and Ouma Prune’s narratives in Imaginings of Sand and Devil's Valley show that when we consider the complex inter-racial relations it presents a messy picture of South Africa’s racial history. Thus the easy converse between the material and spirit world, between humans and animals that is the result of the novels' use of magic realism, destabilizes divisions between the past and the present, the real and the unreal, fact and fiction, to expose South Africa's complex racial history. Brink’s magical realism presents the phenomenon of race in South Africa as fluid, unstable and porous. The stories of rape and violence, of relations that cross the initial 
boundaries between African and European, black and white, African and Coloured, master slave suggest that there are no essential, deterministic racial qualities. In Imaginings of Sand the stories of desire that cross the traditional divisions between Europeans and indigenous tribes compromise clear biological divisions between them.. Kamma/Maria and Adam Oosthuizen’s oldest daughter Lottie takes after the European features of her father. She is adopted by a Christian Boer family who bring her up like a Christian. Her marriage to Bart, who wanted a Christian wife willing to go with him to his farm, dilutes the racial purity. Lottie and Kamma/Maria’s life shows how economic exigencies, religion and desires make Afrikaner identity a hybrid identity that debunks claims of racial purity.

Devil's Valley reveals the intersection between biological differences and Christianity. The Seer's ghost tells Flip that he rechristened his Hottentot wife Billah because it was impossible for him to “sin with a woman's body if she doesn't have a name from the Bible” (Brink Devil's Valley 319). He justifies it as following the example of “Abraham, Issac and Jacob,” who had to make do "with what they could get” (320). The christening of Billah meant that she and her children were "all one family" with the Seer. Thus when Lukas Nimrod married Billah’s daughter it did not create a problem (Brink, Devil's 321). The Seer's story indicates how Christianity was incorporated in the racial discourse. Religion as a basis of differentiation meant that the Smous, despite their crucial role in the valley, were regarded as inferior to the Lermiets.

Rights of Desire exposes how race is determined by legal and cultural issues, rather than just somatic characteristics. In the novel Antjie’s execution exposes race as a complex network of multiple discourses. I have pointed out earlier that the absence of 
Antjie's voice in the court documents related to her execution suggest that she is the occasion for a polemical discourse on racial differences, where the law sides with cultural mores. The court documents are also important in revealing the role of the law in the construction of racial identity. Willem's affair with Antjie threatened the divisions between master and slave and the ideological roots of European moral superiority in colonial South Africa. These divisions were further destabilized when Willelm used Antjie as an accomplice in his wife, the wealthy Boer, Sassara's murder. When the murder is discovered and Antjie's involvement exposed with the help of the slaves the court finds her guilty and executes her. Yet Willelm, the actual murderer, is not even called to the dock. Subsequent analysis of the documents by historians reveal that he was let off scott free because if he was arrested, in the eyes of the law, he would have the same status as Antjie, the slave: they would both be criminals. This event would destroy the carefully crafted discourse of European superiority and unsettle the difference between the Europeans and non-whites in the settler society. Thus by following cultural pressures law creates a narrative that reasserts the boundaries between slaves and masters in the settler society.

As these early acts of miscegenation muddy biological markers of race, the policing of race through other measures like cultural affiliations, religion, and ideology become stricter. The shifting definitions of racial identity in the novels reveal the “ongoing and mutually modifying tension between race as embodiment and race as systemic principle” (Ernest 65). In Chaotic Justice John Ernest points out that "as the concept of race as embodiment becomes less stable or more ambiguous or porous, the systemic controls for race become more pronounced and more complex” (65). During 
Kamma/Maria’s time, despite clear divisions between Europeans and native tribes, there was mixing between races; during Wilhelmina's time there is reluctance to compromise with the non-whites. Thus when the Boer women under Wilhelmina manage to sign a peace treaty with the Ndebele women, the men refused to abide by it and slaughtered the Ndebele tribe. The minute delineation of racial identity leads to a separation, not just from Africans, but from other Europeans as well. Wilhelmina and other Boer women try to stall a political compromise between the British and the Boers because it went against Boer identity. In Devil's Valley the Seer's sexual licentiousness with the Hottentots results in policing of the boundaries. Attempts by the state to assimilate them are foiled repeatedly. Even within the Afrikaners there is a hierarchy. Flip, who came from the interiors, was regarded as inferior by his wealthier Afrikaner peers at the university. Despite his scholarly brilliance he was ousted by Twinkle-toes Van Tonder, whose family connections helped him rise as a historian. We find these finer divisions in Rights of Desire, where Ruben is rejected by his wife's wealthy family because he is a poor Afrikaner from the interiors. The Coloreds' fear of the Blacks continue into the postapartheid era, where Magrieta refuses to serve Tessa’s African boyfriend and refers to the poor Africans Tessa takes lunch to as "bergies” and “skollies”.

Brink's use of magic realism reveals that racial identity is the product of complex processes and its consequences inflect and modulate the direction of these processes at multiple levels. Racial identity is thus defined as constantly "in the process of becoming" (Milovanovic). In essence race is a dynamic system that involves the "processes and consequences” of cultures that differentiate between individuals legally and ideologically (Ernest 37). These novels show that grouping individuals according to categories result in 
the formation of slightly newer identities and formations because these classifications are internalized. For example, the Africans and Coloreds in South Africa have internalized their identities and created a complex dynamic within the non-white community. These new cultural dynamics in turn result in improvisation and metamorphosis of the systems of domination and control. This rift within the non-whites, along with ethnic lines, was exploited by the NP to destroy possibilities of a unified Black opposition. In the postapartheid era these divisions affect political and social attitudes and the distribution of resources, thereby affecting the possibilities of reconciliation. In short, race is not just about phenotype or culture. It "encompasses complex processes by which individuals are positioned, both socially and geographically, sometimes delimiting and sometimes extending privileges, options and mobility and ideological flexibility”(Ernest 37). The complex and entangled nature of race and racial identity that emerges from Brink's epistemic and ideological critique of narrative historiography through magic realism indicates that, while it is impossible to predict the future of race, it is also impossible to transcend race. As a system race is a network of politics, religion, cultural affiliations and other forces. It is definitive, yet slippery. Brink’s epistemic magic realism provides a map of the complex and dynamic processes involved in the creation, functioning and perpetuation of racial identity.

Brink's novels suggest that in the chaotic currents of race the position of individuals in the complex intersection of discourses is critical to their identity. The sensitivity to initial conditions is most evident in Imaginings of Sand. Ouma and Lizzie, the servant, are siblings because Lizzie was the consequence of Johann Wepener raping the servant Salie’s daughter Lida, while Ouma was the result of Salie raping Wepener's 
daughter Rachel in retaliation. Even though this dual rape means that the Wepeners are as Colored as Lizzie and her descendants, their economic position determines their racial identity. Since Lizzie is the child of the servants she is identified as Colored, while Ouma is racially classified as white. We see the same sensitivity to initial conditions play out in Devil's Valley. Though Twinkle-Toes Van Tonder and Flip are Afrikaners, Flip’s origin in a poor Afrikaner family from the interior puts him at a disadvantage to Twinkle-Toes. Despite Flip’s scholarly excellence, the upper-class powerful family connections help Twinkle-Toes get the prime jobs and assignments. Not surprisingly, at fifty, TwinkleToes has established his reputation as a historian, while Flip, the brilliant student, languishes as a struggling journalist.

Central to the conception of race in all three novels is the notion of feedback. The glut of information that loops back into itself to create self-same patterns means that small local incidents have enormous impact. The intricate divisions of race have been built over time through private and local incidents that feed into each other, continuously resituating the differences between the various races. A case in point is Antjie in Rights of Desire or the Seer in Devil's Valley. In Devil's Valley we see how the myth of terra nullis and Christianity as a marker of difference emerges gradually through small actions. The Seer's rechristening of the Hottentot Billah to satisfy his god-fearing soul incorporates Christianity in the racial discourse. Christening Billah whitewashes all her descendants according to the Seer's ghost. The use of Christianity to whitewash racial difference plays out in the myth of terra nullis. When challenged about her claim that the Lermiets populated the uninhabited valley Ouma Prune explains that heathen Bushmen and Hottentots did not count since they were not saved by Christ and consequently 
equivalent to “vermin” (Brink, Devil’s 106). Regarding non-Christians as bestial, because they were unsaved, enabled Boers to present the valley as uninhabited by humans.

Ouma's story reminds us that when Christianity is used for racial division it becomes racialized. In Rights of Desire Antjie’s personal history becomes instrumental in creating racial divisions that ossify through time to result in rigid racial identities like Magrieta's reluctance to serve Tessa’s African lover Zolani or her derogatory attitude to Africans. Antjie's trial and its tragic outcome reveal how a personal relationship can play a role in public discourses on racial identity. The disproportionate effect of small changes mean that maps of racial systems, like maps of chaotic systems, reveal changes in configurations and contingencies, and shifts in the role of the various elements across time.

The iterative loops of racial patterns in South Africa are fractal, rather than Euclidean. Fractals help to map the feedback loops, and trace the shape of the strange attractors in the chaotic system. In The Fractal Geometry of Nature Benoit Mandelbrot points out "Clouds are not spheres, coastlines are not circles” (1). Fractals map irregular natural systems that "exhibit ... an altogether different level of complexity” (1). Fractals are irregular because they involve “chance," and "the degree of their irregularity and/or fragmentation is identical on all scales” (Mandelbrot 1). Fractals as a way of measuring the scale of irregularities have been extended to include movement of stock markets and other social systems. Homogeneity in scaling does not mean that the past and the present are unchanged. Rather, fractals map the ways the past morphs into the present, so that the present is always an iteration of earlier patterns. As a result chaotic systems reveal clearly identifiable similarity of patterns across scale. Fractals enable us to trace the way in 
which innovations in past patterns of dominance control new historical conditions. For example, Willelm's exploitation of Antjie was complicated by the fact that Antjie was in love with him. This puts her at odds with Cupido, who was attracted to her, but was forced to aid and abet his master's sexual peccadilloes with Antjie because he was a slave. Antjie's sexual attraction made her betray her own kind. In the present this pattern repeats itself in Margarita's life, where her daughter rejects her for taking help from her employers. In fact, Magrieta is closer to her employer Ruben and his late wife Riana than her own children.

Imaginings on Sand reveals how the gradual definition of racial identity is premised on the policing of women' sexualities and the efforts by women to resist the patriarchal roles imposed on them. Kamma/Maria, who is given a Christian name and rejected by her people for consorting with a Boer, expresses her sorrow through her songs. Her daughter Lottie makes marks in the sand since she has no shadow. The same erasure of identity besieges Wilhelmina, who, despite her immense capabilities, is forced to play second fiddle to her incompetent husband. Wilhelmina's life of wandering behind her ailing husband repeats itself in Louisa's life as she is forced to abandon her musical ambitions to follow her husband, a government officer, to small town postings. Louisa's futile rebellion through voting against her husband is foiled when her husband is rejected by a landslide. If he had lost by a single vote her rebellion would have been recorded, instead of being lost amidst a multitude of similar rejections. Her rebellion, like Lottie's marks in the sand, left no lasting impression. Acts of violence such as Samuel strangling her husband with her hair repeats itself in Anne's protest against her loss of identity in the form of her final carnage. Kamma/Maria's marginal status echoes in the life of another 
Colored Character Trui. Like Kamma who was rejected by her tribe after she bartered herself to Adam for peace and was never trusted by Adam, Trui fears retribution from the Blacks and is reprimanded by her son for working for the whites. The achronological sequence of Ouma's stories, which begins with her mother Rachael, jumps back into the far past to Kamma/Maria before leaping forward to Petronella, alternates with Kristien's attempts to cope with the escalating tensions in her family to underscore how past patterns reiterate themselves each time.

In Devil's Valley, even though Flip is oblivious to the consequences of fractal dimensions of race, the reader can see how it makes escape impossible. Talita Lightfoot, the ethereal dancer who was used to entice the government's men into the church, disappears from historical accounts. Henta, the young light-footed girl who roams the woods with her cohorts, but has no memory, is the embodiment of Talita in the present. Mooi-Jana’s tragic story (she is a beautiful girl who is killed by her father Lukas Strong to save his racial pride after she rescues him from the British army by sleeping with the soldiers) repeats itself in Emma. Emma’s biological father Lukas Death, who does not acknowledge his paternity, shoots her to save his pride when she tries to escape with Flip, an outsider. The stories of Talita and Henta, Mooi-Jaana and Emma are not identical, but across time they show a repetition of the patterns of patriarchal exploitation of women.

Fractals suggest that chaos is a descriptive system, rather than a prescriptive or prophetic system and this has repercussions on our understanding of racial reconciliation. Fractals reveal the repetition of patterns across scale: the smallest units reveal the same patterns as the largest units. Consequently racial patterns exist at the microcosmic as well as the macrocosmic level. While it may be possible to trace the fractal scales of the 
strange attractor called race in South Africa it is impossible to pin down its cause, or predict its future movements. Briggs points out that "the order of chaos imposes a definite limit on our ability. With the use of computers scientists can see chaos, can understand its laws, but ultimately cannot predict or exert control over it” (Briggs 27). Despite its inability to predict the future, the attractors of race need to be tracked because they present us with a map to the complex racial divisions of the present. Without this map it is impossible to decide on future action. Chaos implies that racial categories are not set in stone, but have been formed gradually over time, through small, seemingly insignificant acts that result in shifts in the discursive system of race. This means that transcending race reduces the complex processes involved in racial configurations at a given epoch.

The fractal dimensions of race in South Africa affect our understanding of reconciliation. Race in South Africa is a "dissipative structure”. Dissipative structures are "dynamic systems that are simultaneously disintegrating and emerging" and that "are offered as relatively stable societal structures that remain sensitive and responsive to their environment” (Baker, qtd in Milovanovic 6). Dissipative structures are relatively stable, yet in flux. They thus offer possibilities of change even as they remains constrained by the past. The dissipative structures of race force us to account for racial complexity and reimagine progress as infinite possibility within a social world bounded by the effects of a racialized past, a progress that implies most fundamentally the ongoing attempt to accurately describe how manifestations of racial history position individuals, create highly variable concepts of identity and organize variable standards of social justice. (Ernest 67-68) 
Ernest's analysis reminds us that the chaos of race requires a change in our understanding of reconciliation. Instead of transcending racial differences, or racial history, the fractal dimensions of race force us to envision reconciliation as a process of mapping the past to create a positive dynamic by changing the balance of discourses. In this vision of reconciliation one cannot ignore the impact to the ethical dimension in changing the existing dynamic and creating more positive patterns of interaction. Dragan Milovanovic, in his analysis of the relation of chaos theory and social justice, observes that chaotic structures present change as a perennial state of being. Extending Milanovic's reading of social justice in chaotic systems as an endless process, it is possible to see that reconciliation in South Africa becomes a process without telos. Preferential treatment programs fail to achieve reconciliation because they do not address the complexity and dynamism of race when they treat reconciliation as a single gesture that revokes the past. This does not mean that preferential treatment programs are irrelevant. It implies the need for programs that account for the complexity of race in their approach. Race as an unstable dynamic system means that reconciliation is a process without closure.

Reconciliation as an endless process, in the end, transforms the characters' notions of redress and ultimately their relation to South Africa. In Imaginings of Sand and Rights of Desire, the fantastic events that bring home the complexity of South Africa's racial history force Kristien and Ruben to revise their idea of making amends. As Kristien listens to the stories that reveal the chaotic nature of racial relations in South Africa she abandons her naïve hope that she can collect Ouma's stories and leave for London, or the belief that giving Bird House to Trui will reverse the injustices against her family. As she sees the frustrations and fears of Afrikaner women reiterate themselves in her sister 
Anna’s carnage, Kristien decides to stay back and "work with others, to bring about a world ... in which it will no longer be inevitable to be only a victim” (Brink, Imagining 348). Kristien's final decision is testimony to her recognition of the need for structural changes in society to change the hostile racial dynamic. In Rights of Desire Ruben's recognition of his complicity with apartheid leads to a rejection of simplistic attempts to undo history. Therefore, when Tessa, traumatized by the attempted gang-rape by a group of Black men, begs Ruben to make love to her he refuses, despite temptations. The attempted rape on Tessa was a display of the power and frustration of the Africans that has deep roots in South Africa's colonial history and is more than a criminal act. Making love to her will not reverse the racial history that informs the act. The fact that Antjie's ghost roams the house even after he has buried her reiterates reconciliation as a constant process. He admits that Antjie's ghost reminds him that "there is a world outside ... which requires me and strangely concerns me” (Brink, Rights 306). Ruben and Kristien’s acceptance of their responsibilities in the new era signal their recognition that personal rejection of and protest against apartheid neither cancels their complicity with South Africa's racial past, nor absolves them of their responsibility in the reconciliation process. In Devil's Valley Flip's failure to understand the implications of his complicity with South Africa's racial history makes the novel the most pessimistic of the three. Even though he realizes that stories are not about "this one's crime and that one's sin," but about “the involvement of a whole community,” Flip does not give up his dream of escaping from the valley. However, his attempt to leave the valley behind is foiled by the ghost of Lukas Seer blocking his way. Flip’s failure to escape to the new South Africa implies that escaping from the past, to a post-racial utopia, is a pipe dream. 
Brink’s magic realism suggests that the ethical response to the conundrum of history is to abandon the search for the authentic past for a critical exploration of the ideological basis of accounts of the past. In short, ideological critique needs to replace the battle for dominance over discourse. Ideological critique of history ultimately exposes the various attractors in the chaotic system of race. Identifying the different attractors of the chaotic system of race may not help us predict the movement of the system. It does, however, force us to revise our tendency to seek equilibrium. Race as a chaotic system rings an effective death knell to the dreams of a simple solution to racism, of reconciliation as an end goal. But mapping out and recognizing the "labyrinthine" trajectory of race, its ability to reinvent itself across time as the dynamic between its various attractors fluctuate, mark the first step towards a realistic relation with the other, one that acknowledges and respects the role of history (Ernest 67). Brink's emphasis on ethical action raises questions about the role of forgiveness in reconciliation. Can one hope for forgiveness in this system within which one is historically implicated, despite personal politics? Even if forgiveness is forthcoming from the racial other, can individual or collective forgiveness erase historical transgressions? In the following chapter I shall compare Nadine Gordimer’s first post-apartheid novel with Antjie Krog's memoir to understand the role of forgiveness in South Africa's reconciliation process. 


\section{Chapter 4}

\section{Between Fact and Fiction: Withheld Autobiography as an Ethical Response to the Other.}

Thus far, I have argued that literature offers a way to negotiate the complex

historical and interpersonal dynamics, negotiations that are essential if reconciliation is to move beyond sloganeering. That same body of literature suggests how difficult it is to address the role of the personal, particularly for white authors in the "new" South Africa. Indirect narrative strategies such as irony and magic realism help white authors negotiate between complicity and agency, and guilt and advocacy to gesture to the power imbalances created by South Africa's racial history. Literature thus offers a counterdiscourse to the watchwords of reconciliation: collaboration and identification. But how does the process of marking the limits of advocacy, of relinquishing active agency, play out in that most self-centered of genres, the autobiography? For white authors autobiography is especially challenging because a focus on the white self can seem like navel gazing, compared to the tangible and acute problems of the non-whites.

Yet the post-apartheid era is marked by a proliferation of white autobiographies. Beginning with Rian Malan’s My Traitor's Heart in the eighties, white autobiographies include J. M. Coetzee’s memoir trilogy Boyhood, Youth, and Summertime, Gillian Slovo's Every Secret Thing: My Family My Country and Andre Brink’s A Fork in the

Road. These texts are essentially engaged, to some degree, in "negotiating the meaning of Whiteness for the purpose of re-gaining a place in the "national portrait gallery" (da Silva, Redemption 93). The general narrative trajectory of these texts involves the protagonist's encounter with the brutality and injustice of the apartheid, consequent 
recognition of their culpability in the country's racial history, followed by efforts to exonerate themselves by creating a new identity. In the process, the protagonists move from ignorance to knowledge about their times and from a secure identity to estrangement from themselves. These narratives are, thus, marked by the white author's awareness of the conundrum of "African Whiteness" as at once of Africa and uncannily non-African (da Silva Redemption 92) ${ }^{\text {Ixxviii }}$

White complicity with South Africa's racist past along with the desire for inclusion into the new nation complicates the formation of a new identity. According to David Huddart, in postcolonial autobiography, the "de-definition” of the individual from colonial identities is followed by efforts to connect to a larger network. He defines this movement as a move from Said's filiation network to affiliation network, from nature to culture. ${ }^{\text {Ixxix }}$ For white South Africans, reterritorialization into wider networks needs validation by the non-white other. Forgiveness will affirm the new white self and initiate them into the new nation space. ${ }^{\mathrm{lxxx}}$ White autobiographies are, thus, a performance of complicity and contrition in the hope of absolution and exoneration by the racial other. Despite being a postcolonial nation, white South Africa's affiliation with the larger networks such as the nation is affected by their complicity with the nation's racist history. Complicity inhibits connection with the non-white other because it makes complete dissociation from white racial identity impossible. This in turn hinders identification with the racial other.

Complicity also hinders the scope of forgiveness. The ultimate purpose of these white narratives--performance of contrition in the hope of forgiveness by the racial other-is controversial because their authors conceive of forgiveness as the condition for 
achievement of reconciliation. Reconciliation is, thus, read as an event that will heal the insurmountable historical differences. In reality, reconciliation is a dynamic process of creating new patterns of interaction with the other that account for different experiences of history. Complicity with the country's racism implies that individual forgiveness does not cancel out the inequalities in society. If forgiveness by the other does not cancel the effects of South Africa's long history of racism or create a new identity, how does one forge a relationship with the other that transcends the liberal association of forgiveness with reconciliation?

Racial politics makes autobiography a dubious genre choice for white South Africans because the country’s racial history complicates the formation of the autobiographical subject and the relation between addresser and addressee. According to da Silva,

Faced with the rapidly changing political conditions that once framed the I White self in Africa as a ‘stable’ locus of privilege and power, self-writing forms allow White writers in Southern Africa to reclaim some of the influence they once held over the telling of a national story and the making of cultural memory. Through a 'public rehearsal of memory', these narratives confound the historical and the personal by resituating the personal story above the collective one, at times obfuscating the relationship between knowledge, power and privilege by divesting whiteness of the ideological weight it holds still in the history of Southern Africa. (White Autobiography 472) 
Da Silva's analysis points to the fact that white autobiographies are problematic not just because autobiographies assert a universal coherent self that does not exist in real life, but because, despite their intentions, they ultimately assert white power and camouflage existing imbalances and inequalities.

Given the contradictory demands of reconciliation and autobiography in South Africa, white authors can negotiate the complex demands of forgiveness and complicity by attending to Spivak's injunction that postcolonial autobiography involves withholding autobiography. The term was first used in Spivak’s analysis of Assia Djebar’s novel Fantasia, where the narrator connects to the neglected Algerian freedom fighter Zohra by sharing a story about two eighteenth-century prostitutes, instead of her life story. Based on this example Spivak claims that withheld autobiography establishes a connection of “responsibility,” rather than “interpellation,” with the audience. Spivak’s withheld autobiography does not mean debilitating silence. Instead, it projects a critical attitude towards autobiography by focusing on the way power structures inflect the autobiographer-listener relation. ${ }^{\text {lxxxi }}$ She reads autobiography as a "trying myself out, as ephemeral teller to you” (Spivak, Circumfession 11). Unlike traditional autobiography, where the first-person narrator imposes his narrative on the listener, withheld autobiography adapts the addresser's narrative to the demands of the addressee. Withheld autobiography is a site where the negotiations of social power relations influence not only the formation of the autobiographical subject, but also the autobiographical address. Because it shows the social processes involved in the creation of the autobiographical subject as well as in the dynamic between the addresser and addressee Spivak describes it as “a form of politics". In withheld autobiography the egoistical discourses of 
autobiography are opened for the other, who guides and sets the terms of the exchange. Spivak’s withheld autobiography thus is different from Sidonie Smith’s definition of autobiography as an “exclusionary genre,” which misreads others narratives to create a coherent self (Smith, Decolonizing xviii). Smith’s idea focuses on social processes involved in the creation of the autobiographical subject, while withheld autobiography considers social, ideological and power structures involved in the dynamics between the addresser and addressee of self writing. Withheld autobiography allows the addresser to signal his or her complicity in power structures and resist reinscribing the hierarchy in the communication pattern of autobiography. This becomes significant in South Africa where the usual power imbalance between the addresser and addressee in an autobiography is complicated by race.

Withheld autobiography is useful in reading white South African narratives of guilt because the protagonists are witness to the witness of trauma. As witness to the witness of trauma, "the listener has to be a witness to the trauma witness and witness to himself” (Laub 51). This means that the "the listener has to feel the victim's victories, defeats, silences, know them from within so that they can assume the form of testimony” (Laub 51). At the same time, the listener has to be aware that s/he "does not become the victim" (Laub 15). In addition, the listener must not "hinder or obstruct the listening with foregone conclusions and preconceived dismissals, should not be an obstacle or a foreclosure to new, diverging, unexpected information” (61). In white South African narratives of guilt and expiation, the act of being witness to the traumatic sufferings of the racial other is further complicated by the fact that witnessing takes place in a narrative about the growth of the white self. The demands of being a witness are complicated by 
the autobiographer's need for witnesses to vindicate the new self. By adopting withheld autobiography the white autobiographer abdicates active narrative agency and opens him/herself to discovering newer connections and the limits to the relationship with the other, without compromising their role as witnesses.

In this chapter I examine the possibilities offered by withheld autobiography in South Africa by examining the narratives of guilt and redemption in Nadine Gordimer's None to Accompany Me and Antjie Krog's Country of My Skull. While Krog's memoir is a collage of personal narrative, victims’ testimony, poetry, and newspaper reportage, Gordimer’s text is a novel about a British South African lawyer Vera Stark’s change in identity after her encounter with the plight of her non-white clients in the post-apartheid era. In both these works the white identity crisis is brought about by being witness to the testimony of the racial other. In Krog's memoir the narrator is caught between the impossibility of finding a witness for her narrative and the demands of being witness to the other; in None to Accompany Me the demands of being witness and the demand for a witness to vindicate the new self is split between the protagonist Vera and the omniscient narrator. By comparing the two texts I argue that narratives of white guilt and expiation by South African white writers are performances of contrition that need to withhold autobiography to signal the power imbalance between the different racial groups. Withheld autobiography by these white women, I argue, creates the conditions for traumatic testimony in both the texts. In the following sections I shall show how Gordimer’s novel and Krog's memoir negotiate their complicity with South Africa's racial history to create a narrative of the white self that is not dependant on forgiveness of the other for validation. 


\section{Nadine Gordimer: Limits of Realism}

Nadine Gordimer's relentless efforts to represent the horrors of apartheid through her fiction and the openly political stance of her apartheid novels earned her the reputation of the conscience of South Africa. While her first two novels advocate a liberal stance against the apartheid, her third novel, The Bourgeoisie World, reveals a movement away from liberalism. In Burgher's Daughter she criticizes the Black Consciousness movement. The very political stance of her apartheid fiction has meant that, as the political pressures on literature eased in the post-apartheid era, her fiction was seen as retreating into private issues. Her oeuvre has, therefore, been read as a progression from the overtly political statements of her apartheid novels to the "more spiritual dimension" of her post-apartheid novels (Coetzee Essays 250) ${ }^{\text {lxxxii }}$ However, in her essay “Living in the Interregnum," Gordimer denies a political agenda to her work. She claims that she tries to ensure that her essential gesture as author is not overshadowed by the necessary gesture of her art in the politically charged atmosphere of the apartheid ${ }^{\text {Ixxiiii }}$ This does not mean that "her writing is politically reactionary," rather it argues against "taking up prior political positions” because it “mars the truthfulness of writing” (Clingman 11). Clingman helps us understand why Gordimer regards her fiction as more truthful than any other writing. In her fictional works Gordimer, the cardholding member of the ANC, writes without being circumscribed by the pressures of her political leanings. Her art, according to Clingman, even in its most overtly political form, is loyal to her vision, rather than to the Manichean politics of South Africa.

The categorization of Gordimer's oeuvre into apartheid era political novels and post-apartheid era personal novels does not account for the fact that Gordimer's novels 
have displayed a "dialectic interplay in which the exploration of history and character, of external and internal worlds, becomes entirely indivisible” (Clingman 9). This dialectic interplay is evident in My Son's Story, where political events transform the home as the narrator's mother is discovered to be a terrorist. In her post-apartheid novel The Pick-up the dialectic between politics and the personal plays out in the way globalization and immigration policies direct the relation between Julie and Abdu, an illegal immigrant. The constant oscillation between the private and the public, the personal and the political, has been identified by Stephen Clingman in The Novels of Nadine Gordimer: History from the Inside as Gordimer’s attempt to present reality as it "happens to be” (Gordimer qtd in Clingman 11).

Gordimer differs from her contemporaries such as Coetzee and Brink in her faith in realism as the best mode of revealing the truth about the apartheid. If Coetzee's formal experimentation marks one end of the spectrum for protest literature, then Gordimer's realism marks the opposite end. She explains "My novels are not anti-apartheid because of my personal abhorrence of the apartheid, but because the society that is the very stuff of my work reveals itself ...If you write honestly about life in South Africa apartheid damns itself” (Clingman 12). Clingman describes Gordimer's assumption that the writer is a mirror to society and that writing is an unmediated act as "naïve realism". The author as a transcendental figure describing the injustices of the system was a strategic measure adopted during apartheid. In the post-apartheid era, with the surfacing of stories that challenge association of Black and white with good and evil respectively, the author's assumption of a transcendental position is ethically questionable. 
Gordimer’s naïve realism becomes problematic in the post-apartheid era, where binary divisions between good and bad and white and Black are no longer valid. The surfacing of the horrors of apartheid in the post-apartheid era has forced white South Africans, particularly those who identified themselves as opponents of apartheid, to reassess their relation to the nation's racial history. As a consequence, the author as a transcendental entity morphed into the author as a historical figure living in a complex political and social terrain. Under the circumstances, writing is not just political pamphleteering, but an ethical act. In None to Accompany Me the naïve realism of the omniscient narrator interferes with the model of ethical listening established by the protagonist Vera Stark. Even though None to Accompany Me is not an autobiography in the traditional sense, in order to witness the sufferings of the non-white characters, Vera's mode of interaction follows Spivak’s model of withheld autobiography. The structure of withheld autobiography helps Vera avoid the pitfalls of egoistical notions of advocacy that resemble traditional autobiography. However, the omniscient narrator's transcendental role in the text disrupts Vera's witnessing.

The novel is set right after the end of apartheid. The unbanning of ANC and PAC and other political parties has allowed the exiled leaders to return. It has allowed Vera and Ben Stark to unite with their old exiled friends Didymus and Sibongile Maqoma. With the end of apartheid, non-whites move in the city in the quest for middle class respectability, forcing whites flee in the face of onslaught. As a result, many middle class apartments in exclusively white areas are taken over by non-whites, who move in, ignoring the lease agreements and changing the nature of the exclusive white strongholds. The sense of joy and optimism is marred by the fact that the end of apartheid has not 
reduced violence or racism. In fact, despite the return of exile and freedom of movement, for many people things have remained unchanged.

The continuation of racial animosity and violence is embodied in the incidents at Phambli Park and Odendaal Lands. Phambli Park is a township occupied mainly by the Coloreds. For the Colored people of Phambli Park who are "neither white and living far from the wrath that overflows from the black hostels ... nor black and fleeing into the velds from a burning shack” the post-apartheid era does not change things (Gordimer None 82). Their lives are shaken by the violence between Blacks from the hostel and the displaced Black squatters settled in their boundaries. For the residents of Phambli Park the "upgraded" legal township is nothing more than corrugated roofs and dirt roads where they dream of building proper homes. If the state of the residents of the legal upgraded township is pitiable, the squatters are worse off. After one of them is murdered in an altercation with Blacks from the hostel, most have taken refuge in a hospital. While Phambli Park reveals how life remains unchanged for many non-white South Africans, the Odendaal case shows how racist practices adapt themselves to the new discourses of land rights. Tertius ODendaal's family lands are taken over by displaced squatters. Unable to evict them and eager to cash in on the opportunity, he applies to the government for permission to establish a township so that he can charge the squatters exorbitant rent. Odendaal's plans for a township and Phambli Park present the postapartheid moment as filled with ambiguity as structural inequalities and identity categories from apartheid continue into the present.

The ambiguities of the post-apartheid moment challenge Manichean divisions between Black and white. Zeph Rapulana seems to be separated from Odendaal and Vera 
Stark by his Black identity until we realize that his “Afrikaans was Odendaal’s,” while Vera, the English South African, speaks "badly scented Afrikaans like the English townspeople” (25). For every Zeph or Oupa, for whom the end of apartheid opens up opportunities for education and career, there is Oupa's wife, who remains with her two children in the shelter for wives of men working in the city. For every Sibongile, whose return from exile opens opportunities for a political career, there are the poor women at Phambli Park for whom life continues to be as violent and hopeless as before. Didymus reveals how the violence and inhumanity in the liberation camps abroad match apartheid in their brutality. The easy difference between the racist state and its non-white victims becomes more complicated in the post-apartheid period. For example, we find that land claims need to be investigated because the non-whites are not above making false claims on the land. In the novel the post-apartheid South Africa is a space where differences are blurred. Consequently, mere chronicling of events does not account for the complex issues at stake.

The complex terrain of race, gender and class identities that are the consequences of apartheid increases the need for advocacy in the new dispensation. The ethics of advocacy, according to Sanders, is "the task of giving the domain of the words over to the other” (55). But the other, particularly the traumatized racial other, can inhabit the discourses and control the domain of words in the presence of an appropriate witness. Of all the characters Vera is the only one who seems capable of being witness to the trauma of the victims because she joined the organization "not out of white guilt," but "out of a need to take up, to balance on her two feet the time and place to which by birth, she understood she had no choice but to belong” (Gordimer, None 20). In her work she does 
not "patronize these applicants struggling to establish themselves in English" and she doesn’t try to “ingratiate herself chummily, as many whites feel obliged to do” (Gordimer None 14). Her empathy and respect for the people she represents distinguish her from her colleagues and help her in her investigations of land rights claims, where she encounters the traumatic experiences of the victims of land displacement.

Vera's skills are put to the test as she finds her sense of identity shattered by her encounter with the horrors of the apartheid. Vera considered herself an opponent of the apartheid. She took pleasure in defying apartheid and allowing her friends Sibongile and Didymus to come to her house. After apartheid is lifted, when Sibongile and Didymus returned to South Africa, she used her resources to find them their home and an exclusive school for their daughter Mpho. Yet her sense of alliance with the non-whites, who form her circle of friends, is shaken after her encounters with Zeph and Oupa. She realizes her difference from her non-white friends and clients when she misinterprets Zeph's words: “Meneer Odendaal, don’t be afraid. We won’t harm you” (Gordimer, None 25). She initially reads those words as signs of generosity and forgiveness. However, pondering over the phrase, days later, she realizes that what she read as "tolerance and forgiveness" were actually a "threat" (Gordimer, None 32). Her failure to understand the meaning of Zeph's words drives home to her the difference between her experience and that of the squatters. The failure of prescribed standards and acceptable meanings becomes clearer in her interactions with Oupa. Watching Oupa excitedly tell her about his plans to enjoy the city life and his apartment, Vera recognizes that "in one way he was like any other young man in training for a professional career; a stage when ... the youngster has as yet no responsibilities” (Gordimer None 53). In another way, he was also a man burdened with 
family, a man for whom apartheid ensured that school was traded for Robben Island and for whom "growing up had not been followed in recognized chronology" (Gordimer, None 53). This meant that his ability to explore the town unfettered, like other young men, was hampered by his financial responsibilities to his family in the village. But, his aspirations for a better life were not shared by his wife and children, who still live in the shelter for women whose husbands' work in the city. Not surprisingly, he connects with Sibongile and Didymus’s young daughter Mpho, who has lived in London all her life, more than he does with his wife. Vera realizes that applying the normal rules of fidelity in marriage to Oupa, a man whose life has not followed the normal trajectory, does not result in a fair assessment. The inability to understand the inner codes of their language despite a shared agenda, and the failure of the prescriptive codes of her urban English South African existence to adequately understand the young non-white men make Vera rethink her relation to history.

The irrelevance of established codes when interacting with the racial other, ultimately, makes Vera realize the benefits of withheld autobiography in relating to Oupa and Zeph. When Oupa expresses to Vera his admiration of those who dared to defy the whites and threaten their power, even through illegal acts like robbery Vera remained silent. Describing Vera’s response the omniscient narrator notes, Mrs. Stark was comfortably silent, ... she made no remark on what he had just innocently confirmed: ... the unacknowledged self that came into being in prison still existed within him, a pride in defiant community with anyone, everyone, who had the daring to defy the power of white men ...; silent because this was a self that, by nature of what she was, could not exist among her selves. (16). 
While the truth about the extent of Black defiance in prisons may be debatable, Oupa's support for acts of defiance against the whites is his attempt to narrate and order his experiences of apartheid, experiences that cost him his childhood and had him experience prison in his adolescence. By remaining silent about the way this defiance of the whites also resulted in exploitation and violence against their own group, Vera's creates a safe space for Oupa to tell his story, to allow his life and its many facets to come to the fore. By withholding her judgment about the appropriateness of Oupa's confession to her, or the darker side of Black bravado Vera underlines their different experience of history.

The need to withhold autobiography comes to the fore when Vera agrees to help Oupa prepare for the party at his new apartment. While driving with Oupa to see his new apartment at one twenty one Delville Wood, Vera realizes that Oupa's city pad was the site of her clandestine rendezvous with the Hitler baby, Otto Abarbanel. However when Oupa mentions the place all she discloses is an "odd smile” (Gordimer None 54). She asserts her voice only when Oupa asks her to show him how to operate the stove. Even then, she does not explain the reason behind her familiarity with the oven, letting him assume that as a woman she is naturally at home in the kitchen. Vera's decision to remain silent about her earlier association with Oupa's apartment can be read as shame about her betrayal of marriage. But her refusal has another significance. For Oupa, whose childhood and adolescence were spent fighting apartheid and imprisoned in Robben Island, this site of her marital infidelity is the first step towards fulfilling his dream of a career and a life of travel. If she shared her connection with the apartment she would spoil his pride in his new digs. Vera’s silence that creates a safe place for Oupa makes him regard her as a mother figure. 
Vera’s withholding of autobiography may inhibit her desire to narrate her story, but it allows unexpected connection to emerge. With Zeph Vera's ability to defer her legal expertise to his knowledge of the realities of the squatters' lives leads her to develop closer ties. Their professional camaraderie results in the development of unexpected empathy and friendship. When she reads about the Odendaal shooting she rushes to check if he is safe. Her unexpected concern, which moves him into "grasping her arm" "and her automatic response of "placing of her hand for a moment, over his knuckles," was a “repetition of the compact to begin a love affair with her Hitler Baby, Otto, years ago" (Gordimer None 120). But, unlike the gesture with which Otto marked the beginning of her affair, this gesture “was not sexual” (Gordimer None 121). Vera and Zeph’s instinctive tactile gestures prompted by Vera's concern for his wellbeing signals their recognition of their human bond. It marks "the beginning of some new capability” in Vera, "something ... that she was only now ready for” (Gordimer None 122). This new relation with Zeph that defies all the prescribed boundaries of racial interaction brings a “reassurance ... she no longer found elsewhere with anyone” (Gordimer, None 123). Despite being based on a mutual ability to relate to their shared humanity, Vera's friendship with Zeph remains respectful of the differences between Vera, “a middle-class city woman” and an English South African, and Zeph, a rural leader. Even when she sells her house and becomes Zeph’s tenant they remain respectful of their differences. Respect for their differences enables them to develop a camaraderie where Zeph can approach her for her expert advice and she can seek his opinion on political issues. The common point between Vera's relation with Oupa and Zeph is that these relations have developed based on the need of the two non-white characters. 
But the ultimate test for autobiographies of the postcolonial condition is their ability to be open to the subaltern. In her analysis of Assia Djebar’s novel Fantasia, a withheld autobiography, Spivak notes that "to achieve autobiography in the double bind of the practice of the conqueror's writing is to learn to be taken seriously by the gendered subaltern... who has not mastered the practice”(Spivak, “Circumfession” 10). While Oupa is disempowered compared to Vera and, even, other non-whites like Didymus and Sibongile, he is not a subaltern, according to Spivak's definition of the subaltern as gendered. In fact, in the case of the true subaltern in the novel, Oupa's wife/widow, we find that that Vera is unable to withhold autobiography and establish a relation of responsibility. Oupa's wife/widow's life remains unchanged despite the political changes. She continues to live with her two young children in a shelter for wives of men employed in the city, dependant on her husband, whose dreams do not include her. At Oupa's funeral Vera finds herself unable to find a way to connect with Oupa's widow because she is uncomfortable offering condolences by praising Oupa as a husband when she knows that he was unfaithful and eager to escape the shackles of family and explore the world.

Vera’s failure to withhold autobiography is compensated by Zeph Rapulana, who accompanies her to the funeral. Listening to Zeph offer the usual condolences to Oupa's widow, Vera feels that Zeph’s representation of Oupa as a dutiful father and husband does not correspond to the actual Oupa, who “did not think only of his family," but "yearned for a girl who has seen things and possessed knowledge he would never have," who "did not die peacefully, his body, in the attempts made to keep it alive, suffered tortures his interrogators in prison had never thought of” (216). However Zeph’s 
representation of the late Oupa as a loving father and husband is another act of withheld autobiography. In the car Zeph tells Vera that Oupa had confessed to him that "He was going to disappear, and travel the world, he was going to Cuba, England and China, especially Cuba. (217). Clearly Zeph was not ignorant of the fact that Oupa "did not want to go back" (Gordimer, None 217). By keeping his personal narrative involving Oupa out of the picture and presenting a narrative about Oupa that his widow can identify with Zeph is sensitive to the needs of the widow in a way that honest depiction of Oupa's desire to forget his family would not be. Zeph's silence reveals his awareness of the differences in power between Oupa and his wife, and between himself and Oupa's widow. The contrast between Oupa's widow's mute silence and Zeph's deliberate silence about his personal experience with Oupa underlines the complex power structures underlying their brief interaction.

The consequences of Vera withholding autobiography in the novel are very different from Zeph withholding autobiography in Oupa’s funeral. Oupa takes the opportunity to use the space created by Vera's silence to insert his story, while his wife remains silent. The different responses of Oupa and his wife point to the power difference between African men and woman in post-apartheid South Africa. The African man, despite his sufferings and brutalization under the apartheid, is able to try and build his life in the new dispensation. Oupa is able to move in the city, find a job, dream of mobility and improvement. Zeph Rapulana, the suave and shrewd autodidact who is well versed in legal and political matters, becomes the spokesperson of his disenfranchised people and is given a high position in the emerging Black government. The African men have the power of language to correspond with the Afrikaners and the English South Africans. 
This contrasts with Oupa's widow, who is dependant on her husband for survival, and cramped in two rooms, at the shelter for wives. With her husband dead and children to consider, Oupa's widow has little scope or luxury of verbalizing, let alone writing, her story of suffering and grief.

Oupa's widow's silence (she is also the only character without a name and is identified by her relation to her husband Oupa) is not relieved by the omniscient narrator's insight to her mind. The omniscient narrator's silence is unusual because he provides us with insights into minds of characters. Vera remains silent about her association with Oupa's new apartment at One Twenty One Delville Woods. However, the narrator reveals Vera's thoughts. The narrator also gives us insights into Sibongile’s mind as she tries to deal with her growing estrangement from Didymus that was the result of her rising political star just as his was on the wane. After she rejects Didymus's sexual advances the narrator informs us that "the pain of repentance, so useless for this little spite, is actual between her ribs” (Gordimer None 135). The narrator's silence about the most impoverished and most vulnerable character of the story suggests the limits to his omniscience. It marks the silencing that cannot be voiced. The silence of the widow and the narrator's decision to refrain from impersonating her voice marks her position of power and dramatizes how access to power affects the conditions for autobiography.

While Gordimer is careful about giving voice to the one subaltern character in the novel, she shows little restraint in revealing the thoughts of other characters through the narrator. The omniscient narrator is just as easily able to give us insights into the minds of non-white characters such as Sibongile and Didymus as he is into the minds of white characters. The omniscient narrator is not just a source of information of the state of mind 
of the different characters, but also a moral guide. For example, describing Sibongile’s decision to unburden herself to Vera when their temporary hotel residence proved unbearable the narrator writes "It was Vera Stark to whom she suddenly felt she could unburden herself... and, by implication of a grant of intimacy, place responsibility on her (Gordimer None 46). The narrator's analysis of the motivations behind Sibongile “suddenly” wanting to unburden herself to her white friend Vera reveals Sibongile’s manipulative nature. As the moral center the narrator can be read as the author's representative in the novel. However, the omniscient narrator's ability to read the minds of characters across racial and gender boundaries in a novel set in post-apartheid South Africa dilutes her narrative authority. In South Africa, where the history of racial differentiation and exploitation makes it impossible for racial groups to identify with each other, the ability of the narrator to transcend racial differences suggests that he is above race and above gender. However, in South Africa no one remains beyond race. By creating a novel whose narrator transcends race divisions Gordimer erases her racial identity and its privileges and subscribes to the post-racial politics her protagonist Vera rejects.

\section{Country of My Skull and Authorial Credibility}

Gordimer's novel shows that the faithful representation of reality does not necessarily fulfill the conditions for ethical relation with the other because it can end up in reinforcing existing racial paradigms. In contrast, Krog’s memoir reveals how autobiography, a genre closely associated with reality, has to use fragmented narration, collage, and, even, invent an affair in order to negotiate the difference in experience of history between the white autobiographer and her non-white addressees. In Krog’s first 
English work Country of My Skull the narrator's role as witness to witness of trauma compels a withholding of autobiography. One of the most cited works on the TRC, Krog's Country of My Skull: Guilt, Sorrow and the Limits of Forgiveness in the New South Africa is a memoir about her experiences reporting the TRC hearings for SABC. It charts her confrontation with the horrors of apartheid that tests her identity as a dissident and transforms her sense of self and relation to her community. According to Michael Heyns Krog's memoir is "a personal rite of passage from the relatively secure world of the liberal Afrikaner to a frightening sense of complicity with the perpetrators and the horrors recounted at the hearings" (44). This metamorphosis leads to a search for a new relation with the country through efforts to establish a new relation with the racial other. Krog's new identity is the result of being witness of witness to the trauma suffered by the victims of apartheid, during the TRC hearings. Her narrative of transformation and metamorphosis thus has to make space for her role as witness to witness of trauma.

As witness to the testimony of the other she has to be self-effacing as well as aware of the difference between herself and the other. Krog achieves this through incorporation of testimony, and poetry, into her memoir. The use of multiple genres creates a patchwork, where the different realities undercut each other to offer many alternative versions. Her book is like a collage-“it cuts, cites and decontextualizes through decoupage as a means of expression, at the same time it reassembles, recontextualizes and aggregates through assemblage” (Rostan 146). Describing this collage, Antjie writes, “I am not reporting or keeping minutes, I’m telling. ...I cut and paste the upper layer, in order to get the second layer told, which is actually the story I want to tell.” (Krog, 225). Her statement declares that her purpose is not to search for 
historical veracity, as much as it is to understand the underlying forces informing South Africa’s racial history. As part of a collage her voice is one among many in the polyphony of voices.

Given the focus on the autobiographer's white angst caused by encountering the horrors of apartheid through Black testimonies, it is not surprising that the book aroused strong reactions. Smith and Schaffer point out that some witnesses "recoiled from her profiling of their pain; others failed to recognize themselves through the perceptions of the writer; still others resented what seemed to them as an appropriation of their pain to her project of reconciliation”(Smith, Human Rights 78). For example, ex-ANC combatant Yazir Henri notes that "the disembodiment of my testimony has made the struggle to reclaim my voice, memory, and agency, harder. The dispossession of my voice, through a continuous recycling of my, by now, unmoored testimony, was compounded by the superimposition of other voices and narratives onto my own” (qtd. in Smith, Human Rights 78). In his highly critical reading of the Krog narrative, Mark Libin goes so far as to suggest that Krog “foregrounds her emotional response ... her guilt and sorrow, as well as self-loathing ... [in a way that] ultimately overflows, engulfs and finally overwhelms the testimony of witnesses she endeavors to record” (123). The negative reaction of the people whose testimonies have appeared in Krog's narrative suggests that she failed to be a responsible witness.

While the criticism of Krog's memoir raises valid points about using excerpts from the victims' testimonies in a narrative of white angst, it, however, fails to account for the constraints placed on the autobiographer by the ethical demands of being witness to the witness of trauma. Only Gillian Whitlock considers the text in terms of Krog's role 
as a listener. In “Consuming Passions: Reconciliation in Women’s Intellectual Memoir,” Whitlock argues for reading the text as "a performance of listening and acknowledgement that calls for different professional practice among the intelligentsia” (Whitlock “Women” 13). She writes: "Witnessing these public testimonies of trauma and loss through memoir has been one way of engaging with these testimonies. ... it sets out a way of listening and attending, and it emerges as a deliberately staged discursive framework for cross-cultural communication in a community beset by the aftermath of trauma.” (13). According to Whitlock, Krog’s narrative style presents reconciliation as “a discursive field that both requires and organizes the interaction of testimony and memoir" (13). Whitlock’s perspective is important in reading Krog because she moves beyond looking at the text purely in terms of a memoir to focus on the narrator's role as listener. In this section I read Krog's memoir as a demonstration of being witness to a witness of trauma and the hazards of witnessing trauma. Krog's role of being a witness motivates the text's unusual form and destabilizes the centrality of her voice in the memoir.

The most controversial part of her collage is the transcript from the hearings of the victims of the TRC. These transcripts account for a quarter of the text. Always unedited, the excerpts from the hearings are, at times, framed by commentary from the narrator, sometimes stand alone, or are arranged as a series of uninterrupted excerpts. For example, the chapter "Stretched Thinner and Thinner over Pitches of Grief” consists of a collage of excerpts from transcripts that are barely distinguishable from each other. The transcripts are also not identified by name. Chapter four, “The Narrative of Betrayal Has to be Reinvented Every Time,” in contrast, consists of only two excerpts from the TRC testimonies: Basil Snayer’s and Yassir Henry’s, without any analysis or synthesis. This 
inconsistent method of using excerpts has bewildered critics. Sarah Ruden points out "the stories are not true stories because they have no background or beginnings or endings, which we hold consciously or unconsciously as marks of real experience” (Ruden 169). Krog has also been accused of devaluing the testimonies by presenting them without any recognizable narrative structure. For example, commenting on Krog's incorporation of unedited excerpts from the shepherd Lekotse's testimony Ruden points out that "Lokotse's story would be more 'real"” if the scenes were rearranged in the order in which they happened"(172). This demand for editorial control is also voiced by Laura Moss who points out that Krog’s excerpt from Nomonde Calata's testimony presents Calata as a pitiable victim; whereas, the entire testimony, which extends beyond the cry, presents her as a pragmatic person.

Ruden and Moss's criticism of Krog's memoir does not account for the multiple roles Krog has to negotiate as a reporter of the TRC hearings and a white South African woman. Editing the transcripts to present a smooth narrative would be unethical on a number of counts. First, it would be presumptuous for a white South African woman to edit the words of the victims from whom she is separated by her racial privileges would be presumptuous. By editing and rearranging the testimonies to make them appear aesthetically pleasing she would be speaking for the other by cancelling the difference between herself and the other. It would presume that she, a white Afrikaner woman who has benefitted from apartheid, is able to understand the other. Second, it would violate her responsibilities as a witness to witness of trauma. As journalist and audience of the TRC hearings she is witness of the second and third level, according to Laub's categories. ${ }^{\text {lxxxiv }}$ As a witness of traumatic witnessing she is part of a process where 
knowledge is not a "factual given,” but an "advent” (Laub 62). The silences, digressions and displacements in time that characterize these testimonies are symptoms of events that are not registered, even though they have happened. Thus, to edit out the pauses, the struggle with words, would be to disrespect the victims. ${ }^{\text {Ixxxv }}$

The testimonies of Nomonde Calata and the shepherd Lekotse are cases in point. In Lekotse's transcript there is a break in the sense of time. He begins "On that day/ it was at Night" when describing the events of the night when the police forced themselves into the house. But his rambling narrative is repetitive, digressive and chronologically disruptive. Describing the way the police broke down the door, he digresses into the present to talk of how the door was repaired by his children before returning to the events of the night. These digressive ramblings contain inconsistencies. In the transcript Lekotse claims he hurt his shoulder. When the commissioner points out that his statement claims he hurt his ribs he retorts "are you not aware that/ the shoulder is related/ to the ribs/ sir?" (281). The shepherd's digressions about his damaged door and disobedient children, that disrupt the smooth chronology of the account, can be confusing. However his digressions are a symptom of the trauma caused by his realization that the police are not there to protect him, an illiterate shepherd who had never broken the law. Editing Lekotse's testimony to make it concise would erase the shepherd's trauma and make Krog fail in her responsibility as the second-level of witness.

The excerpts from Nomonde Calata's transcripts have also been criticized because decontextualized quotations from her testimony transform her into a symbolic figure. Moss, in particular, feels that Krog's text "oscillates between commenting on the symbolism of Nomonde Calata's emotional testimony and the symbolism of the death of 
her husband in the national narrative of reconciliation” (Moss 95). The absence of comments on the role of the Craddock Four in the resistance movement destroys the specificity of Calata's story, according to Moss. She further notes that the excerpts excise the ordinariness of Calata's life in the present and her very pragmatic approach to reconciliation. It represents Calata as just a victim, when the whole testimony reveals that she is also a savvy woman. On the flip side, presenting the entire transcript of Calata would also minimize her trauma, embodied by her heartbreaking cry as she fails to find words to express her shock at learning of her husband's death. Unlike Lekotse's testimony, which is uninterrupted by comments, Calata's testimony is presented as excerpts quoted by Krog and Professor Kondlo as they discuss ways to represent the significance of her testimony in a cartoon. Her testimony intrudes into their discussion as they replay sections of the recording of her testimony. The high point of this recording is her wordless cry as language failed to express her grief and shock that forces the hearing to adjourn. When she returns her voice is "tired" and "resigned" (57). Krog and Kondlo’s conversation focuses on the moment of breakdown in language because her cry is testimony to her trauma at having her life violated and her husband murdered by the protectors of law and order. The nature of trauma according to Laub is that the survivors are often very successful in real life. But at the core of their success is a sense of fragility. Calata's cry brings out that fragility in her life underneath her show of self-sufficiency and pragmatism. To seek to overshadow this by focusing on her pragmatism minimizes her trauma. It elides the emptiness that marked her life after the horrific incident of police raids and her husband's death. 
Krog's use of Calata's testimony also underscores the difference between memoir and testimony. Calata's testimony alternates with conversations between Professor Kondlo and Krog as they figure out a way to present the full significance of a Black woman testifying in a British Town Hall, in South Africa. The conversation between the professor and the journalist presents a sharp contrast to Calata's testimony. ${ }^{\text {lxxxvi }}$ While Krog and Kondlo move freely, discussing the ramifications and significance of Calata's testimony, in contrast, is halting, broken by sobs, tears, and pauses. The contrast between the eloquence of the two witnesses who analyze her testimony and Calata struggle to articulate her experience with the police raid and her husband's brutal death jarrs the reader and highlights the difference between testimony and autobiography. Calata’s breakdown in eloquence when recollecting the way she discovered her husband's murder indicates that she is reliving the events, struggling to register them as events that have happened and is, therefore, unable to analyze them like her audience. The contrast in eloquence signals the differences between Nomonde Calata's position and that of her mainly white audience.

The difference in the experience of history that is signaled by the contrast between the victim's rough halting testimonies and Krog's smooth memoir is evident in Krog's references to the transformation of the testimonies into sound bytes. In the news bulletins for the radio the complex stories that emerge from the hearings are converted into snappy news stories. Krog points out that she has to reduce the entire story of Phindile Mfeti’s mysterious disappearance after he went out to have his jeans shortened, and his wife's request to the commission for a token of her husband for burial to a fortysecond sound byte. In order to create sensational news stories out of these testimonies of 
loss and trauma Krog has to "pick out a sequence ... remove some pauses” and edit everything down to a "twenty second sound byte," before "feeding it to Johannesburg" (45). For example, Krog knows that “when Tutu starts with 'ah-ah-ahm' he is “struggling” to present difficult truths in a "neutral harmless way” (306). But Tutu’s “ahahms have to be cut out for the broadcast," even though deleting these stutters edits away their significance (306). Just as the radio’s inability to convey Dirk Coetzee’s signs of PTSD makes him appear to be an unrepentant killer, so also editing pauses and stutters in speech creates a different narrative of events. The use of adjectives like "sexy" and the preference for stories that provoke tears reveals the way the media sensationalizes stories. The juxtaposition of the transformation of the testimonies into sound bytes for the radio alongside Krog's own incorporation of the testimonies serves to separate Krog's use of the testimonies from the way media sensationalizes the traumatic experiences of the victims.

The difference in eloquence between the victims’ testimonies and Krog's memoir places the ethical demand of being witness to witnessing on the audience. The raw unedited transcripts, which come without comments or explanations or preface, mean that the reader is forced to engage with the transcripts. In the process of reading the reader becomes witness to the process of witnessing itself. For example, the chapters which consist only of unedited transcripts force the reader to witness the trauma of the victims through reading. However, since the excerpts from Calata's transcript are interwoven in the discussion between Professor Kondlo and Krog, the reader is not only witness to Calata’s soul wrenching grief, but to the Professor and Krog's act of witnessing Calata's trauma as well. The absence of commentary on the transcripts mean that the difference in 
the level of eloquence between Krog's memoir and the transcripts confronts the reader with the differences in experience of history that separates Antjie Krog the Afrikaner poet /journalist from the victims.

As a result of Krog witnessing the victims’ trauma, her growing sense revulsion against her community is complicated by a sense of complicity with them. On one hand she laments the absence of a leader among the Afrikaners who, unlike De Klerk, is willing to "take responsibility". On the other hand, she also recognizes that the perpetrators are as “'familiar” as my brothers, cousins and school friends” (121). As a result she feels that "between us all distances are erased" because she and the perpetrators share a common culture, "and part of that culture over decades hatched the abominations for which they are responsible" (121). In addition, she has "more in common with the Vlakpass 5” because by confessing their crimes they are accepting responsibility; just like millions of other Afrikaners have sought to come to terms with their collective guilt. Yet her complicity doesn't mean identification, as she is critical of her community. Her irreverent attitude to leaders like President Botha suggests her discomfort with her complicity. After her interview with Botha she describes him as "not senile, or old, or suffering from effects of a stroke,” but “a fool” (355). Krog's critical awareness of her complicity is different from her mother's sense of reverential identification. Her mother's essay on the death of Prime Minister Verwoerd expresses a deep reverence. Watching the plane carrying Verwoerd's body fly over her, Krog's mother writes, “the life of the man I only saw and admired from afar has touched my life” (125). The contrast between Krog’s mother's essay and Krog's memoir reveals the difference between the two women's relation to their racial group. By writing their personal narratives both the women 
transgress the boundaries of patriarchal discourses. However, her mother's essay subscribes to the racist and patriarchal doctrines of the apartheid. Krog, however, questions the doctrine even as she is forced to acknowledge her historical complicity with South Africa’s racial history.

One of the consequences of Krog's being a witness of witness to trauma is a destabilization of her identity. As a protestor against apartheid she believed in the goodness of Blacks and villainy of the whites. But with the end of apartheid as Black violence and desire for revenge spills out from the townships and threatens her parents' farm she begins to have mixed feelings. As she listens to the hearings she recognizes that apartheid included Black on Black violence. Krog's experiences at the hearings alienate her from her family. The distance between Krog and her family is brought about in an incident when she returns home from hearing. She writes,

I walk into my home one evening. My family are excitedly watching cricket on television. They seem like a happy close knit group. I stand in the dark kitchen a long time. Everything has become unconnected and unfamiliar. I realize that I don’t know where the light switch is. (Krog 63) Krog's description reveals how her experiences have alienated her from her family. Their ability to understand her efforts to come to terms with her culpability in South Africa's racial history is, therefore, limited. In this sense, she is more at home in the job where she is with other journalists who are sharing the experience of witnessing the trauma of the victims. Krog's defense mechanism against apartheid is to have an extra-marital affair with a colleague. 
The most interesting aspect of Krog's affair in her memoir is that in the first South African edition of the text she confesses that the affair was an invention, while in the US editions there is no such confession. In the South African edition, she claims it is a rhetorical strategy when her friend Patrick asks "And the affair that you describe in here. Is it true?” (Krog 1998, 171). She writes, “I had to bring a relationship into the story so that I could verbalize certain personal reactions to the hearings. I had to create a new character that could not only bring in new information, but also express the psychological underpinning of the commission” (Krog 1998, 171). However, in the US edition there is no such confession. Laura Moss points out that in the US edition Krog's affair betrays the documentary nature of the text and drawing attention to it as a perspective of an individual and not an authoritative account of the past as it seems to have been regarded. Kim Rostan claims that the move from a monogamous relation, her marriage, to the open polygamous relation of an extra-marital affair in the end symbolizes the need for an open discourse after the closed and secretive discourse of the apartheid. She writes, the "private interests of the silent marital relationship in these passages may be a figurative obstacle to embodied community-building and reconciliation. The infidelity ... may be read with some imagination as a mediation on the complex demands of extending personal loyalty and passion to a community beyond one’s most immediate relationships” (Rostan 157). However, Rostan’s analysis does not consider the effect of Krog's admission that the affair was a lie on the readers. The fiction of an extramarital affair immediately blurs the difference between truth and fiction in her book. If she can lie about an affair she could have lied about her transformation as well. Krog's invented 
lover makes us question the narrator's sincerity in the final poem, a prayer to the other, to be included in the new body politic with skepticism.

The imagination of an extra-marital affair also creates the space for Krog to express her transformation. One of the effects of being witness to the way apartheid corrupts and brutalizes human beings is that Krog manifests the physical effects of trauma. Her hair falls off during the hearings and she feels disconnected. This kind of physical manifestation of sickness is not unusual for witnesses of trauma. Since she feels alienated from her family and community, the invention of characters allows the narrator to "disclose a self that reacts affectively to the hearings, and acts the reactions out" (Sanders 161). While the invention of a lover enables Krog to explain things to people who have not experienced the apartheid or the TRC, ultimately the love becomes a source of succor. ${ }^{\text {lxxxvii }}$ Krog's invention of the lover resembles Laub’s analysis of the Colonel Menachem's use of his mother's picture as he hid from the Nazi's as a child. ${ }^{\text {lxxxviii }}$ For the Colonel this picture provided him sustenance while he lived under the terrible conditions of the Holocaust. Laub identifies this picture as the imagined audience, the addressee, for the boy. In a similar way, as Krog grapples with the victims' witness of their trauma, she invents a lover to compensate for the absence of a real one; she invents an addressee to cover the absence of a real one to witness her own transformation. Ultimately, in the South African edition Krog's admission of her affair and need to create an audience is a comment on the absence of such an audience for white South Africans. As a white woman she is cut off from the Blacks who give testimony. As an Afrikaner journalist reporting on the TRC hearings she is estranged from her family who do not share her experiences of being witness to the witness of trauma. The journey from 
alienation to a sense of larger community that marks postcolonial autobiography is denied to her because, as an Afrikaner woman in post-apartheid South Africa, she cannot presume on a unity between herself and the racial others. Consequently her story about her transformation does not result in political legitimacy. ${ }^{\text {lxxxix }}$

While critics have analyzed the psychological effects of the affair and the discovery of its fictional nature, its rhetorical function in the text has gone unexamined. The narrator's memoir, already decentered by the incorporation of unedited testimonies, is further put under the scanner by her extra-marital affair. The unedited testimonies that disrupt her memoir are the result of Krog's refusal to exercise her editorial control over the testimonies. Her refusal gives the victims of apartheid their voice, even in her memoir. Thus the incorporation of testimonies can be read as acts of withheld autobiography that negotiate the tricky position of being witness to witness of trauma. Krog's invented affair, which questions her memoir, presents the excerpts of the testimonies as the only trustworthy and unquestionable sections of her text. Thus, Krog's fictional affair turns the entire text into a withheld autobiography that lets the victims hold center stage.

Krog's awareness of the slim chances of her new identity being accepted by the racial other is expressed through her poem. The poem is a paean to the TRC, which enabled this transformation in herself, and a plea to an unnamed "you” to include the narrator into the new South Africa. The poem addresses two separate versions of "you.” The first "you” is mentioned in the first line "because of you / this country no longer lies/ between us but within” (Krog 364). The “you” who made it possible to turn the country from one that divides its population to one that bridges the divisions is different from the 
"you" addressed in the end: "You whom I have wronged, please/ take me/ with you" (Krog 365). The first "you” refers to the TRC, whom she praises in the paragraph before. After observing that "with all its mistakes, its arrogance, and its racism" the TRC "has been ... brave ... in the winds of deceit, rancor and hate" and "kept alive the idea of common humanity, Krog writes, "I want this hand of mine to write it. For us all; all voices, all victims" before embarking on the poem (Krog 364). However the "you" that is addressed at the end is not the TRC because the latter cannot carry the author with it. Instead, it is addressed to the other, the racial other, who can bestow the forgiveness she seeks and include her in the new order. The poem makes it clear that the one who transforms Antjie's relation to the country is not the one who can bestow forgiveness. This difference, along with the fact that the poem ends in an appeal for inclusion, rather than an assurance of inclusion, mean that reconciliation continues beyond the TRC. The difference between the two versions of "you" accounts for the instability in her new insight and identity given the precariousness of reconciliation.

At the end of the text, the narrator's plea to be taken with the "you" is a secession of power. By removing certitude about the narrator's place in his country the text gives way to the addressee. Smith points out that in autobiographical writing the position of power is with the audience. She writes that "as arbiter the 'silent' partner in the autobiographical contract assumes certain privileges of power $\ldots$ because $\ldots$ the site of confession or self-exposure dramatically reverses power's conventional dynamics: the one who remains silent and who listens exerts power over the one who speaks” (Smith Women 49). By highlighting the presence of the silent witness to her narrative, to her impassioned appeal for forgiveness, Krog acknowledges the importance and power of the 
racial other in her life. She is, thus, able to be hospitable to the other, in the words of Sanders, even though the text is about her development and her relation to the land.

The precariousness of South African reconciliation becomes evident in the epilogue, which was added to the second South African edition and the first US edition. In contrast to the rest of the book, the epilogue focuses on the politics after the final report was released, including the parliamentary debates on reconciliation, and Mbeki's speech vilifying the whites. If the first edition ended with a paean cum plea, the second edition's poem is pessimistic. She writes

voices slung

in anger

over the solid cold length of our past

how long does it take for a voice to reach another

in this country help bleeding between us (372).

The poem makes it clear that the "country of my skull” has become the country “bleeding” between us. It makes it clear that once the TRC’s mediating activity is removed, political manipulation turns reconciliation into a witch hunt. The rest of the epilogue tracks the failure of the state to promote reconciliation. The gerrymandering of politicians coexists alongside the negotiations and compromises ordinary people make in their daily practices in order to survive. The negotiation across race, class, and gender for Krog is the space where reconciliation takes place.

\section{Forgiveness and Withheld Autobiography}

In both the texts we find that the protagonist's recognition that they are complicit in South Africa's racial history results in a desire for forgiveness, absolution and 
redemption. But confession, forgiveness and absolution belong to a different order: a religious order. Forgiveness in the religious sense cancels history and remakes the sinner. The ultimate source of forgiveness, in religion, is God, a transcendental figure, existing beyond the realm of human experience. In short, forgiveness can be granted by someone who is located outside human history. In the secular world of South Africa the perpetrators and victims are locked in a history that inflects them irrespective of their personal position and action. Even though racism and the racial history of South Africa resemble Original Sin, tainting racial groups irrespective of their personal actions, the religious concept of forgiveness does not apply to the secular and fallen world of South Africa because the ones who can grant forgiveness are as much marked by race as the ones who demand forgiveness. In South Africa, structural factors that gave rise to racism shadow the "new" order. Therefore, forgiveness in the religious sense is not only impossible, but presumptuous to demand from the racial other.

Even in this historical order, forgiveness remains possible only when the conditions that created inequalities disappear, or when there is compensation. Mrs. Kondile tells Krog in Country of My Skull: “It is easy for Mandela and Tutu to forgive ... they lead vindicated lives. In my life ... not a single thing has changed since my son was burnt by barbarians. ... Therefore I cannot forgive (Krog 142). Mrs. Kondile’s statement suggests that in the secular world forgiveness from the victims can be realistically anticipated only if there is an improvement in the historical conditions. In addition, forgiveness by an individual does not cancel out the effects of a racial system that has habitually privileged one group at the cost of denying the other its humanity. Since forgiveness is unrealistic and does not change the racist foundations of South African 
society and culture, autobiographies of guilt and expiation are naïve. They repeat the racist patterns, where the racial other is once again reduced to being an object in the discourse of the other. Krog and Gordimer's works suggest that a representation of the social processes that govern the interaction between races is more ethical than conventional autobiography. Their use of withheld autobiography as a pragmatic strategy of representation accounts for the historical processes at work in the autobiographical address. Instead of speaking for the other or interpellating the other in the narrative, withheld autobiography represents racial complicity and the limits between the self and the other in post-apartheid South Africa. Withheld autobiography thus enables the white narrator/autobiographer to move from charting a new self to charting the processes that constrain the formation of racial subjects in South Africa. 


\section{Epilogue}

Orania, a small town on the banks of the Orange River in South Africa, shot into the limelight last summer. With South Africa hosting the World Cup Soccer 2010, this little town stood out for being immune to the soccer fever that gripped the entire nation. Orania remained unaffected because, as an exclusive Afrikaner town, it follows rugby, the Afrikaner sport de rigueur, rather than soccer, the sport of the Africans. In South Africa, where the majority of the population is non-white, Orania stands out as a town that is $100 \%$ white. Formed in the early 1990s, when 13 Afrikaner families moved into an abandoned worker's camp near the Orange River after Mandela’s release from prison, it is modeled after American utopian settlements like New Harmony and Brooks Farm according to its founder Carol Boshoff III. Orania identifies itself as the last bastion of Afrikaner values in an English-language-dominated global order and an affirmativeaction-dominated national order. ${ }^{\mathrm{xc}}$ Accordingly, non-white visitors are not welcome and cannot work, attend church, or stay overnight. ${ }^{\text {xci }}$

Even as Orania has been read as a sign of reconciliation derailed, South Africa continues to capture the global imagination as a symbol of racial reconciliation. In the recent years there has been a spate of Hollywood films on South Africa's reconciliation efforts. These films include District 9(2009), Disgrace (2009), In My Country (2004), a remake of Antjie Krog's Country of My Skull, Goodbye Bafana (2007), and Red Dust (2004). These films are the latest in a long tradition of films, beginning with D. W

Griffiths’ The Zulu's Heart, that reveal Hollywood's fascination with South Africa. ${ }^{\text {xii }}$ These new films about South Africa differ from earlier black-white buddy movies based 
on South Africa because they focus on post-apartheid stories and represent South Africa as a symbol of successful reconciliation. For example, Invictus focuses on Nelson Mandela’s strategic use of the Rugby World Cup of 1995 to foster racial bonding. The film is replete with images of racial hostility giving way to racial amity. But the most moving image occurs at the end of the film when the Afrikaner policemen dance with an African rag-picker outside the stadium as South Africa lifts the rugby trophy. This image of the different racial groups coming together to celebrate a victory presents reconciliation as a fait accompli.

To the world, post-apartheid South Africa is a conundrum. On one hand, the TRC has become a model for subsequent truth commissions. Films like Invictus uphold a nation erupting in joy as a symbol of the triumph of reconciliation. On the other hand, stories of exclusive white enclaves such as Orania and rising corruption have been read as signs of derailed reconciliation. These extreme representations of South Africa as a symbol of the success or failure of reconciliation misread the true significance of South Africa. All these representations regard reconciliation as a finite process, an event that transforms history. However, when we turn to literature as means of understanding the limits and possibilities of reconciliation, we can see that the real value of South Africa's reconciliation efforts is far more complex and intangible than its role as model for future truth commissions.

To be sure, the complex literary response to South African history reminds us that reconciliation efforts offer a mixed message, which perhaps helps explain the reluctance of post-colonial theorists to embrace reconciliation as a desirable realm of possibility. In the twenty-first century, when war and reprisals have replaced dialogue and negotiation 
as modes of interaction with the other, post-apartheid South Africa makes a strong case for the theorization of reconciliation as a strategy for defraying hostility in post-conflict societies. South Africa's reconciliation efforts may have been the result of political compromise, yet it shows how negotiation can help post-conflict societies move beyond the politics of blame or the politics of confrontation and hostility. As a postcolonial nation, South Africa also presents reconciliation as a strategy for dealing with the effects of colonialism in postcolonial theory. But despite the dominance of reconciliation in postcolonial nations, postcolonial theory remains skeptical of reconciliation because it is associated with compromise and status quo. Reconciliation efforts in settler colonies such as Canada and Australia, however, have maintained status quo and hardly changed life for the aboriginals. ${ }^{\text {xciii }}$ However, the notion of critical reconciliation that emerges through the literary texts lets the victims direct reconciliation process. Krog's memoir is a perfect example of how narrative strategy can ensure that even a narcissistic genre like memoir does not use the non-white sufferings as a pretext for a public account of the new white subjectivity.

The events leading to the formation of South Africa's TRC reminds us that reconciliation needs to be based on reality, a reality where political change and actual social transformation are often at odds, instead of idealistic concepts of perfect accord. The continuation of white supremacy and the creation of a new powerful Black elite in the post-apartheid era remind us that the defeat of one dominant group is, usually, followed by the rise of another. The rise of a few members of a disenfranchised community is, therefore, not a sign of the end of inequality or a radical transformation of the racist social infrastructure. Election of non-white candidates does not cancel out 
history or the lived reality of the oppressed group, unless there are corresponding changes in the social structures. This has particular relevance for contemporary USA, where the election of the first African American President is heralded as the beginning of the postracial age. In fact, post-apartheid South Africa indicates that, as a long and complicated process of negotiating differences through the flux of history, reconciliation efforts, at their best, often follow a direction contrary to political trends.

South Africa's reconciliation model is very different from the apologyforgiveness model followed by most settler nations, and this is what makes the literary responses to South African history so important. In South Africa, Archbishop Tutu's use of a religious rhetoric in the TRC notwithstanding, official reconciliation efforts have steered clear of associating reconciliation with discourses of apology and forgiveness. The TRC has been careful to avoid demanding forgiveness from the victims or apology from the perpetrators during the hearings. Instead, the TRC focused on discovering the true nature of apartheid that emerged from the polyvalent narratives about apartheid. Like the TRC, the different novels examined in this dissertation are skeptical of apology and forgiveness as ways to reconciliation. The failure of forgiveness to guarantee reconciliation is perhaps most dramatic in Krog's Country of My Skull. The silence that greets the autobiographer's apology and plea for reconciliation indicates that apology and forgiveness are autonomous processes. If Krog reveals that apology and forgiveness are autonomous processes, then Coetzee reveals the difference between repentance and its performance in apology. At the university hearing Lurie refuses to apologize for raping a student because he does not regret his actions. Yet, later in the novel he impulsively decides to visit his victim Melanie's parents and prostrates himself before Melanie’s 
father to apologize. However, Lurie's inability explains how he plans to act on his repentance underscores the gap between repentance and its performance in apology. In this complicated process, law as a means of negotiating between the past and the present proves inimical. The main problem with law is that its claims to adhere to universal principles create ahistorical equivalences. Moreover, in the enforcement of law the universal principles are used to serve specific interests. Perhaps the strongest indictment against law is in J. M Coetzee’s Disgrace. In Disgrace, Lurie’s daughter Lucy refuses to report being gang-raped by Africans to the police because the law will punish her rapist and treat racism as pathology, thereby ignoring the need for social change. Law as the means of redress is equally mocked in Nadine Gordimer's None to Accompany Me. Vera, the lawyer and advocate for the land rights cases, is the strongest critic of law. Ever pragmatic about the limitation of the law to correct wrongs, she regards law as nothing more than damage control.

The rejection of law and forgiveness by the white authors is, in the end, a rejection of reconciliation as a miraculous event that wipes the slate clean. Since racial reconciliation involves changing the founding premises of a racist society to create a positive dynamic between hostile groups, and structural changes in society take time, one-time gestures are not enough. Both Gordimer and Brink argue for reconciliation as a process that moves beyond escapism and grand gestures to engage with the historical forces that shape experiences. In Gordimer's None to Accompany Me, Sibongile, the returned exile who becomes a successful politician, is disappointed that the end of apartheid has not improved the living conditions of the non-whites. , However, Vera, the lawyer who defends the land rights claims of the non-whites doesn’t expect miraculous 
changes. While Vera's work for the Legal Foundation can be read as nothing more than a matter of stalling the government's dictates, her relations with non-white colleagues suggest how reconciliation can be achieved without recourse to law. Her relationship with Oupa and Zeph demonstrate how respect for differences can be the basis of rewarding friendships that bypass patterns of hostility as well as relations of condescension. Such relationships, it should be emphasized, are to be understood not as the means towards the resolution of conflict, but rather as an ongoing process of negotiating the conflict — that is, resolution as method, not as product. Reconciliation, Gordimer's novel implies, is not about escaping from the past or forgetting the past, but of tackling the past so that the individual is not mired in it.

Like Gordimer, Brink provides examples of reconciliation that mock at the expectation that history can be erased through individual action. In all the three novels analyzed in this dissertation the protagonists discover that there is no escape from the past and that token gestures cannot erase the history of abuse. Kristein in Imaginings of Sand realizes that recording the unofficial history of her family to restore their Colored servants to the rightful place within the family does not undo the past. She therefore decides to remain in South Africa and help realize a new future. In Rights of Desire Antjie’s ghost, who haunts Ruben's house even after he has buried her bones, symbolizes the inadequacy of symbolic gestures even as it signals their importance. Antjie’s continuing presence forces Ruben to realize that escaping from the reality of post-racial post-apartheid South Africa in music and books or by bribing officials to secure better housing for his old Colored servant does not change the past. He thus vows to engage with the problems of post-apartheid South Africa. While Ruben and Kristein recognize 
reconciliation as a process, Flip, the protagonist of The Devils' Valley, is unable to understand the limitations of grand gestures in effecting reconciliation. One of the ironies of the novel is that Flip still believes that helping Emma, the much maligned orphaned daughter of the village belle, to escape from the Valley will atone for his complicity with the past. His inability to recognize his own complicity in racism leads to Emma's death. Yet he continues undeterred, held up by the belief that he will be able to escape. However, the narrative dashes this naïve hope because when he reaches the entrance to the valley he discovers that his path is blocked by the ghost of Lukas Seer.

In Coetzee and Krog's texts the narratives underscore the impossibility of building common grounds, while their narrative strategies enact and embody possible ways of connecting with the other. By exposing the difficulty of forgiveness through law and through the performance of apology Coetzee shows the impossibility of identifying the other. Yet, Coetzee's refusal to offset the protagonist David Lurie's racist views with positive representations of the non-white characters draws attention to the differences between Coetzee, an Afrikaner author, and the non-white characters. At the same time, his use of irony mocks at Lurie's views, decentering him as the narrative authority. Like Coetzee, Krog's autobiography reveals the impossibility of forgiveness. At the same time her fragmented narrative style, which foregrounds the victim's voice, shows how reconciliation can function in the absence of forgiveness.

In the novels discussed in this dissertation, the open-endedness and complexity of narratives enable authors to critique the limits of reconciliation and enact the possibilities of establishing relations of responsibility without drowning the voice of the other. Literature's reflexive ability to understand the complex web of forces at work in a 
historical context enable it to imagine possibilities that escape more empirically grounded discourses. Even though post-apartheid literature is guarded in its optimism and presents a future that is immensely difficult to realize, its visions of hope are based on a deep understanding of the messy reality of South Africa's racial history. This is not to say that fiction is always reflexive-for many of the realistic novels of the apartheid reveal how literature can become instruments of propaganda. However, the white authors I analyze move beyond propaganda to contradict simplistic notions of collaboration and harmony that the political change encourages. They demonstrate that South Africa needs its novelists, poets and even autobiographers if its reconciliation is to move from grandstanding and political posturing to sustainable action. ${ }^{\text {xciv }}$

South Africa's contribution to discourses on post-conflict strategies for peace includes not only a model for future truth commissions, but also a nuanced understanding of reconciliation. South Africa's conception of reconciliation emerges through political documents and literary representations. Representations of inter-racial interactions in South African white writing argue for reconciliation as a critical and dynamic process of negotiating the differences in the experience of history and opening discourses to the racial other. Since reconciliation is a dynamic process that is sensitive to its historical context, post-apartheid South African does not offer a formula for reconciliation that can be applied elsewhere. South Africa's contribution to the question of reconciliation is that it forces us to recognize reconciliation as a fragmented, uncomfortable and complicated process. This, rather than moments of complete amity between the racial groups, is its vision of reconciliation, state and popular culture notwithstanding. 


\section{Notes:}

\footnotetext{
i See Ndebele 41-59. See Brink "Interrogating Silence” 14-28.

ii The Nationalist Party was led by the Afrikaners and came to power in 1948. They initiated apartheid

iii I do not mean that the apartheid created ethnic divisions within the Black community. Apartheid used already deeply entrenched ethnic identities to prevent the formation of a unified African opposition. Ethnic divisions have always existed in South Africa because it was inhabited by numerous tribes. But these ethnic identities were reinforced during apartheid. For more on the pre-apartheid ethnic identities see Beinart 4. iv Till the Afrikaner dominated National Party came to power, the Afrikaners chafed under the British rule. The National Party came in to power after defeating the South African National Party, a British majority party.

${ }^{\vee}$ See Beinart 3-4.

${ }^{v i}$ South Africa's racial question was initially between the Boers and the British, where the Boers felt that
} they were being oppressed by the British, who were more powerful and controlled the mining areas. The indigenous population was dismissed as the other question. The victory of the NP in 1948 was regarded as the victory against the British dominated party and the opportunity for the Afrikaners to establish their volk. It was to realize this dream of Afrikaner nationalism that the apartheid policies were devised and instituted.

${ }^{v i i}$ My identification of South Africa's reconciliation as a dynamic and non-teleological process of marking difference does not, however, regard South Africa along the lines of Western discourses about Africa that Achile Mbembe identifies in On the Postcolony. Mbembe claims that western discourses on Africa presents Africa as "the mixture of the half-created and incomplete"(3). However even though I regard reconciliation as a process without end, I see the lack of an endpoint as intrinsic to the nature of reconciliation, rather than a sign of inadequacy or inferiority of the place.

viii For more on the relation of the settler to the mother country also see Lawson, and Prentice.

${ }^{\text {ix }}$ We can see the truth of the statement behind Coombes's analysis when we consider the three settler countries-Australia, South Africa and Canada. These 3 settler colonies differ from each other in their relation to the indigenous population. In the case of Australia and Canada indigenous people, the settler white population is the majority while the indigenous people who were decimated, segregated are the minority. Moreover in the case of Canada the federal government was responsible for the assimilation of the indigenous people to the mainstream culture. In Australia for instance the individual state governments are responsible for the indigenous people. In South Africa, even though the whites were a minority, they held the political power and practiced segregation of the most extreme kind. ${ }^{\text {ix }}$ This identity directed the nature of the reconciliation efforts between the settlers and their descendants in the $21^{\text {st }}$ century.

${ }^{\mathrm{x}}$ My articulation of reconciliation draws on two recent works on reconciliation and forgiveness. The first is Julie McGonegal's Imagining Justice: The Politics of Postcolonial Forgiveness and Reconciliation. Arguing for the need for reconciliatory politics, McGoneal's project formulates reconciliation by combining Fanon and Gandhi. She argues that reconciliation is "involves something more than mere departure from violence, it involves an entire yet ongoing and perpetually unfinished project of transforming the brutal conditions that are a legacy of colonialism” (33). McGonegal's project, which covers settler societies in Australia, Canada and South Africa focuses on how reconciliation affects the politics of forgiveness and justice. However, reconciliation itself is a complex project that extends beyond questions of possibilities of forgiveness. While McGonegal's conception of postcolonial reconciliation is close to my conception of literature, Shane Graham's South African Literature After the Truth Commission: Mapping the Loss argues for the need to move beyond institutional measures of reconciliation like the TRC to socio-spatial transformation of the landscape of South Africa. Based on space theories of David Harvey and Henry Lefebvre, Graham argues for the way trauma and memory changes the landscape of South Africa. However Graham does not enter into a discussion on the way ethical relations are affected by the truth and reconciliation discourse.

${ }^{x i}$ See WSJ.

xii Comaroff's views correspond with that of David Goldberg who comments that "as modernity commits itself progressively to idealized principles of liberty, equality and fraternity ... there is a multiplication of racial identities and the set of exclusions they prompt, rationalize, enable and sustain” (7) Here Goldberg 
points to the phenomenon where difference and divisions seem to multiply making the common ground seem utopian. See Racist Culture.

xiii Comaroff perceives the increasing use of legislation to gain rights and the commodification of history as the result of neoliberalism in South Africa. Under neoliberalism the liberating postmodern "skepticism towards metanarratives" that creates space for local, specific histories and narratives becomes commodified.

${ }^{\text {xiv }}$ For more on post-racist states see Goldberg, Racial State, 248.

${ }^{\mathrm{xv}}$ Goldberg defines assimilation as "blending into the mainstream ...renouncing ... one's subjectivity"(Racist Culture 219). Integration however allowed "cultural groups ... effective control of their autonomous cultural determinations and expressions at social margins, while maintaining a supposedly separate, and thus neutral set of common values to mediate their relations at the centre"(219). Incorporation in contrast refers to the "dual transformations that take place both in the dominant values and in those of the insurgent group as the latter insist on more complete incorporations into the body politic and the former grudgingly gives way(220).

${ }^{x v i}$ I want to clarify that the multiple languages the divide the communities does not mean that Afrikaans is solely spoken by the Afrikaners and Coloreds. Afrikaans would also be spoken by the many of the Africans, especially those who worked for Afrikaners. However, the Africans living in the Bantustans would be familiar with their tribal languages, and not English or Afrikaans. Despite this cross-racial sharing of tongues I make this statement because there is no one language that is shared by the majority of the population.

xvii The experience of the impossible is analogous to Robert Young's "quest for the singular, the contingent event, which by definition refuses all conceptualization" that relates "to the project of constructing a form of knowledge that respects the other without absorbing it to the same (Young, White Mythologies, 41).

xviii For postcolonialism as a process see McClintock “Angel of Progress”, and Quayson 3.

${ }^{x i x}$ By "ironic project" Seshadri means that postcolonialism must "rehearse continually the conditions for the production of its own discourse or be doomed to fall into a form of cultural anthropology" (66).

${ }^{\mathrm{xx}}$ Gates refers to African American literature in his comment. Despite the reference to a specific literature, his comments remain relevant for South Africa because South Africa's deep racial history means that literature cannot transcend race.

xxi See Keen 167.

xxii See CNN, Telegraph.

xxiii The term "ubuntu" is a word from the tribal languages which means humanism. For a more detailed analysis of the meaning of the word see The Truth and Reconciliation Commission Final Report Vol1, 125128.

xxiv See Mamdani.

${ }^{x x v}$ Saidiya Hartman and Stephen Best claim that justice is fugitive when historical wrongs are concerned. Yet they claim that measures of redressal have to be made as a way of marking the impossibility of attaining justice and closure from the past. See Best and Hartman.

${ }^{x x v i}$ My comparison of reconciliation as process to democracy to come is similar to Julie McGonagal's claims. See McGonagal 7-8. However, Gonagal's argument relates justice and forgiveness and their "yet-to realized"state to the "post" in postcolonialism. I extend her argument to suggest that it also relates to the "yet-to-be realized state of post-apartheid South Africa.

xxvii Democracy to come according to Derrida refers to the fact that democracy is indeterminate, taking different forms in different hsotorical contexts. It also refers to the fact that sometimes to maintain democracy the state has to suspend democratic apparatus like at times of war etc. See Rogues . xxviii See Barber. Barber's essay reveals the different debates centered round the new state of South Africa that emerged at the end of apartheid and resulted in reconfiguring the old identities in South Africa.

${ }^{x x i x}$ Analysis of narrative aspect of truth commissions has focused on its ability to challenge the monolithic apartheid history with a multi-layered history. Albie Sachs claims narrative truth creates a "dialogic history" where "multiple perspectives, experiences and interpretations of events of the different participants" are allowed expression (Sachs 97). One function of narratives is to convey a nuanced and multi-layered narrative. Apartheid, thus, mutates from a racist Afrikaner regime that spawned white and black violence to a reification of British and Dutch colonial policies, marked by white/black as well as black/black violence.

${ }^{\mathrm{xxx}}$ Skorupski, 93. 
xxxi John Austin defines performative utterance as an utterance which performs an action. Austin argues that since performative utterances create the values through performance, they are beyond truth evaluation. John Searle, however, identifies a two-way connection between performative utterances and concepts: "performative utterances create conventions in a particular situation, but they are governed by the broad conventions as well”.

${ }^{x x x i i}$ For more on the relation between operative acts and performative utterance see John Scorupski 150151.

xxxiii My distinction between acting and performing is based on the concept outlined in Judith Butler, "Performance Acts and Gender Constitution”. See Butler 900-911.

xxxiv Theatricality is based on Greg Denning's notion of theatre as "space set for spectatoring" that involves the notion of viewing a space as closed around with convention that the audience and actors enter into the conspiracy of their own illusions"(105). According to Denning "the brilliance of theatre is that it represents experience and offers us conventionalities by which representation can be interpreted.”(127). See Denning. In the hearings of course these conventions had to be created by the TRC through the hearings.

${ }^{x \times x v}$ For more on the Benzien hearings and the ambiguities it presented see Graham 23-31.

${ }^{x x x v i}$ Mamdani calls, the elision of everyday injustices of apartheid. It also gave rise to fears that it turned non-victims into spectators, obscuring their lives. However, these criticism do not take into account the fact that mass media create community through temporal simultaneity. Moreover, by watching the hearings the greater public outside the hearings are made to bear witness to the stories.

xxxvii The definition of symbol is based on Charles Samuelson Pierce's differentiation between index, icon and symbol.

xxxviii See Sanders 149.

${ }^{\text {xxxix }}$ Rosemary Jolly points out that the violence of realistic representation of the other during the apartheid was that it was exclusive of other groups who were seen through the binary logic of racial discourse.

Moreover, it excluded the singularity of the other because its attempts to realistically portray the extent of horrors could be "pornographic in its effects and its concern to deconstruct the repetitive structures of colonialism."(Jolly 111). For more on the violence of representation in apartheid white writing see Jolly Chapter 5.

${ }^{\mathrm{xl}}$ Authors and critics who harangued about the need to free South African literature from ideological determinism and its realistic bias include among other Andre Brink, Njabulo Ndebele, and Albie Sachs. For more on the debate see Sachs "Preparing Ourselves for Freedom", Ndebele "The Rediscovery of the Ordinary: Some New Writings in South Africa” and Brink "Interrogating Silence: New Possibilities Faced by South African Literature”.

xli Dorothy Driver questions this iron-clad distinction between apartheid and post-apartheid literature. See Driver.

xlii See Attridge J.M. Coetzee and the Ethics of Reading 1-12.

xliii For more on Coetzee's subversion of conventional literary genres see Penner J.M. Coetzee: Countries of the Mind.

${ }^{\text {xliv }}$ For a detailed discussion of how the different discourses marginalize the other see Jolly Colonization, Violence and Narration in White South Africa Writing, Chapter 2.

xlv Irony is conventionally regarded as a rhetorical concept. It has also been regarded as a marker of the ironist's crisis by psychoanalysis. The first perspective regards the confusion of the ironic address to a linguistic legerdemain. The psychoanalytic perspective locates the dual meanings of irony as indicative of a conflict in the speaker. However, the irreconcilable dual meaning of irony can also be indicative of existential dilemma. Friedrich Schlegel was one of the first philosophers to regard irony as a philosophical concept. However, Schlegel was unable to resolve the instability of meaning philosophical irony created in the aesthetic field. As a solution to the instability in meaning created by philosophical irony in a text, Soren Kierkegaard points out that the negative energies of irony cancel out the instability of meaning to establish the primacy of the text. The difference between irony as an aesthetic category and irony as philosophy is that the latter does not seek to resolve the contradictions since they are reflective of existential conditions. For my chapter I use Schlegel and Kierkegaard to analyze the play of irony in Disgrace because they help connect the novel's ironic representation of the other to the contradictions created by the country's racist history. For irony as an aesthetic and rhetorical concept see Booth The Rhetoric of Irony. For irony and psychoanalysis see Stringfellow. The Meaning of Irony: A Psychoanalytic Investigation. For irony as a 
philosophical concept see Kierkegaard The Concept of Irony and Schlegel "On Incomprehensibility”. For a critique of philosophical irony see Roy "Hegel contra Schlegel; Kierkegaard contra De Man.”

${ }^{\text {xlvi }}$ For more on the politics of international awards see Graham Huggan, Chapter 5, Sarah Brouilette Chapter 4.

xlvii The Immorality Act forbade sexual relations between different races. The Prohibition of Inter-Racial Marriage Act, which came earlier, forbade inter-racial marriage.

xlviii The apartheid was identified with Protestant Christian ethos of the Afrikaner community

${ }^{x l i x}$ Kaaps is a creolized dialect that borrows from Afrikaans and some local African language and is mainly spoken by the Cape Coloured population of South Africa, who are mainly situated in Cape Town.

${ }^{1}$ Zoe Wicomb essay on Disgrace offers numerous examples from the novel which indicates that Melanie is Colored despite the lack of reference to her racial identity. See Wicomb.

${ }^{\text {li }}$ In Racist Culture Goldberg uses the term non-racialism which he opposes with his concept of anti-racism. In Racial State he uses the term racelessness

lii Postimperial melancholia according to Gilroy is "associated with the neotraditional pathology of what, in the British setting, Patrick White has identified as the morbidity of heritage”( Melancholia 101).

liii It can be argued that in the colonial period the Afrikaners, or Boers as they were called then, were at threatened by the power of the British Empire and were hardly in a position of glory. However, they were still dominant over the indigenous tribes and the colonial period was identified with events like the Great Trek, which were key to defining Afrikaner identity in South Africa.

liv Lucy's refusal to report the rape has been read as a sign of the fact that her rape was a result of racial history that bound the different groups in a relation of perverted familiarity where each appeared to the other as a manifestation of their racial history. I agree that this is one possible reading, but it does not account for the fact that the present that Lucy refers to is a post racial present where racial crimes are relegated to the private domain and when they are reported they are seen as individual acts rather than as symptoms of a social malaise.

lv Sanders' definition of reparation as restoring and making is based on the two German terms used to explain reparations: weidergutmachung and weiderherstellung. Sanders bases his definition on Melanie Klein's work (120-134).

lvi I define space as not just an absolute physical phenomenon but fluid. It is based on David Harvey and Doreen Massey's notion of space as a network of relations that exhibit the power structures of the time. lvii The inadequacy of imagination to capture the other as a full bodied presence is revealed in the opera sequence. This criticizes the Romantic movement of the $18^{\text {th }}$ century which privileged the imaginative faculty for its ability to create new forms out of intimations of reality. The criticism of imagination as a creative force par excellence also criticizes Lurie who identifies with William Wordsworth. In the end the opera is a criticism of the high European tradition that is associated with the colonial exploitation and its appropriation of the other through representation.

lviii Here the other doesn't represent the absolute other form whom the self is estranged, but all that the dominant culture has relegated to the sidelines and silenced to maintain its homogeneity. For more on definition of the other see Attridge, Singularity of Literature.

lix I am not suggesting that being unable to sympathize with his daughter's rapists signals a lack of humanity. However, what is disturbing in his behavior with Pollus is the use of racist rhetoric and physical violence. The racist rhetoric and violence on the racial other has a long history in South Africa. If one contrasts Lurie's behavior with Pollux and Lucy's behavior it is possible to see how one can respond to the other without falling into the racist patterns of the past.

${ }^{1 x}$ The term focalization was used by Gerard Genette to refer to the difference between the narrator and narrative perspective. It was expanded by Meike Bal in Narratology to refer to "the relation between the vision and that which is being 'seen' perceived"(142).

${ }^{\text {lxi }}$ For more on the connection between Lurie's unreliability as a narrator and his failure as a paternal figure see Marais.

Ixii The difference between representation as "speaking for" as in politics and representation as " "representation' as in art and philosophy" (256), according to Gayatri Chakravorty Spivak, is that they refer "to two different modes-proxy and portrait. Re-presentation as description leaves the intellectual “transparent" (Critique 257). In contrast, representation as proxy in politics elaborately stages the representation of a consciousness outside it. Representation as the act of being representative in the 
political sense involves a strategic substitution of oneself as representative consciousness. The common point between representation and re-presentation is that "beyond both are where the oppressed subjects speak, act and know for themselves" (259). But representation as proxy is the ethical mode because it draws attention to itself as a staging of the other, i.e. the distance between the self and the other. Spivak makes this distinction to point out that while representation is always an imperfect version of the heterogeneous original, it can maintain the distance between the self and the other, even as it tries to recuperate the voice of the marginalized.

lxiii For more on the two levels of irony see Schlegel and Kierkegaard.

${ }^{\text {lxiv }}$ It is important to note that philosophical irony or secondary irony may seem to resemble Wayne Booth's notion of "unstable irony", but they are different concepts. Booth's notion of irony is a rhetorical concept while Schlegel and Kierkegaard's concept refers to an irreconcilable and impossible historical and existential dilemma.

${ }^{\mathrm{Ixv}}$ See Ayon Roy for a discussion on the aesthetic challenges posed by the relation between irony and the ironist in PMLA Jan 2009 (107-109).

${ }^{16}$ For more about Disgrace and counterfocalization. see Gayatri Chakravorty Spivak "Ethics and Politics in Tagore, Coetzee and Certain Scenes of Teaching” and Mike Marais.

${ }_{\text {lxvi }}$ For more about the connection between textual agency and irony see Roy.

lxvii Looking at irony from the perspective of postmodern notions of subjectivity forces us to read irony less as a power play and more as a result of the relation of individuals to discourses. In this sense postmodern irony as theorized by Hutcheon differs from Kierkegaard or Schlegel who still regard it as power play. Ixviii See Jenkins 5-6.

lxix Jenkins defines upper case history as "way of looking at the past in terms which assigned to contingent events and situations an objective significance by identifying their place and function within a general schema of historical development usually constructed as appropriately progressive” (5). Jenkins defines history in the lower case as "history construed in academic and 'particularistic' forms which, while insisting ... it was 'proper' history, modestly eschewed metanarrative claims that it was discovering in the past meaningful trajectories, purposes and teleologies” (6).

${ }^{\mathrm{Ixx}}$ For more on the relation between history and fiction see Hayden White, Frank Ankersmitt.

${ }^{\text {lxxi }}$ See Kossew "Reinventing History, Reinventing the Novel: The Politics of Reading Andre Brink's Imaginings of Sand."

Ixxii Christopher Warnes tracks the term "magical realism" back to Novalis. However this ancestry of the term is not generally traced back to Novalis. Wendy Farris, Lois Parkinson Zamora, Seymour Menton all trace the origin of the term back to Roh. In this case it is also noteworthy that Maggie Ann Bowers distinguishes between Roh's use of the term magic realism and the term "magical realism" as it is practiced by Marquez, Rushdie etc today. She associates magic realism is "the concept of the "mystery [that] does not descend to the represented world, but rather hides and palpates behind it"' with Roh and magical realism "as understood in Rushdie's words as the 'commingling of the improbable and the mundane"”(3). Bowers claims that "in magic realism 'magic refers to the mystery of life; in marvelous and magical realism 'magic' refers to any extraordinary occurrence and particularly to anything spiritual or unaccountable by rational science"(20). However other theorists have not made such distinction. In this essay I shall use magic realism and magical realism to mean the same thing.

${ }^{\text {lxxiii }}$ For more on Roh's definition of magic realism see Roh 15-33.

${ }^{\text {lxxiv }}$ For more on the distinction between magic realism as it is understood in art and magic realism as it is practiced in literature see Lies That Tell The Truth: Magic Realism Seen Through Contemporary Fiction From Britain by Anne Hegerfieldt. See Hegerfieldt 12-17.

${ }_{\text {lxxv }}$ See Zamora.

lxxvi See Carpentier.

lxxvii See Kossew "Reinventing History, Reimagining the Novel: The Politics of Reading Andre Brink’s Imaginings of Sand."

lxxviii Da Silva's comment is in sync with J. M. Coetzee's description of white South Africans as "no longer European, but not yet African” (Coetzee, White Writing 11).

lxxix See Huddart, Chapter 1.

${ }^{\operatorname{lxxx}}$ The desire to seek communion with the Africans and Coloureds, instead of a bond with the landscape, marks a shift in literature from the colonial times. In White Writing: On the Culture of Letters in South 
Africa Coetzee points out that for the colonial poet literature addressed to Africa was a means of seeking "a dialogue with Africa, a reciprocity with Africa, that will allow him an identity better than that of visitor, stranger, transient" (8). The problem with South Africa's racial history was that the European settlers loved the land, instead of loving the people who lived on and worked the land. This desire for a bond with the landscape changes in the 1960s, according to Coetzee, because "the ultimate fate of whites was going to depend ... on an accommodation with black South Africans than on an accommodation with the South African landscape” (Coetzee, White Writing 8). In post-apartheid South Africa ethical relations with nonwhite South Africans were the need of the hour, instead of accommodation. But the silence that greeted the colonial poet as he struggled to find a language to describe the alien African landscape repeats itself in the post-apartheid autobiographical desire for a non-white listener.

${ }_{\text {xxxi }}$ See Spivak Postcolonial Critic

lxxxii Ileana Dimitrui describes her post apartheid novels as a move from politics to the personal realm.

Ixxxiii In "The Essential Gesture" Gordimer writes that the essential gesture of an author is "individual" (286). The essential gesture contrasts with the necessary gesture which remains "responsible to a given social order" (278).

lxxxiv Dori Laub identifies 3 stages of witnessing: "the level being witness to oneself within the experience; the level of being witness to the testimonies of others; and the level of being a witness to the testimonies to the process of witnessing itself" (75)

${ }^{\text {Ixxxv }}$ In this context Kim Rostan's analysis of the unedited transcripts in Krog's memoir is beneficial. In “The Ethics of Infidelity in Country of My Skull” Kim Rostan points out that the testimonial citation preserves the "testimonial eloquence as well as the silence" (Rostan 148). She reads the excerpts of testimonies as dramatization of traces of events and emotions that remain beyond the bounds of the self. According to her "the de-formation and decontextualization of testimony are not simply sound bites, but traces of events that resist naming and knowing” (Rostan 150).

${ }^{1 x x x v i}$ Spivak identifies the difference between autobiography and testimony. Autobiography differs from other life writings such as testimony, for example, because in an autobiography the "intention of the subject is to objectify without loss of subjectship" (Spivak, Circumfession 7). In contrast, testimony is the "genre of the subaltern giving witness to oppression, to a less oppressed other" (Spivak, Circumfession 7). In a testimony "editorial control varies in degree but is never absent" and the editorial subject is "never decentered” (Spivak Circumfessions 7, 8). Spivak's analysis implies that autobiographies signal a position of privilege.

lxxxvii In the essay “I. me, mine” Krog writes, "I remember writing Country of My Skull” and it seemed pages and pages of horror, and grief and death. After some weeks I was in need for the opposite, for softness, kindness, caring, loveliness and poetry. That brought the affair. I cling to that "I" in the affair to get through the book" (103)

Ixxxviii See Laub 86-91.

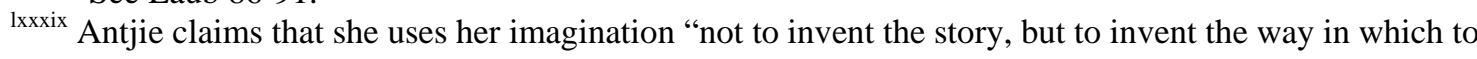
tell the story" (106). See Krog "I, me mine".

xc See Milner

${ }^{\text {xci }}$ See Bruillard.

xcii Other films following Griffiths include In the Heat of the Night (1967), and The Willby Conspiracy (1975), Cry Beloved Country and Dry White Season among others. See Johnson.

${ }_{x c i i i}$ Gillian Whitlock points out in her essay “Active Remembrance: Testimony, Memoir and the Work of Reconciliation" that "there is little evidence to date that the vast difference in the material circumstances of indigenous and non-indigenous peoples in Australia and Canada has been lessened by the symbolic aspects of reconciliation"(25). She notes that the reconciliation efforts in Canada and Australia have had little effect on the fact that "the material and lived experience of First Nations and indigenous people in Canada and Australia continue to be shaped by extraordinarily high rates of poverty, death, unemployment, youth suicide substance and sexual abuse, domestic violence and family breakdown” (25).

${ }^{x c i v}$ The importance of literature in providing a counterdisocurse to the popular notions of reconciliation rampant in South Africa discounts an instrumental view of literature. This becomes particularly important because literature associated with troubled and violent contexts is seen as irrelevant after the period of struggles over. I am forced to make this comment because of discussions of the role of Afrikaner literature after the end of apartheid. I think this discussion is relevant not just in South Africa, but also in USA, where African American literature is associated with a kind of activist role that has been regarded as redundant in 
the post Jim Crow era. See Chronicle of Higher Education article "Does African American Literature exists”. 


\section{Works Cited:}

Abrams, M. H. A Glossary of Literary Terms. Boston: Thompson, 2005. Print.

Anderson, Benedict. Imagined Communities: Reflection on the Origin and Spread of Nationalism. New York: Verso, 2006. Print.

Ankersmitt, F. R. “Historiography and Postmodernism.” The Postmodern History Reader. Ed Keith Jenkins. New York: Routledge, 1997, 277-297. Print.

Attridge, Derek. J.M Coetzee and the Ethics of Reading. Chicago: Chicago UP, 2004. Print.

-- --- ---. Singularity of Literature. New York: Routledge, 2004. Print.

Attridge, Derek and Jolly Rosemary. "Introduction”. Writing South Africa: Literature, Apartheid and Democracy 1970-1995. New York: Cambridge UP, 1998. Print.

Austin, John. How To Do Things with Words. Cambridge: Harvard UP, 1962. Print.

Bal. Mieke. Narratology: Introduction to the Theory of Narrative. Toronto: University of Toronto Press, 1997. Print.

Barber, James. "South Africa: The Search for Identity”. International Affairs, 70:1(1994). 67-82. Print.

Barkan, Elazar. Restitution and Negotiating Historical Injustices. New York: Norton \& Company. 2000. Print.

Bell, Richard H. Understanding African Philosophy: a Cross Cultural Approach to Classical and Contemporary Issues. New York: Routledge, 2002. Print.

Beinart, William.Twentieth Century South Africa. Oxford: Oxford UP, 1994. Print.

Best, Stephen and Saidiya Hartman. "Fugitive Justice”. Representations. 92 (Fall 2005). 1-15. Project Muse. Web. 20th November 2008.

Bhaba, Homi K. "Dissemination: Time, Narrative and the Margins of the Modern Nation" Nation and Narration. Ed Homi K. Bhabha. New York: Routledge, 2000. 291-322. Print.

— — —. “The Other Question”. Location of Culture. New York: Routledge, 1994. Print.

Bhargava, Rajeev. “Restoring Decency to Barbaric Societies”. Truth vs Justice: Morality of Truth Commissions.ed Robert I Rotberg and Dennis Thompson. Princeton: Princeton UP, 2000. 45-67. Print. 
Briggs, John. Fractals: Patterns of Chaos. New York: Simon and Schuster, 1992. Print.

Brink, Andre. Devil’s Valley. New York: Mariner Books, 2001. Print.

_ _ _ Fork In the Road: A Memoir. London: Harvill Secker, 2009.

_ _ _ Imaginings of Sand. Orlando: Harcourt and Brace, 1995. Print.

_ _ _ . "Interrogating Silence: New Possibilities Faced by South African Literature”. Writing South Africa: Literature, Apartheid and Democracy 1970-1995. ed Derek Attridge and Rosemary Jolly. New York: Cambridge UP, 1998. 14-28. Print.

_ _ _. "Reimagining the Real." Reinventing a Continent: Writing and Politics in South Africa 1982-1995. London: Secker and Warburg 1996, 145-164. Print.

_ _ _. Rights of Desire. New York: Houghton Mifflin Harcourt, 2001. Print.

— — —. "Stories of History: Reimagining the Past in Post-Apartheid Literature." Negotiating the Past: Making of Memory in South Africa. Ed Sarah Nuttall and Carli Coetzee. New York: Oxford UP, 1998. Print.

— — - "What You Never Knew You Knew: An Interview With Andre Brink." Interview by John Higgins. Pretexts: Literary and Cultural Studies. 8.1 (1999): 7-15. Print.

Booth, Wayne. Rhetoric of Irony. Chicago:Chicago UP, 1974. Print.

Bowers, Maggie Ann. Magic(al) Realism. London: Routledge 2004. Print.

Bruillard, Nicholas. “World Cup: Is South Africa's White Town Racist?” Globalpost.com. Global Post. 21 ${ }^{\text {st }}$ June 2010. Web. 25 ${ }^{\text {th }}$ June 2010.

Butler, Judith. "Performance Acts and Gender Constitution” Literary Theory: an Anthology. Ed. Julia Rivkin and Michael Ryan. Malden: Blackwell Publishing, 2004. Print.

CNN. “Zuma Appeals for Calm After Terreblanche’s Death.” CNN.com. Cable News Network. $4^{\text {th }}$ April 2010. Web. April 5, 2010.

Clingman, Stephen. The Novels of Nadine Gordimer: History From the Inside. Amherst: University of Massachusetts Press, 1986. Print.

Coetzee, J.M. Boyhood. London: Vintage 1998.

_- _. Disgrace. London: Vintage, 1999. Print.

_- _. Giving Offense: Essays on Censorship. Chicago: University of Chicago Press, 1996. Print. 
_ _ _ . "Nadine Gordimer.” Inner Workings: Literary Essays 2000-2005. New York: Viking, 2007. 244-256. Print.

_ — _. Summertime. New York: Viking 2009.

_ _ _ White Writing: On the Culture of Letters in South Africa. New Haven: Yale UP. 1988. Print.

_ _ _ Youth. London: Vintage 2003.

Comaroff, Jean. "The End of History, Again? Persuing the Past in the Postcolony” .Postcolonial Studies and Beyond. Ed Ania Loomba et al. New Delhi: Permaneant Black, 2005. 125144. Print.

Coombes, Anne E. "Memory and History in Settler Colonialism”. Rethinking Settler Colonialism: History and Memory in Australia, Canada, Aotearoa New Zealand and South Africa. Ed Anne E. Coombes. New York: Manchester University Press, 2006. 1-12. Print.

Da Silva, Tony. "Narrating Life Writing and Whiteness in the New South Africa: Gillian Slovo's Every Secret Thing." ARIEL: A Review of International English Literature. 2008: 91-107. Freely Accessible Arts and Humanities Journals. Web. $15^{\text {th }}$ November 2010.

_ _ _. "Narrating a White Africa: Autobiography, Race and History." Third World Quarterly. 26.3: 471-478. Academic Search Complete. Web. 24 ${ }^{\text {th }}$ December 2010.

Derrida, Jacques. Monolingualism of the Other or the Prosthesis of Origins. Trans. Patrick Mensah. Stanford: Stanford UP, 1996. Print

- - - Rogues: Two Essays on Reason. Trans Pascale-Anne Brault and Micheal Nass. Standford: Stanford UP, 2005. Print.

Dening, Greg. Performances. Chicago: University of Chicago Press. 1996. Print.

Dimitrui, Ileana. “Nadine Gordimer: Getting a Life After Apartheid.” Current Writing. 21:1-2 (2009): 117-137.

Disgrace. Dir. Steve Jacobs. Perf. John Malkovitch. Fortissimo Films. 2009. Films.

District 9. Dir. Neil Blomkamp. Perf. Charlto Copley, David James, and Jason Cope. Tri-Star Pictures. 2009. Film.

Driver, Dorothy. “South Africa: Under a New Dispensation”. Eurozine. 20.3.2006. Web. 25.7.2009. 
Durix, Jean Pierre. Mimesis, Genres and Postcolonial Discourse: Deconstructing Magic Realism. New York: Palgrave Macmilan, 1998. Print.

During, Simon. "Postcolonialism and Globalization: A Dialectical Relation after All?" Postcolonial Studies. 1.1(1998): 31-47. Academic Search Complete. Web. $4^{\text {th }}$ December 2010.

du Toit, Andrew. "The Moral Foundations of South African TRC: Truth as Acknowledgement and Justice as Recognition”. Truth vs Justice: Morality of Truth Commissions.ed Robert I Rotberg and Dennis Thompson. Princeton: Princeton UP, 2000. 45-67. Print.

Farris, Wendy. "Scheherazade’s Children: Magical Realism and Postmodern Fiction.” Magical Realism: Theory, History and Community. Ed Lois Parkinson Zamora and Wendy B Farris. Durham: Duke University Press, 1995. 163-190. Print.

Felman, Shoshana and Dori Laub. Testimony: Crises of Witnessing in Literature, Psychoanalysis and History. New York: Routledge, 1992. Print.

Friedman, Susan Stanford. "Women’s Autobiographical Self: Theory and Practice.” Women, Autobiography and Theory: A Reader. Ed Sidonie Smith and Julia Watson. Madison University of Wisconsin Press, 1998. 72-82. Print.

Ernest, John. Chaotic Justice: Rethinking African American Literary History. Chapel Hill: University of North Carolina Press, 2009. Print.

_ — _. "Representing Chaos: William Craft's Running a Thousand Miles for Freedom." PMLA. 121.2 (Spring 2007): 469-483. Print.

Gates, Henry Louis. "Editor’s Introduction: Writing "Race” and the Difference it Makes.” Critical Inquiry. 12.1 (Autumn 1985): 1-20. Jstor. Web. 12 January 2011.

Germana, Michael. Standards of Value: Money, Race and Literature in America. Iowa City: University of Iowa Press, 2009. Print.

Gellner, Ernest. Nations and Nationalism. Ithaca: Cornell University Press, 1983. Print.

Gilroy, Paul. Against Race: Imagining Political Culture Beyond the Color Line. Cambridge: Harvard UP, 2002. Print.

_ _ _ Postcolonial Melancholia. New York: Columbia UP, 2005. Print.

Genette, Gerard. Narrative Discourse: An Essay In Method. Trans Jane. E. Lewin. Ithaca: Cornell UP, 1980. Print.

Goldberg, David Theo. Racist Culture: Philosophy and the Politics of Meaning. Malden: 
Blackwell, 1993. Print.

_ _ — The Racial State. Malden:Blackwell Publishing, 2002. Print.

Gordimer, Nadine. "Living In the Interregnum” The Essential Gesture: Writing Politics and Places. Ed Stephen Clingman. New York: Alfred Knopf, 1988. 261-284. Print.

— — - None to Accompany Me. New York: Penguin, 1995. Print.

Graham, Shane. South African Literature After the Truth Commission: Mapping the Loss. New York: Palgrave McMillan, 2009. Print.

Gutman, Amy and Dennis Thompson. "Moral Foundations of Truth Commissions". Truth vsJustice: Morality of Truth Commissions.ed Robert I Rotberg and Dennis Thompson. Princeton: Princeton UP, 2000. Print.

Hallward, Peter. Absolutely Postcolonial. Manchester: Manchester UP, 2002. Print.

Handwerk, Gary J. Irony and Ethics in Narrative: From Schlegel to Lacan. New Haven: Yale UP, 1985. Print.

Hartman, Saidiya. Scenes of Subjection: Terror, Slavery and Self Making in Nineteenth Century America. New York: Oxford University Press, 1997. Print.

Hegerfeldt, Anne C. Lies That Tell the Truth: Magic Realism Seen Through Contemporary Fiction From Britain. Amsterdam: Rodopi, 2005. Print.

Heyns, Michiel. "The Whole Country's Truth Commission: Confession and Narrative in Recent White South African Writing. MFS: Modern Fiction Studies. 46.1 (Spring 2000): 42-66. ProjectMuse. Web. 12 ${ }^{\text {th }}$ December 2010.

Huddart, David. Postcolonial Theory and Autobiography. New York: Routledge, 2008. Print.

Hutcheon, Linda. "Circling the Downspout of Empire: Postcolonialism and Postmodernism" Postcolonial Studies Reader. Ed Bill Ashcroft et al. New York: Routledge, 1995. 130135. Print.

Invictus. Dir Clint Eastwood. Perf Morgan Freeman, Matt Damon. Warner Bros. 2009. Film.

Jenkins, Keith. "Introduction: On Being Open About Our Closures.” The Postmodern History Reader. Ed Keith Jenkins. New York: Routledge. 1-30. Print.

Jolly, Rosemary. Colonization, Violence and Narration in White South African Writing: Andre Brink, Breyten Breytenbach, and J.M. Coetzee. Athens: Ohio University Press, 1996. Print. 
Johnson, Reed. "South Africa in the Hollywood Eye.” Latimes.com. Los Angeles Times. $8^{\text {th }}$ November 2009. Web. $3^{\text {rd }}$ January 2011.

Joseph-Villain, Melanie. "Magic Realism in Two Post-Apartheid Novels by Andre Brink" Commonwealth. 25.2: 17-31. Print.

Keen, Suzanne. Empathy and the Novel. New York: Oxford UP, 2007. Print.

Kiss, Elizabeth. "Moral Ambition within and Beyond Political Constraints: Reflections on Restorative Justice". Truth vs Justice: Morality of Truth Commissions.ed Robert Rotberg and Dennis Thompson. Princeton: Princeton UP, 2000. 68-98. Print.

Kierkegaard, Soren. The Concept of Irony with Continental References to Socrates. Trans. Howard Hong and Edna Hong. New Jersey: Princeton UP, 1998. Print.

Kossew, Sue. "Introduction" Critical Essays on J. M. Coetzee. Ed Sue Kossew. New York: G. K. Hall, 1998.1-17. Print.

- _ - Pen and Power: A Postcolonial Reading of J. M. Coetzee and Andre Brink. Atlanta: Rodopi 1996. Print.

_ _ _ . "Reinventing History, Reimagining the Novel: The Politics of Reading Andre Brink's Imagining of Sand. Journal of Literary Studies. June 1997, 113-126. Print.

Krog, Antjie. Country of My Skull. Johannesburg: Random House, 1998. Print.

- - - . Country of My Skull: Guilt, Sorrow and the Limits of Forgiveness in the New South Africa. New York: Three Rivers 2000. Print.

_ _ _ . “ 'I, me, mine!’ Autobiographical Fiction and the I.” English Academy Review: Southern African Journal of English Studies. 22.1: 100-107.

Lawson, Allen. "Postcolonial Theory and the Settler Subject.” Unhomely States: Theorizing English-Canadian Postcolonialism. Ed Cynthis Conchita Sugars. Broadview Press: Petersborough, 2004. 151-165. Print.

Levinas, Emmanuel. Entre Nous: On Thinking-of-the Other. Trans. Michael B Smith and Barbara Harshav. New York: Colombia UP, 1993. Print.

Lorenz, Edward. The Essence of Chaos. Seattle: University of Washington Press, 1995. Print.

Lyotard, Jean Francois. The Postmodern Condition: A Report on Knowledge. Minnesota: Minnesota UP, 1979. Print.

Mamdani, Mehmood. “Amnesty or Impunity: A Preliminary Critique of the Truth and 
Reconciliation Commission of South Africa”. Diacritics, 33:3-4(2002): 33-59. Jstor. Web. 27 $7^{\text {th }}$ March 2006.

Malan, Rian. My Traitor's Heart: A South African Exile Returns to Face his Country, Tribe and Conscience. New York: Grove Press, 2000.

Marais Mike. “J.M. Coetzee’s Disgrace and the Task of the Imagination”. Journal of Modern Literature. 29.2(2007): 75-94. Academic Search Complete. Web. 3 February 2009.

Mbembe, Achille. On the Postcolony. Berkeley: University of California Press, 2001. Print.

McClean, Stewart and Emily Miller. “Apartheid's Last Stand: Inside South Africa’s Village Orania.” Mirror.co.uk. The Mirror. 11th August 2010. Web. 14th August 2010.

McClintock, Anne. “'No Longer in a Future Heaven': Gender, Race and Nationalism”. Dangerous Liaisons: Gender, Nation and Postcolonial Perspectives. Ed Anne McClintock, Aamir Mufti and Ella Shohat. Minneapolis: University of Minnesota Press, 1998. 69-88. Print.

_ _ _ . "Angel of Progress.” Imperial Leather: Race, Gender, and Sexuality in the Colonial Context. New York: Routledge, 1995. 391-396.

McDonald, Peter. “Disgrace Effects.” Interventions. 4 (2002).3. 321-330. Project Muse. Web. $28^{\text {th }}$ January 2009.

McGonegal, Julie. Imagining Justice: The Politics of Postcolonial Forgiveness and Reconciliation. Montreal: McGill-Queen’s University Press, 2009. Print.

Millner, Caille. "Whites-Only Town: Utopian Dreams Marry Racist Ideals in South Africa." Newamericamedia.org. New America Media. 13 ${ }^{\text {th }}$ May 2003. Web. 27 ${ }^{\text {th }}$ June 2010.

Milovanovic, Dragan. "Postmodernist vs the Modernist Paradigms." Chaos, Criminology and Social Justice: The New Orderly (Dis)order. Ed Dragan Milovanovic. Westport: Praeger, 1997. 3-28. Print.

Moss, Laura. "Nice Audible Crying: Editions, Testimonies, and Country of My Skull." Research In African Literatures. 37.4 (Winter 2006): 85-104. ProjectMuse. Web. 17 October 2010.

Murray, Martin. Revolution Deferred: The Painful Birth of Post-Apartheid South Africa. New York: Verso, 1994. Print.

Ndebele, Njabulo S. "The Rediscovery of the Ordinary: Some New Writings in South Africa" South African Literature and Culture: Rediscovery of the Ordinary. Manchester: Manchestser UP, 1994. 41-59. Print.

Noyes, John K. "Nature, History and the Failure of Language: The Problem of the Human in 
Post-Apartheid South Africa.” Relocating Postcolonialism. Ed David Theo Goldberg and Ato Quayson. Malden: Blackwell, 2002. 270-281. Print.

Parry, Benita. "Problems in Current Theories of Colonial Discourse.” Oxford Literary Review. 9(1987):27-58. Print.

\section{_ _ _ _ Postcolonial Studies: A Material Critique. New York: Routledge, 2005. Print.}

Pechey, Graham. “The Post-Apartheid Sublime: Rediscovering The Extraordinary”. Writing South Africa: Literature, Apartheid and Democracy, 1970-1995. ed Derek Attridge and Rosemary Jolly. New York: Cambridge UP, 1998. 57-74.

Penner, Dick. J.M. Coetzee: Countries of the Mind. Connecticut: Greenwood Press, 1989. Print.

Phelps, Teresa Godwin. Shattered Voices: Langauge Violence and the Work of Truth Commissions. Philadelphia: University of Pennsylvania Press, 2004. Print.

Prentice Charles. "Some Problems Of Response to Empire in Settler Postcolonial Societies”. DeScribing the Empire: Postcolonialism and Textuality. Ed Chris Tiffin and Alan Lawson. New York: Routledge, 1994. 45-58. Print.

Quayson, Ato. Postcolonialism: Theory Practice or Process. Malden: Polity Press, 2000. Print.

Radhakrishnan, R. "Revisionism and the Subject of History." The Postcolonial and the Global. ed Revathi Krishnaswamy and John C Hawley. Minneapolis: University of Minnesota Press, 2008. 69-81. Print.

Ramazani, Jahan. The Hybrid Muse: Postcolonial Poetry in English. Chicago: University of Chicago Press, 2001. Print.

Roach, Joseph. Cities of The Dead: Circum-Atlantic Performance. New York: Columbia University Press, 1996. Print.

Roh, Francis. “Magic Realism: Post-Expressionism (1925).” Magical Realism: Theory, History and Community. Ed Lois Parkinson Zamora and Wendy B Farris. Durham: Duke UP, 1995. 15-32. Print.

Roy, Ayon. “Hegel Contra Schlegel; Kierkegaard Contra de Man” PMLA. 124(January).1: 107126. Print.

Rostan, Kim. “Ethics of Infidelity in Country of My Skull.” Current Writing. 19.2(2007):144162. Print.

Ruden, Sarah. "Review Article: Country of My Skull: Guilt and Sorrow and the Limits of Forgiveness in the New South Africa.” Ariel: A Review of International English Literature. 30.1(1999): 165-179. Print. 
Sachs, Albie. "His Name Was Henry". After the TRC: Reflections on Truth and Reconciliation in South Africa. Ed Wilmot James and Linda Van deVijver. Athens: Ohio UP, 2000. 94-100. Print.

— — _ . "Preparing Ourselves for Freedom.” Writing South Africa: Literature, Apartheid and Democracy 1970-1995. ed Derek Attridge and Rosemary Jolly. New York: Cambridge UP, 1998. 239-248. Print.

Sanders, Mark. Ambiguities of Witnessing: Law and Literature in the Time of A Truth Commission. Stanford: Stanford UP, 2007. Print.

Schaffer, Kay and Sidonie Smith. Human Rights and Narrated Lives: The Ethics of Recognition. New York: Palgrave MacMilan, 2004. Print.

Schegel, Friedrich. “On Incomprehensibility”. Friedrich Schlegel's Lucinde and the Fragments. Trans. Peter Firchow. Minneapolis: University of Minnesota Press, 1971. 257-272. Print.

Searle, John. Speech Acts: An Essay in the Philosophy of Language. New York: Cambridge UP, 1969. Print.

Seshadri-Crooks, Kalpana. “At the Margins of Postcolonial Studies.”. ARIEL: A Review of International English Literature. 26.3 (July 1995):47-71.

Skorupski, John. Symbol and Theory: A Philosophical Study of Religion in Social Anthropology. New York: Cambridge UP, 1976. Print.

Sky Canaves. "In South Africa, Chinese is the New Black.” WSJ.com. Wall Street Journal. 19 June 2007. Web. 19 June 2008.

Slovo, Gillian. Every Secret Thing: My Family, My Country. London: Virago, 2010.

Smith, Sidonie. A Poetics of Women's Autobiography: Marginality and the Fictions of Self Representation. Bloomington: Indiana UP 1987. Print.

Spivak, Gayatri Chakravorty. A Critique of Postcolonial Reason: Towards History of the Vanishing Present. Harvard: Harvard UP, 1999. Print.

___ . Death Of a Discipline. New York: Columbia University Press. 2003. Print.

- - - "Ethics and Politics in Tagore, Coetzee and Certain Scenes of Teaching". Diacritics. 32.3-4 (Fall-Winter) 2002, 17-31. JStor. Web. 21 March 2009. .

_ — _. "Questions of Multiculturalism.” The Postcolonial Critic. Ed Sarah Harasym. Routledge: New York, 1999. Print. 
_ _ _. "Subaltern Studies: Deconstructing Historiography”. The Spivak Reader: Selected Works of Gayatri Chakravorty Spivak. ed Donna Landry and Gerald McLean. New York: Routledge, 1996. 203-236. Print.

_ _ _. "Subaltern Talk: Interview with the Editors". The Spivak Reader: Selected Works of Gayatri Chakravorty Spivak. Ed Donna Landry and Gerald McLean. New York: Routledge, 1996. 287-308. Print.

_ — — . "Three Women's Texts and Circumfession” Postcolonialism and Autobiography: Michelle Cliff, David Dabydeen, Opal Palmer Adisa. Ed Alfred Hornung and Ernstpeter Ruhe. Amsterdam: Rodopi, 1998.7-22. Print.

Travis, Molly Abel. "Beyond Empathy: Narrative Distancing and Ethics in Toni Morrison's Beloved and J.M. Coetzee's Disgrace." JNT: Journal of Narrative Theory. 40.2(Summer 2010): 231-250. Print.

The Telegraph. :Obituary: Eugene Terreblanche.” Telegraph.co.uk. The Telegraph. $4^{\text {th }}$ April 2010. Web. $5^{\text {th }}$ April 2010.

Truth and Reconciliation Commission. Truth and Reconciliation Commission of South Africa Report 5 Vols. London: McMilan, 1999. Print.

Turner, Victor. Dramas, Fields, and Metaphors. Ithaca: Cornell University Press, 1974. Print.

Walkowitz, Rebecca. Cosmopolitan Style: Modernism Beyond the Nation. New York: Columbia UP, 2006. Print.

Warnes, Christopher. Magic Realism and the Postcolonial Novel: Between Faith and Irreverence. New York: Palgrave Macmilan, 2009. Print.

Warren, Kenneth. “Does African-American Literature Exist?” Chronicle.com. Chronicle of Higher Education. 24 ${ }^{\text {th }}$ February 2011. Web. 24 ${ }^{\text {th }}$ February 2011.

Watson, Julia and Smith Sidonie. "Decolonization and the Politics of Discourse in Postcolonial Women’s Autobiographical Practices” De/colonizing the Subject: The Politics of Gender in Women's Autobiography. Minneapolis: University of Minnesota Press, 1992. xiii-xxxi. Print.

White, Hayden. "Historical Emplotment and the Problem of Truth.” The Postmodern History Reader. Ed Keith Jenkins. New York: Routledge. 392-396. Print.

Whitlock, Gillian. "Active Remembrance: Testimony, Memoir and The Work Of Reconciliation”. Rethinking Settler Colonialism: History and Memory in Australia, Canada, Aotearoa New Zealand and South Africa. Ed Anne E. Coombes. New York: Manchester UP, 2006. 1-12. Print.

_ _ — "Consuming Passions: Reconciliation in Women’s Intellectual Memoir.” Studies in 
Women’s Literature. 23.1(Spring 2004): 13-28. Jstor. Web. 18 October 2010.

Wicomb, Zoe. "Shame and Identity: The Case of the Colored in South Africa." Writing South Africa: Literature, Apartheid and Democracy 1970-1995. ed Derek Attridge and Rosemary Jolly. New York: Cambridge UP, 1998.91-107. Print.

Wilson, Richard. The Politics of Truth and Reconciliation in South Africa. Cambridge: Cambridge UP, 2001. Print.

Valdez, Patricia. "The Right to Truth”. After the TRC: Reflections on Truth and Reconciliation in South Africa. Ed Wilmot James and Linda Van deVijver. Athens: Ohio UP, 2000. 21-31. Print.

Young, Robert. White Mythologies: Writing History and the West. New York: Routledge, 2004. Print.

_ _ _ Postcolonialism: An Historical Introduction. Malden: Blackwell Publishing 2001. Print.

Zamora, Lois Parkinson and Farris Wendy B. "Introduction: Daiquiri Birds and Flaubertian Parrot(ie)s.” Magical Realism: Theory, History and Community. Ed Lois Parkinson Zamora and Wendy B Farris. Durham: Duke University Press, 1995. 1-11. Print. 


\section{Curriculum Vitae}

\section{SOHINEE ROY}

West Virginia University

100 Colson Hall

1503 University Avenue

PO Box 6296

Morgantown WV 26506-6296
109 South Walnut Street, Apt\#2

Morgantown WV 26501

304-685-8390

Email: roysohinee@yahoo.com

\section{EDUCATION}

\section{Degrees:}

- $\quad$ PhD in English Literature, West Virginia University. April 2011 (expected) Dissertation Chair: Dr. John Ernest

Title: Beyond Protest: Ethics of Reconciliation in the Post-apartheid Novels of South African White Writers

- $\quad$ MA in English Literature, Jadavpur University. 2002

- BA(Hons) in English Literature (minor in Film Studies), Jadavpur University. 2000

Awards:

- West Virginia University Graduate Dissertation Fellowship Spring 2011.

- Nominated for International Society for Study of Narrative (ISSN) Graduate Paper Award 2011.

- Nominated for South Atlantic Modern Language Association (SAMLA) Graduate Paper Award 2010.

- Jackson Fellowship Fall 2004- Spring 2010

- Vehsa Graduate Travel Award 2010

- Stephen Crocker Dissertation Fellowship Fall 2008-Spring 2009

\section{RESEARCH}

\section{Publications:}

\section{Peer Reviewed Articles:}

"Home and the World: Women's Place in the Home and Nation in Ice-Candy Man." Journal of Commonwealth and Postcolonial Studies. (forthcoming)Fall 2010.

Under Review: 
"Speaking with a Forked Tongue: Disgrace and the Irony of Reconciliation in Post-apartheid South Africa.” ARIEL: A Review of International English Literature. (submitted October 2010)

“South Africa’s Truth and Reconciliation Commission: An Event that Launched a Process.” Africa Today. (Submitted July 2010).

Non-peer Reviewed:

“Rabindranath Tagore,” Companion to the World Novel 1900 to the Present. Ed Michael Sollars. New York: Facts on File, 2008.

"Nashtaneer." Companion to the World Novel 1900 to the Present. Ed Michael Sollars. New York: Facts on File, 2008.

Roy, Sohinee. Sister Nivedita: A Passion for India. New Delhi: Rupa and Co. 2007.

Essays and book reviews in The Statesman 2001-2003.

\section{Conference Presentations:}

Unreliability as a Narrative Trope. Moderator. NeMLA Annual Conference. New Brunswick. April 2011.

“Making Friends with Ghosts: Andre Brink and Magic Realism in Imaginings of Sand.” NeMLA Annual Conference. New Brunswick April 2011.

"Speaking with a Forked Tongue: Disgrace and Irony as Reconciliation in Post-Apartheid South Africa.” 2010 International Conference on Narrative. Cleveland, Ohio. April 8-11, 2010.

"Speaking with a Forked Tongue: Disgrace and Irony as Reconciliation in Post-Apartheid South Africa." $19^{\text {th }}$ Annual British Commonwealth and Postcolonial Conference. Savannah, Georgia, February 26-27, 2010.

"Homophobia and National Identity in A Question of Power." $19^{\text {th }}$ Annual British

Commonwealth and Postcolonial Conference. Savannah, Georgia, February 26-27, 2010.

"Rights of Reconciliation: Disgrace and Post-Racial Politics in Post-Apartheid South Africa." SAMLA Annual Conference. Atlanta, Georgia. November 6, 2009.

"Truth and Reconciliation Commission of South Africa: An Event that Launched a Process." SAMLA Annual Conference. Louisville, Kentucky. November 8, 2008.

"Reworking or Adaptation: Bride and Prejudice and the Politics of Globalization." MMLA Annual Conference. Chicago, Illinois. November 2006. 
"Space and Time in Amitav Ghosh's The Shadowlines.” Colloquium for Department of Foreign Languages, West Virginia University. Morgantown West Virginia. 2005.

“Desire and Pride: Alienation in Dr Faustus and King Lear.” Interdisciplinary Conference on Alienation and Madness. Calcutta University. Calcutta, India. October 2001.

“That Rascally Wabbit: The Genealogy of Bugs Bunny.” with Malini Roy. JUSAS Annual Conference. Jadavpur University. Calcutta, India. December 2000.

\section{TEACHING}

\section{West Virginia University}

\section{Courses}

ENGL 262: British

Survey2

ENGL 102:

Composition and

Rhetoric

ENGL 132: Short

Story and Novel

ENGL 131: Poetry

and Drama

ENGL 262: British

Survey 2

ENGL 101

\section{Function}

Instructor: Full

Responsibility

Instructor: Full

Responsibility

Instructor: Full

Responsibility

Instructor: Full

Responsibility

Instructor: Full

Responsibility

Instructor: Full

Responsibility

\section{Institution}

West Virginia

University

West Virginia

University

West Virginia

University

West Virginia

University

West Virginia $\quad$ Spring 2006

University

West Virginia

University

Fall 2006-Fall

2010

Spring 2008

Fall 2010

Spring 2007

Fall 2004-

Summer 2006
Date

Summer 2010

Type

Distance

Learning

\section{Guest Lecturer}

Courses

ENGL 374:

Postcolonial

Literature

ENGL 372:

Commonwealth

Literatures

\section{Function \\ Guest Lecturer}

Guest Lecturer
Institution

West Virginia

University

West Virginia

University
Date

$11 / 2 / 2010$

11/16/2007
Instructor: Dr

Claycomb

Type

Instructor: Dr

Gwen Bergner

\section{J.D. Birla Institute}

Course

Function

Institution

Date

Type 
$\begin{array}{llll}\text { General English } & \text { Instructor: Full } & \text { J.D. Birla } & \text { Jan 2003-May } \\ & \text { Responsibility } & \text { Institute } & 2003\end{array}$

\section{RELATED WORK EXPERIENCE}

- Assistant Professor. North Central College. Starting September 1, 2011.

- GTA. West Virginia University 2004-2010

- Research Assistant for Dr John Ernest. Spring 2008.

- Graduate Student Assistant for Summer Seminar “Ireland and Globalization” by Marjorie Howes. Co-ordinator: Dr. Lisa Weihman. West Virginia University. Summer 2005.

- Editorial Assistant: Victorian Poetry. West Virginia University. 2004-2005.

- Journalist/ Copyeditor: The Economic Times. India. 2003-2004.

- Adjunct. J.D. Birla College, Calcutta (India). Spring 2003.

\section{Research/Teaching Interests:}

- $20^{\text {th }}$ century World/Anglophone and Postcolonial Literature

- Postcolonial Theory

- Victorian Literature

- Romantic Literature

- Commonwealth/Modern British Literature

- Contemporary Novels

\section{PROFESSIONAL DEVELOPMENT}

Preparing Future Faculty Workshop. Leader: Jenny Douglas, West Virginia University Office of Graduate Life. May 2010.

West Virginia University Summer Seminar. World Literature and Translation. Seminar Leader Rebecca Walkowitz, Rutgers University. Summer 2010.

\section{SKILLS}

\section{Language}

- Native fluency in Bengali and Hindi

- Blackboard, Qwerk Express 


\title{
SERVICE
}

\section{University and Profession:}

- Graduate Student Representative: Electronic Thesis and Dissertation Task Force, West Virginia University. 2008-present

- Graduate Student Assistant (Awards Committee): NeMLA 2011.

- Special Interest Group Technology: 2009-2010

Worked with 5 group members to create online resource for writing instructors using Blackboard.

- Volunteer Editorial Assistant: WVU Press. West Virginia University. 2007-2008

- Copy Editor: Special Issue on J.M. Coetzee. Stirrings Still. 3.1(Summer 2006)

- Graduate Assistant: WVU Summer Seminar. Irish Literature and Globalization. Seminar leader Marjorie Howes (Boston College). Summer 2005

- MA Representative: Jadavpur University 2001-2002

- MA Representative: Library Committee, Jadavpur University 2001-2004

\section{Community:}

- Board of Directors, Caritas House (non-profit) 2008-2009.

\section{Membership in Professional Organizations:}

Modern Language Association

International Society for the Study of Narrative

Northeast Modern Language Association

\section{REFERENCES:}

\author{
Dr. John Ernest \\ Distinguished Eberly Professor, Dissertation Chair. \\ Email:John.Ernest@mail.wvu.edu \\ Phone: 304-293-9714 \\ Dr. Gwen Bergner \\ Associate Professor \\ Email: Gwen.Bergner@mail.wvu.edu \\ Phone 304-293-9705
}




\section{Dr Ryan Claycomb}

Assistant Professor

Email: Ryan.Claycomb@mail.wvu.edu

Phone: 304-293-9710

Joann Dadisman.

English 102 Coordinator.

Email:jdadism2@wvu.edu

Phone: 304-293-9711

For References please contact

West Virginia University Career Services:

Career Services Center

West Virginia University

Mountainlair Building - SOW

PO Box 6008

Morgantown WV 26505-6008*

Phone: 304-293-2221

FAX: 304-293-6862

CareerServices@mail.wvu.edu 